\title{
Climate-Chemical Interactions and Effects of Changing Atmospheric Trace Gases
}

\author{
V. Ramanathan, ${ }^{1,2}$ L. Callis, ${ }^{3}$ R. Cess,,${ }^{4}$ J. Hansen, ${ }^{5}$ I. Isaksen, ${ }^{6}$ W. Kuhn, ${ }^{7}$ A. Lacis, ${ }^{5}$ \\ F. Luther,,${ }^{8,9}$ J. MAhlman, ${ }^{10}$ R. ReCK, ${ }^{11}$ AND M. SChLESINGeR ${ }^{12}$
}

\begin{abstract}
The problem concerning the greenhouse effects of human activities has broadened in scope from the $\mathrm{CO}_{2}$-climate problem to the trace gas-climate problem. The climate effects of non- $\mathrm{CO}_{2}$ trace gases are strongly governed by interactions between chemistry, radiation, and dynamics. We discuss in detail the nature of the trace gas radiative heating and describe the importance of radiative-chemical interactions within the troposphere and the stratosphere. We make an assessment of the trace gas effects on troposphere-stratosphere temperature trends for the period covering the preindustrial era to the present and for the next several decades. Non- $\mathrm{CO}_{2}$ greenhouse gases in the atmosphere are now adding to the greenhouse effect by an amount comparable to the effect of $\mathrm{CO}_{2}$. The rate of decadal increase of the total greenhouse forcing is now 3-6 times greater than the mean rate for the period 1850-1960. Timedependent calculations with a simplified one-dimensional diffusive ocean model suggest that a surface warming about $0.4-0.8 \mathrm{~K}$ should have occurred during 1850 to 1980 . For the various trace gas scenarios considered in this study, the equilibrium surface warming for the period 1980 to 2030 ranges from 0.8 to $4.1 \mathrm{~K}$. This wide range in the projected warming is due to the range in the assumed scenario as well as due to the threefold uncertainty in the sensitivity of climate models. For the 180 -year period from 1850 to 2030, our analysis suggests a trace gas-induced cumulative equilibrium surface warming in the range of 1.5 to $6.1 \mathrm{~K}$. The important non- $\mathrm{CO}_{2}$ greenhouse gases are $\mathrm{CFCl}_{3}, \mathrm{CF}_{2} \mathrm{Cl}_{2}, \mathrm{CH}_{4}, \mathrm{~N}_{2} \mathrm{O}, \mathrm{O}_{3}$, and stratospheric $\mathrm{H}_{2} \mathrm{O}$. Chlorofluorocarbons (CFCs) (mainly $\mathrm{CFCl}_{3}$ and $\mathrm{CF}_{2} \mathrm{Cl}_{2}$ ), through their indirect chemical effects on $\mathrm{O}_{3}$, have a potentially large stratospheric cooling effect, as large as that due to a $\mathrm{CO}_{2}$ increase. In addition to the direct radiative effect, many of the trace gases have indirect effects on climate. For example, addition of gases such as $\mathrm{CH}_{4}, \mathrm{CO}$, and $\mathrm{NO}_{x}$ can alter tropospheric $\mathrm{O}_{3}$, which is a radiatively active gas. Within the troposphere the indirect climate effects can be as large as the direct effects. On the other hand, within the stratosphere, temperature changes are largely determined by indirect effects of CFCs. Trace gases can also influence stratospheric $\mathrm{H}_{2} \mathrm{O}$ through their effect on tropical tropopause temperatures. Furthermore, increases in tropospheric $\mathrm{H}_{2} \mathrm{O}$, through the temperature- $\mathrm{H}_{2} \mathrm{O}$ feedback, can perturb tropospheric chemistry and alter the concentration of $\mathrm{CH}_{4}$ and $\mathrm{O}_{3}$. The fundamerital issue that needs to be addressed within the context of the trace gas-climate problem is the relative importance of transport, chemistry, and the iñdirect effects of trace gases in governing the long-term trends of tropospheric and stratospheric $\mathrm{O}_{3}, \mathrm{CH}_{4}$, and stratospheric $\mathrm{H}_{2} \mathrm{O}$. Cloud feedback continues to be the major source of uncertainty in the surface temperature sensitivity of climate models. At present, the sign of this feedback is not known. The ocean sequesters the trace gas radiative heating into its interior and thus delays the equilibrium warming. The estimated $e$-folding time for the approach to equilibrium varies from a few decades to a century and depends nonlinearly on $\lambda^{-1}$ and linearly on $\kappa$ where $\lambda$ is the climate feedback parameter and $\kappa$ is the effective ocean thermal diffusivity. The magnitude of $\lambda$, which also governs the equilibrium surface warming, is governed strongly by radiative and dynamiical processes in the atmosphere, and hence the effect of oceans on transient climate change is determined by the interactions between atmospheric and oceanic dynamical as well as radiative processes. The next crucial issue concerns accurate determination of decadal trends in radiative forcings, trace gases, planetary albedo (to determine effects of aerosols and cloud feedback), and surface-troposphere-stratosphere temperatures. The observational challenges are formidable and must be overcome for a scientifically credible interpretation of the human impacts on climate.
\end{abstract}

\footnotetext{
${ }^{1}$ National Center for Atmospheric Research, Boulder, Colorado.

2 Now at Department of Geophysical Sciences, University of Chicago, Chicago, Illinois.

${ }^{3}$ Langley Research Center, National Aeronautics and Space Administration, Hampton, Virginia.

${ }^{4}$ State University of New York at Stony Brook, Long Island.

${ }^{5}$ Goddard Institute for Space Studies, National Aeronautics and Space Administration, New York, New York.

${ }^{6}$ University of Oslo, Oslo, Norway.

${ }^{7}$ University of Michigan, Ann Arbor.

${ }^{8}$ Lawrence Livermore National Laboratory, Livermore, California.

${ }^{9}$ Deceased, September 13, 1986.

${ }^{10}$ Geophysical Fluid Dynamics Laboratory, Princeton, New Jersey.

11 General Motors Co., Warren, Michigan.

12 Oregon State University, Corvallis.

Copyright 1987 by the American Geophysical Union.
}

Paper number 7R0168.

$8755-1209 / 87 / 007 R-0168 \$ 15.00$

\section{Contents}

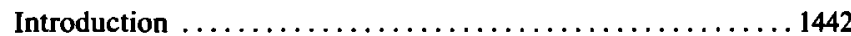

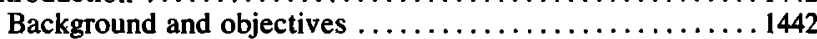

Observed temperature trends and theories of climate change 1442

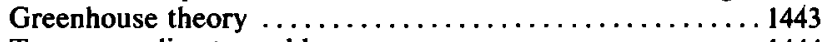

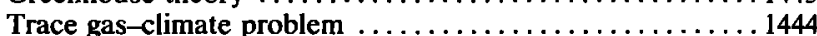

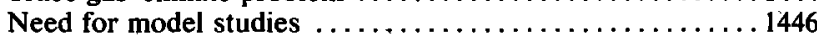

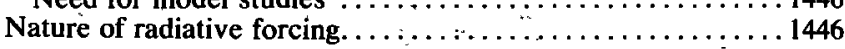

Greenhouse gases with weak solar absorption ........... 1448

Greenhouse gases with strong solar absorption: $\mathrm{O}_{3} \ldots \ldots \ldots 1450$

Additiveness of the greenhouse effects $\ldots \ldots \ldots \ldots \ldots \ldots 1451$

Effects of aerosols ........................ 1451

Current status in trace gas radiative treatment $\ldots \ldots \ldots \ldots . \ldots \ldots 1453$

Theory and models ........................... 1454

Stratospheric response to perturbations $\ldots \ldots \ldots \ldots \ldots \ldots 1454$

Troposphere response and the role of feedbacks ........ 1455

The implications of $\mathrm{H}_{2} \mathrm{O}$-climate feedback $\ldots \ldots \ldots \ldots \ldots 1458$

Effects on atmospheric and surface temperatures $\ldots \ldots \ldots \ldots \ldots 1458$

Direct effects .............................. 1459

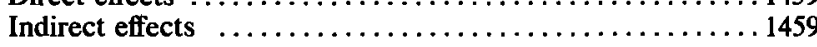


Transient climatic effects of increasing atmospheric $\mathrm{CO}_{2} \ldots 1464$ Observed increases in $\mathrm{CO}_{2} \ldots \ldots \ldots \ldots \ldots \ldots \ldots \ldots . \ldots \ldots 464$

Transient effects ........................... 1465 Results from simplified models $\ldots \ldots \ldots \ldots \ldots \ldots \ldots \ldots 1465$

Results for a realistic $\mathrm{CO}_{2}$ increase $\ldots \ldots \ldots \ldots \ldots \ldots \ldots \ldots \ldots$

Trace gas effects on observed and future climate trends .... 1467

Conceptual framework for the assessment ............ 1467

Greenhouse forcing from 1850 to the 1980 s $\ldots \ldots \ldots \ldots 1467$

Greenhouse forcing projected into next century ......... 1469

Regional effects ........................... 1472

Equilibrium and transient temperature response ......... 1472

Conclusions and unresolved issues .................. 1473

Summary of assessment ......................1473

Changes in other climate forcing terms .............. 1474

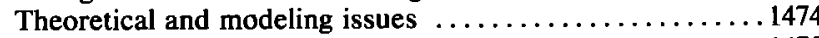

Observational issues ........................ 1475

Appendix: accuracy of band model approaches for $\mathrm{CH}_{4} \ldots \ldots 1475$

\section{INTRODUCTION}

\subsection{Background and Objectives}

It is now generally recognized that anomalies in radiative forcings induced by trace gases of anthropogenic origin can become the dominant factor governing climate change on decadal to longer time scales. One particular example is the greenhouse effect of $\mathrm{CO}_{2}$ increase which has been the subject of scientific curiosity since the latter half of the nineteenth century [Tyndall, 1861; Arrhenius, 1896; Chamberlin, 1899]. Interest in the $\mathrm{CO}_{2}$ problem gained tremendous momentum during the last two decades; this time period witnessed the development of a hierarchy of climate models with interactive clouds, oceans, and cryosphere to examine the climate change that might result from $\mathrm{CO}_{2}$ increase in the atmosphere. The last two decades also witnessed an unprecedented surge of interest in understanding the sensitivity of the ozone layer to chemical pertubations. The combination of these two developments gave rise to a series of scientific discoveries [see World Meteorological Organization (WMO), 1982].

First was the finding that the greenhouse effects of many polyatomic trace gases, for example, the chlorofluorocarbons (CFCs) $\mathrm{CFCl}_{3}$ and $\mathrm{CF}_{2} \mathrm{Cl}_{2}$, were greater than that of a $\mathrm{CO}_{2}$ increase on a molecule per molecule basis. To cite one example, addition of one molecule of $\mathrm{CFCl}_{3}$ (F11) or $\mathrm{CF}_{2} \mathrm{Cl}_{2}(\mathrm{~F} 12)$ to the atmosphere was calculated to have the same surface warming effect as that due to an addition of $10^{4}$ molecules of $\mathrm{CO}_{2}$ [Ramanathan, 1975]. Subsequeritly, it was uncovered that perturbations in stratospheric ozone can have perceptible effects on tropospheric climate through radiative-dynamical interactions between the stratosphere and troposphere. Furthermore; tropospheric ozone, which until recently was assumed to have negligible climate impact, was shown to be very effective in enhancing the greenhouse effect. Over the years, $\mathrm{CH}_{4}$ and $\mathrm{N}_{2} \mathrm{O}$ were added to the list of potentially important greenhouse gases [Wang et al., 1976], and the list is still growing. Finally, it has been estimated that the observed increase in the concentration of $\mathrm{CO}_{2}, \mathrm{CH}_{2}, \mathrm{CFCs}$, and other trace gases, during the next several decades, can lead to a global surface warming that could surpass the observed temperature changes of the past century [Lacis et al., 1981; Ramanathan et al., 1985; Brühl and Crutzen, 1984]. In such estimates the combined effect of increases in trace gas amounts (other than $\mathrm{CO}_{2}$ ) was comparable to the greenhouse effect of $\mathrm{CO}_{2}$ increase. The estimated effects on stratospheric climate were also substantial and far exceed the decadal-scale neutral variations. General circulation model studies suggested that the tropical tropopause temperatures are sensitive to perturbations in ozone and CFCs.

In effect, these unexpected developments forced the scope of the problem dealing with the greenhouse theories of climate change to be broadened from the $\mathrm{CO}_{2}$-climate problem to the trace gas-climate problem. This broadening of the scope of the problem posed a number of new theoretical, modeling, and observational ehallenges that could largely be ignored when dealing with the $\mathrm{CO}_{2}$-climate effects alone. For example, we can no longer ignore the interactions between radiation, chemistry, and dynamics, since these determine the stability of the $\mathrm{O}_{3}$ layer to chemical perturbations. Radiative-dynamical interactions in the troposphere and stratosphere, as well as the exchange of trace gases between these two regions, have emerged as key issues because of the potential importance of stratospheric $\mathrm{H}_{2} \mathrm{O}$ and $\mathrm{O}_{3}$ to climate. On the observational front it became clear that long-term trends in $\mathrm{CH}_{4}, \mathrm{~N}_{2} \mathrm{O}$, CFCs, stratospheric and tropospheric $\mathrm{O}_{3}$, and $\mathrm{H}_{2} \mathrm{O}$ are just as important as the trend in $\mathrm{CO}_{2}$ for understanding long-term climate trends.

The two primary objectives of this review paper are (1) to describe the new scientific challenges posed by the trace gasclimate problem and to summarize current strategies for meeting these challenges and (2) to make an assessment of the trace gas effects on troposphere-stratosphere temperature trends for the period covering the preindustrial era to the present and for the next several decades. We will rely heavily on the numerous reports [e.g., Carbon Dioxide Assessment Committee (CDAC), 1983; Charney, 1979; World Meteorological Organization, 1983a] published on the $\mathrm{CO}_{2}$-climate problem with respect to climate modeling issues, such as model sensitivity, uncertainty in model results, and the role of feedback processes such as cloud and ice albedo feedback. We will discuss in some detail the role of the oceans in governing the transient climate response to time-varying $\mathrm{CO}_{2}$ concentrations. Although the issue of transient climate response is discussed extensively in published reports dealing with the $\mathrm{CO}_{2}$-climate problem, recent work has shed some new light onto this issue. Furthermore, the transient climate response is a crucial issue for assessing the trace gas effects on past and future temperature trends.

The trace gas-climate problem has been reviewed in recent papers [Wang et al., 1986; Dickinson and Cicerone, 1986], but the present review delves into topics that are not adequately described in the earlier reviews. These include physics of the greenhouse effect, nature of the radiative-chemical interactions, radiative-dynamical interactions in the stratosphere and their role in governing stratospheric climate change, recent developments in the role of oceans in governing the transient climate reponse, and a time-dependent estimate of the potential trace gas warming from the preindustrial era to the early twenty-first century.

\subsection{Observed Temperature Trends and Theories of Climate Change}

The most frequently used index of climate change is the observed trends in surface-air temperature over the land areas of the globe. The instrumental record of surface-air temperature has recently been extended backward in time to the year 1860 by Kelly et al. [1984] Kelly et al.'s time series of annual 


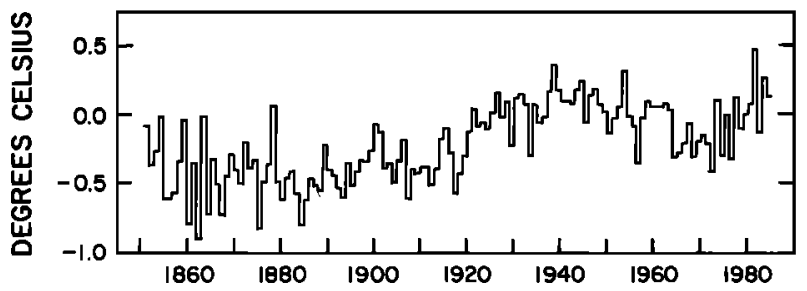

Fig. 1. Observed surface-air temperature trends for land masses of the northern hemisphere [Kelly et al., 1984].

land-averaged (northern hemisphere only) surface-air temperature is shown in Figure 1. The coldest decades in the record occur prior to the 1900 s, and the warmest decades are centered around the 1940s. The cooling trend that began around the 1940 s ended in the 1970 s, and temperatures during the early 1980s are comparable to the peak temperatures registered during the 1940 s. Overall, the post- 1940 period has been consistently warmer than the pre- 1900 period. This tantalizing feature has given rise to numerous theories and plausibility arguments of climate change, most of which involve the observed increase in $\mathrm{CO}_{2}$ and its greenhouse effect.

The suface-air temperature records have been extended for the entire globe, i.e., land and ocean, by Jones et al. [1986] The global time series is somewhat similar to that shown in Figure 1, with one important exception. The global record does not reveal the cooling trend of the 1940-1970 period. Tropospheric temperature trends also reveal a slight warming during 1960 to 1985 [Angell, 1986]. A comprehensive discussion of the trends in surface temperatures and other climate parameters can be found in the work by Ellsaesser et al [1986].

Various factors that govern climate change on decadal to longer time scales have been uncovered. Many of the factors fall under the category of externally (external to the climate system) induced variations in the climate-forcing terms. The first set of factors involves global scale changes in the radiative heating such as those due to trace gases including $\mathrm{CO}_{2}$, frequency of volcanic events, and variations in solar insolation. Factors involving regional-scale changes include changes in radiative forcing (turbidity, deforestation, and desertification), thermal forcing (urban heat island), and thermodynamic forcing (alteration of evaporation and precipitation by deforestation is one example). Decadal-scale climate change may also result from internal fluctuations in the interactions within the land-ocean-cryosphere-atmosphere system. Such internal fluctuations include variations in ocean heat storage, sea ice, and glaciers.

Of the various factors mentioned above, accurate determination of trends has been possible only for $\mathrm{CO}_{2}$ (at least since the 1950s), $\mathrm{CH}_{4}$, and $\mathrm{CFCs}$ (since the 1970s). The greenhouse effect of $\mathrm{CO}_{2}$ has received the most emphasis (in the literature) as a mechanism for climate change, and during the last few years, attention is turning increasingly toward the other trace gases. For all other climate-forcing terms the measurements are either nonexistent or, when they exist, the accuracies are insufficient to determine decadal trends. The lack of measurements has prevented identification of the causal factors for the temperature trends of the last 125 years. Nevertheless, the magnitude of the temperature variations revealed in Figure 1 provides a valuable measure for assessing the importance of trace gas effects.
Several attempts have been made to infer temperature trends in the stratosphere from radiosonde and rocketsonde network [Angell, 1986] (see the review article by Labitzke et al. [1985]). For the lower stratosphere, radiosondes yield hemispheric temperature estimates since 1960. This record suggests a global cooling trend of the order of about $0.3 \mathrm{~K}$ per decade [Angell, 1986] in the 16- to 20-km region for the 1960 to 1985 period. For the upper stratosphere, temperatures have been obtained by rocketsondes since the 1970s, and there still is considerable ambiguity in inferring reliable temperature trends from this limited data set [Labitzke et al., 1985].

\subsection{Greenhouse Theory}

The greenhouse effect is best illustrated by considering the annual and global average radiative energy budget of the earth-atmosphere system. The incoming solar radiation, the reflected solar radiation, and the outgoing long-wave radiation at the top of the atmosphere have been determined by satellite radiation budget measurements, and the values inferred from these measurements are shown in Figure 2. The surface-atmosphere system emits to space roughly $236 \mathrm{~W}$ $\mathrm{m}^{-2}$, which balances the absorbed solar radiation. The emitted radiation is mostly contained in wavelengths longer than 4 $\mu \mathrm{m}$, and hence it is referred to as long-wave, infrared (IR), or terrestrial radiation.

At a surface temperature of $288 \mathrm{~K}$ the long-wave emission by the surface is about $390 \mathrm{~W} \mathrm{~m}^{-2}$, whereas the outgoing long-wave radiation at the top of the atmosphere is only 236 $\mathrm{W} \mathrm{\textrm {m } ^ { - 2 }}$ (see Figure 2). Thus the intervening atmosphere causes a significant reduction in the long-wave emission to space. This reduction in the long-wave emission to space is referred to as the greenhouse effect. The most important radiatively active atmospheric constituents that contribute to this greenhouse effect are $\mathrm{H}_{2} \mathrm{O}, \mathrm{CO}_{2}$, and clouds. Together, these three constituents contribute roughly $90 \%$ of the total effect, and the $\mathrm{H}_{2} \mathrm{O}$ contribution is the largest. The remaining $10 \%$ is due to $\mathrm{O}_{3} \mathrm{CH}_{4}$, and $\mathrm{N}_{2} \mathrm{O}$. Climate model estimates, as well as simple back-of-the-envelope type calculations, suggest that without the greenhouse effect but with the solar absorption held fixed (at the present-day value), the global average surface temperature would be about $254 \mathrm{~K}$ [WMO, 1982].

The radiatively active constituents absorb as well as emit long-wave radiation, but the net effect is to reduce the longwave radiation to space. The fundamental cause for the reduction is the decrease in tropospheric temperature with altitude. The radiatively active gases absorb radiation emitted by the warmer surface but emit to space at the colder atmospheric temperature; hence the net effect is to reduce the radiation to space.

The stratospheric emission and absorption of long-wave radiation make an appreciable contribution to the total greenhouse effect and, furthermore, add a considerable degree of complication to the simplified picture presented above. These complications arise because of the increase in temperature with altitude in the stratosphere and because of the nonuniform ozone mixing ratio.

When the concentration of a radiatively active gas is increased, the long-wave radiation to space is diminished, which upsets the global energy balance shown in Figure 2. If the increase in the gas concentration does not alter the solar absorption, then the greenhouse effect will lead to an increase of radiative energy available to the surface-atmosphere system. 
REFERENCE ATMOSPHERE

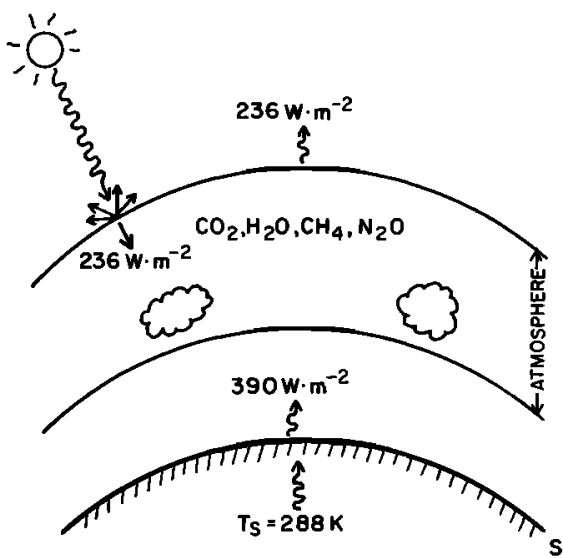

WITH CFC's

$\triangle F=$ GREENHOUSE EFFECTS;

REDUCTION DUE TO

INCREASED IR TRAPPING

Fig. 2. Global energy balance and the greenhouse effect.

To maintain a balance with the net incoming solar radiation, the surface-troposphere system should warm (in response to the excess radiative energy, i.e., radiative heating) and radiate more long-wave radiation to space until the long-wave emission to space balances the absorbed solar radiation (i.e., until the energy balance at the top of the atmosphere is restored). Hence the greenhouse theory is based on this fundamental concept of global energy balance for the surface-atmosphere system as a whole. Almost all of the modern-day climate models (since the pioneering study of Manabe and Wetherald [1967]) are built around this concept of global annual energy balance for the surface-atmosphere system. Numerous studies undertaken prior to the Manabe and Wetherald study, and a few recent studies, have misunderstood the implication of this concept of surface-atmosphere energy balance and have made erroneous interpretations of the surface temperature change due to $\mathrm{CO}_{2}$. These studies infer surface temperature change from surface energy balance alone and ignore the energy balance of the surface-atmosphere system.

1.3.1. Effect of solar absorption. There is a frequently held misconception about the greenhouse effect. It is frequently mentioned that a $\mathrm{CO}_{2}$ increase enhances the greenhouse effect because it allows solar radiation to penetrate to the surface while absorbing long-wave radiation. While it is true that $\mathrm{CO}_{2}$ is nearly transparent to solar radiation, the transparency to solar radiation is not a necessary condition for enhancing the atmospheric greenhouse effect. For example, $\mathrm{H}_{2} \mathrm{O}$ absorbs solar radiation long-wave of $0.9 \mu \mathrm{m}$, yet it is the strongest greenhouse gas. This is because almost all of $\mathrm{H}_{2} \mathrm{O}$ solar absorption occurs within the troposphere (almost entirely within the first $5 \mathrm{~km}$ from the surface). Since the troposphere and surface are efficiently coupled by convection, large-scale motions, and radiation, energy deposited within the lower hall of the troposphere warms the troposphere as well as the surface. Hence gaseous absorption of solar radiation in the lower troposphere will have a surface warming effect. However, solar absorption that occurs within the stratosphere (as in the case of $\mathrm{O}_{3}$ ) would have a surface cooling effect by reducing the energy available to the surface troposphere system. In summary, solar absorption by a radiatively active gas will add to or ameliorate the greenhouse effect, depending on the altitude of solar absorption.

1.3.2. Role of Models. The role of climate models in the greenhouse theory is to estimate the climate response to the excess radiative heating induced by the greenhouse effect. The response, of course, depends on feedback processes involving the land, ocean, cryosphere, and atmosphere (including clouds). In addition to models, empirical studies based on observed satellite data [Cess, 1976] have played an important role in estimating the climate response.

\subsection{Trace Gas-Climate Problem}

Chemical pollutants in the atmosphere can modify the climate through one or more of the following processes:

1.4.1. Radiatively active gases. If the pollutants are radiatively active in the long-wave region, they will enhance the atmospheric greenhouse effect. In particular, several polyatomic trace gases (of anthropogenic origin) have strong absorption features in the 7- to $13-\mu \mathrm{m}$ region (Figure 3 ). This spectral region is referred to as the atmospheric "window," since in this region the atmosphere is relatively transparent. In the 7- to $13-\mu \mathrm{m}$ region, roughly $70-90 \%$ of the surface and cloud emission escapes to space. Consequently, pollutants with strong absorption features in the 7 - to $13-\mu \mathrm{m}$ region are quite effective in enhancing the greenhouse effect. In addition, perturbing gases such as $\mathrm{CO}_{2}$ and $\mathrm{O}_{3}$, which govern the magnitude of stratospheric long-wave emission and absorption, have significant impacts on stratospheric climate.

1.4.2. Chemically active gases. Gases such as $\mathrm{CO}$ and NO, which by themselves have negligible radiative effects, can alter the concentrations of radiatively active gases such as $\mathrm{CH}_{4}$ and $\mathrm{O}_{3}$ by chemical interactions.

1.4.3. Radiatively and chemically active gases. Gases such as $\mathrm{CH}_{4}$ and CFCs are chemically active as well as radiatively active. Methane oxidation in the troposphere can lead to increased tropospheric $\mathrm{O}_{3}$, and the greenhouse effect of the increased tropospheric $\mathrm{O}_{3}$ can be comparable to that of a $\mathrm{CH}_{4}$ increase. Likewise, the breakdown of CFCs in the stratosphere produces reactive chlorine which destroys $\mathrm{O}_{3}$, and the effect of the $\mathrm{O}_{3}$ decrease can either amplify or ameliorate the CFC 


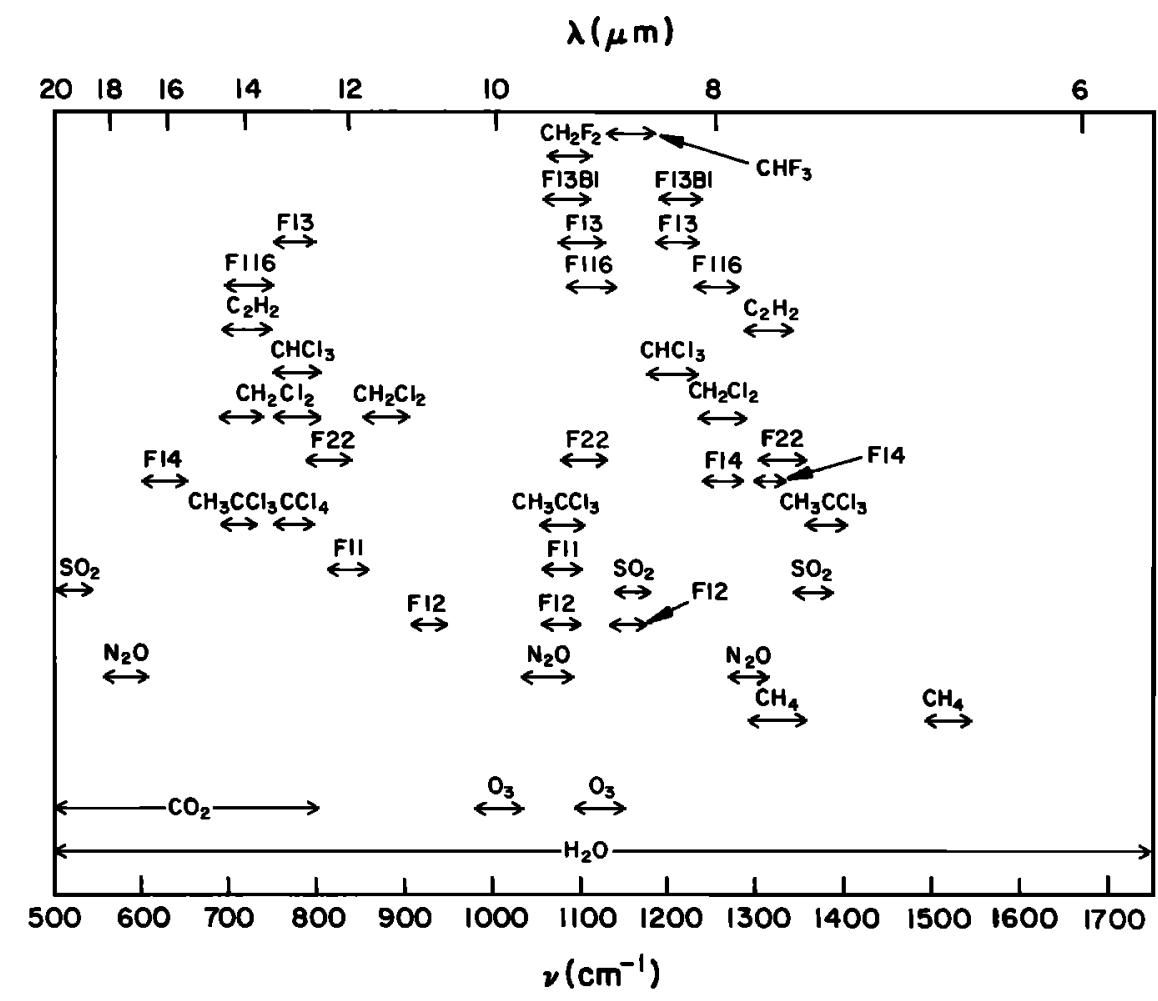

Fig. 3. Spectral locations of the absorption features of various trace gases. The spectral region between 7 and $13 \mu \mathrm{m}$ is referred to as the atmospheric "window." The anthropogenic trace gases have the potentials for making it into a "dirty window." This figure was provided by J. T. Kiehl (private communication, 1986).

greenhouse surface warming, depending on the vertical distribution of the $\mathrm{O}_{3}$ decrease.

1.4.4. Ozone change and stratosphere-troposphere radiative interactions. $\mathrm{O}_{3}$ absorbs solar radiation in addition to absorbing and emitting long-wave radiation; hence stratospheric $\mathrm{O}_{3}$ modulates the solar and long-wave radiation reaching the troposphere. Stratospheric $\mathrm{O}_{3}$ influences tropospheric climate through a complicated set of stratospheric-tropospheric radiative interactions in both the solar and long-wave radiation regimes. The greenhouse effect of tropospheric $\mathrm{O}_{3}$ also plays a significant role in determining the sensitivity of climate to $\mathrm{O}_{3}$ change. Consequently, it is very difficult to generalize the nature, the sign, or the magnitude of the potential climate change due to $\mathrm{O}_{3}$ perturbations.

1.4.5. Radiative-chemical interactions. These effects arise because of the strong temperature dependence of the reaction rates of the various chain reactions in the stratosphere that ultimately govern the stratospheric $\mathrm{O}_{3}$ concentration. The net effect of this dependence is such that a temperature increase (decrease) in the upper stratosphere leads to an $\mathrm{O}_{3}$ decrease (increase). Hence stratospheric cooling due to increased $\mathrm{CO}_{2}$ leads to an increase in $\mathrm{O}_{3}$ which tends to compensate some of the $\mathrm{CO}_{2}$ induced cooling. This $\mathrm{O}_{3}$-temperature feedback results in a negative feedback on temperature perturbations in the stratosphere. Furthermore, a local $\mathrm{O}_{3}$ decrease allows deeper penetration of sunlight and permits enhanced $\mathrm{O}_{3}$ production at lower levels. This interaction between $\mathrm{O}_{3}$ change and penetration of sunlight has a significant impact on the profile $\mathrm{O}_{3}$ change.

1.4.6. Interactions involving stratospheric dynamics. Large-scale motions in the stratosphere have a strong impact on some of the climate change processes described earlier. First, the climate effect of $\mathrm{O}_{3}$ change depends crucially on the vertical and latitudinal distribution of $\mathrm{O}_{3}$ change in the lower stratosphere, which is determined by the interactions between transport and chemistry. The second interaction concerns the effect of altered dynamics due to changes in stratospheric diabatic heating (from $\mathrm{O}_{3}$ change) on the transport of constituents. Perhaps the most important dynamics-transport effect concerns the interaction between trace gas perturbation, tropopause temperature, and stratospheric $\mathrm{H}_{2} \mathrm{O}$.

1.4.7. Climate-chemistry interactions. The greenhouse warming of the surface causes an enhancement in the evaporation of moisture from the land and oceans, resulting in an increase in the tropospheric $\mathrm{H}_{2} \mathrm{O}$. This, in turn, through photolysis and $\mathrm{H}_{2} \mathrm{O}$ chemistry, can perturb $\mathrm{OH}$ in the troposphere. Since $\mathrm{OH}$ plays a dominant role as a cleansing and oxidizing agent for tropospheric gases (including pollutants), the altered $\mathrm{OH}$ can potentially perturb the concentration of radiatively active species such as $\mathrm{CH}_{4}$ and $\mathrm{O}_{3}$ (and possibly others).

The above description basically gives the scope of the problem that we will be dealing with in this review. The nature of the various interactive processes and the potential surface temperature effect of various radiative perturbations are described schematically in Figure 4. The surface temperature change shown in Figure 4 for $\mathrm{O}_{3}$ is for a uniform change in $\mathrm{O}_{3}$ within the troposphere and stratosphere. Since the surface temperature effects of $\mathrm{O}_{3}$ depend very strongly on vertical distribution of the $\mathrm{O}_{3}$ change, the results shown in Figure 4 cannot be scaled for nonuniform $\mathrm{O}_{3}$ change. Finally, the climate sensitivity to radiative perturbation depends on feed- 
(a) Schematic of trace gos effects on climate

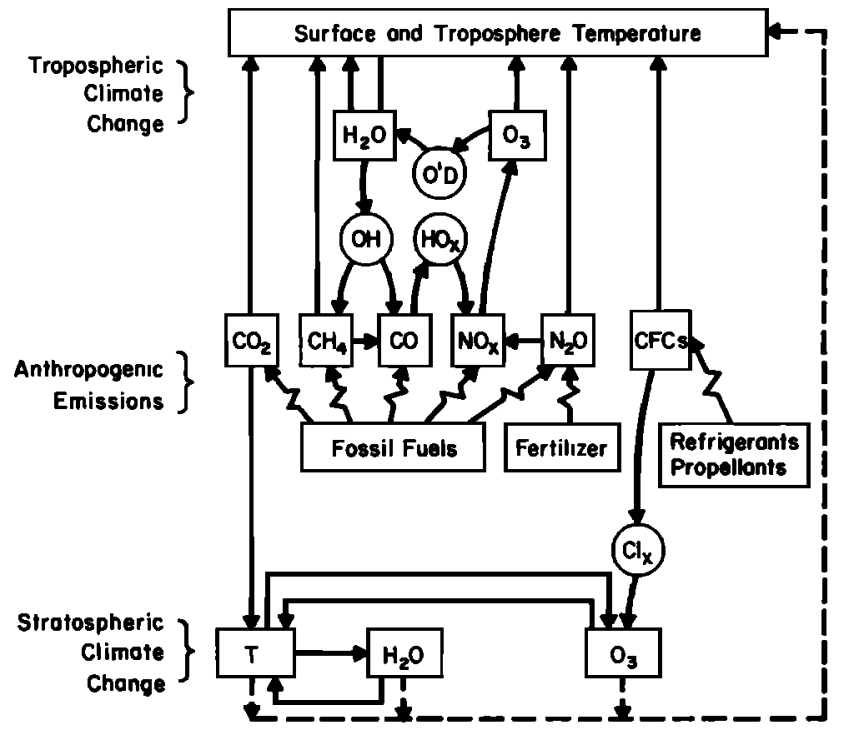

(b) Potential radiative perturbations of climate

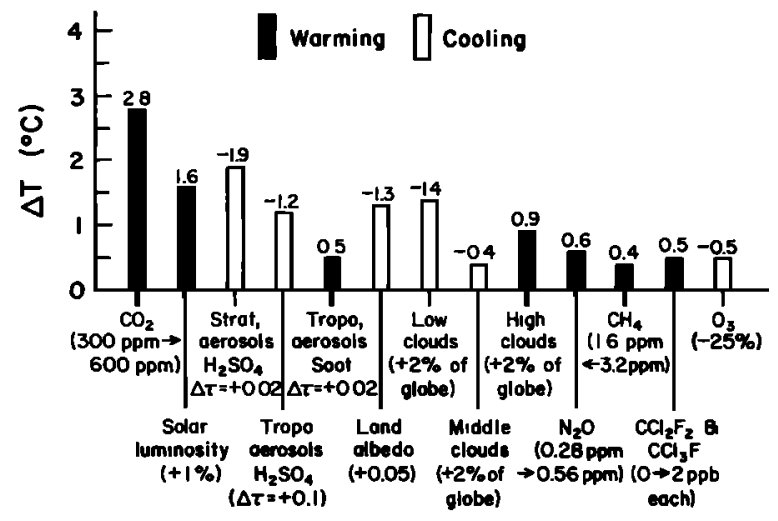

Fig. 4. (a) Examples of climate effects due to chemically and radiatively active gases [Ramanathan, 1980]. (b) Onedimensional radiative-convective model estimates of surface temperature effects of various global radiative perturbations. All of the results, except for $\mathrm{CH}_{4}$, and the figure are adapted from Hansen et al. [1981]. The $\mathrm{CH}_{4}$ result was obtained as follows: The radiative forcing of doubled $\mathrm{CH}_{4}$ as given by $W M O$ [1982] is multiplied by the climate sensitivity of the Hansen et al. [1981] model to obtain $\Delta T_{s}$.

backs involving temperature, $\mathrm{H}_{2} \mathrm{O}$, clouds, ice, and snow cover and on feedbacks between the ocean and the atmosphere (and possibly the biosphere). A comprehensive discussion of these topics is beyond the scope of this report and, furthermore, is unnecessary since several detailed reports [Charney, 1979; Smagorinsky, 1982] are available on this topic.

\subsection{Need for Model Studies}

The nature of the radiative forcing arising from the myriad of interactive processes mentioned earlier is so complex that numerical models with varying degree of complexity are needed to identify the magnitude of the various processes. The array of models needed for the trace gas-climate problem include (1) one-dimensional radiative-convective models to identify the important greenhouse effects and troposphericstratospheric radiative interactions, (2) one-dimensional radiative-convective-chemical models to examine the role of radiative-chemistry interaction in the stratosphere, (3) twodimensional transport-chemistry models to estimate the magnitude of seasonal and latitude variations of $\mathrm{O}_{3}$ change, (4) two-dimensional models to examine the possible magnitude of temperature changes in response to trace gas perturbations, (5) three-dimensional stratospheric models, and (6) threedimensional climate models with and without interactive oceans. Models 5 with comprehensive treatment of radiation and dynamics can play a central role in elucidating the role of dynamics in governing the interaction between radiative perturbations and temperature perturbations. Furthermore, these models are necessary to examine the potentially important problem of how alterations in stratospheric meridional and vertical thermal gradients impact tropospheric dynamics through stratosphere-troposphere dynamical interactions. There is also another important class of three-dimensional models concerned primarily with atmospheric transport and chemistry. Such models are essential for evaluating the robustness of the conclusions of the one-dimensional and twodimensional models concerning $\mathrm{O}_{3}$ perturbations as well as for understanding the nature of interactive chemistry and transport. These three-dimensional models should ultimately lead to the development of self-consistent three-dimensional models that account for the interactions between radiation, chemistry, and dynamics. In models 6 the perturbations in trace gases are prescribed. The model determines the climate change (troposphere and stratosphere) due to the imposed perturbations. These models, in conjunction with the onedimensional radiative-convective models, play a central role in the assessment of trace gas effects on climate.

More detailed discussions of these models are given in section 3.

\section{Nature OF Radiative Forcing}

Radiative forcing due to trace gases can be considered either in terms of the changes in the fluxes of radiative energy into and out of the entire system (i.e., surface-troposphere system) or in terms of the change in the vertical distribution of the radiative heating rates. The choice between the two quantities depends on the region of interest. Within the troposphere the vertical mixing of sensible and latent heat by convection and large-scale motions is considered to be quite rapid in comparison to the time scales associated with radiative adjustments. As a result, the vertical distribution of the tropospheric temperature change is largely governed by dynamical processes, while the mass-weighted tropospheric temperature change is governed by the radiative forcing of the column. Hence as a first approximation, we can ignore the details of the vertical distribution of the tropospheric radiative forcing and focus, instead, on the radiative forcing of the entire surface-troposphere system. Since the surface-troposphere radiative forcing is simply the change in the net radiative flux 
TABLE 1a. Summary of Spectroscopic Data as Given by WMO [1982]

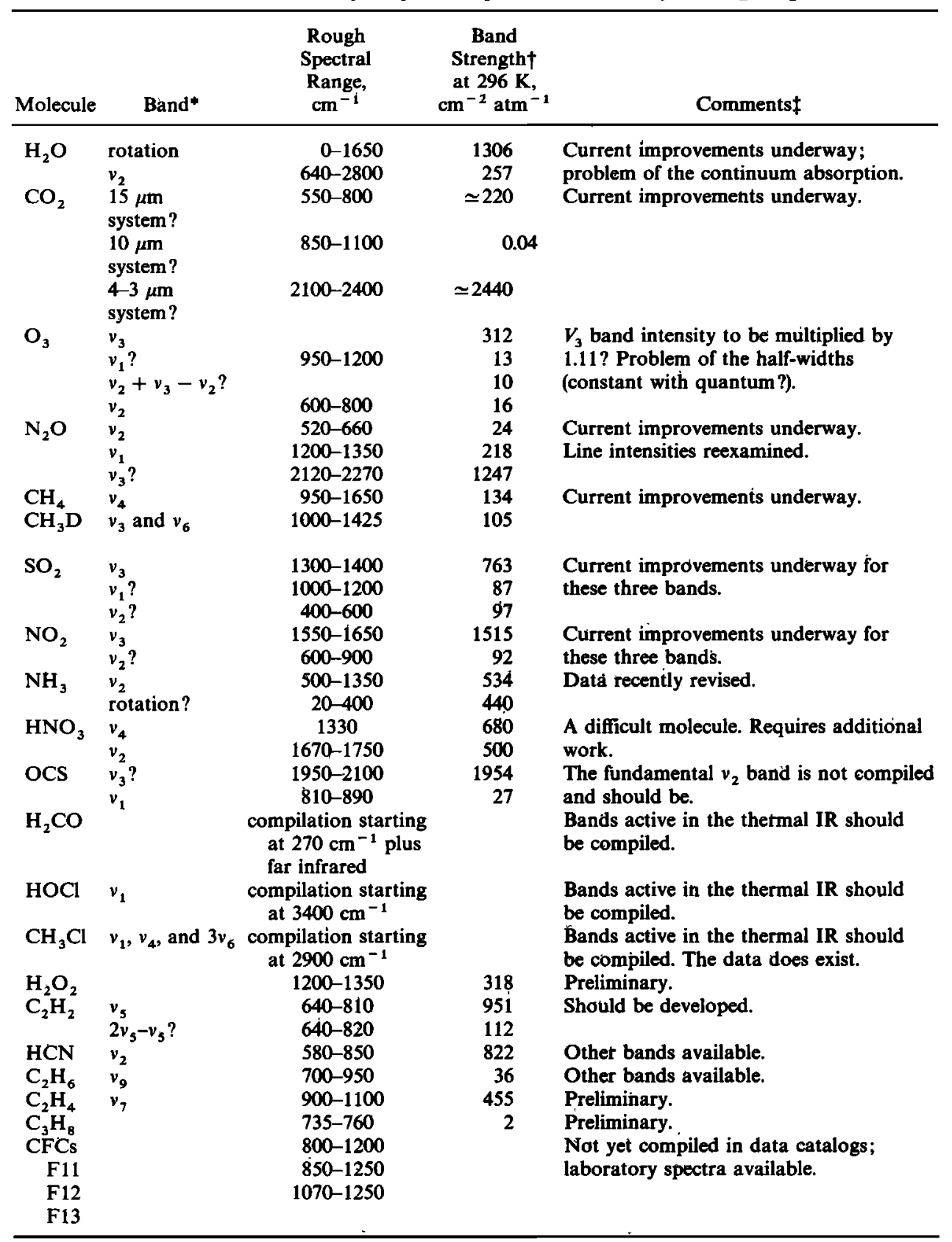

More recent compilations can be found in the work by Smith et al. [1985].

*A question mark indicates bands less important than the main bands but which could eventually play a role in radiation modeling (to be checked).

$\dagger$ Actually, the sum of the strengths of the lines present in the compilation $(296 \mathrm{~K})$. Isotopic band intensities are not added except for the estimate of a band system intensity (for example, the 15- $\mu \mathrm{m} \mathrm{CO}_{2}$ system).

$\ddagger$ Most comments were taken from L. S. Rothman (private communication, 1985).

at the tropopause, it is rather straightforward to assess the importance of trace gas radiative forcing. The only minor complication is that we have to account for changes in stratospheric temperature and long-wave emission in order to compute the flux changes at the tropopause. Within the stratosphere, however, time scales associated with radiative adjustments are comparable to, or faster than, those associated with dynamical processes. As a result, the magnitude of the stratospheric climate change is influenced strongly by the vertical distribution of the radiative heating rate perturbation within the stratosphere.

The trace gas radiative forcing is estimated from radiation model calculations by fixing all other parameters (for example, temperature and humidity) in the model and then computing the changes in the radiative flux due solely to the change in the constituent of interest. Such estimates are fundamental to a proper understanding of the temperature response yielded by climate models. The long-wave absorption features of the 
TABLE 1b. Absorption Features of Atmospheric Trace Gases: More Recent Compilations

\begin{tabular}{|c|c|c|c|c|}
\hline \multirow[b]{2}{*}{ Molecule } & \multirow[b]{2}{*}{$\begin{array}{c}\text { Rough Spectral } \\
\text { Range, } \\
\mathrm{cm}^{-1}\end{array}$} & \multicolumn{2}{|c|}{$\begin{array}{c}\text { Band Intensity, } \\
\mathrm{cm}^{-1}(\mathrm{~atm} \mathrm{~cm})^{-1} 296 \mathrm{~K}\end{array}$} & \multirow[b]{2}{*}{ Reference* } \\
\hline & & $\begin{array}{l}\text { Measurement } \\
\text { Range }\end{array}$ & $\begin{array}{l}\text { Recent } \\
\text { Value }\end{array}$ & \\
\hline & & CFCs & & \\
\hline $\mathrm{CFCl}_{3}$ (F11) & $\begin{array}{c}800-900 \\
1050-1100\end{array}$ & $\begin{array}{c}1540-1828 \\
531-721\end{array}$ & $\begin{array}{r}1828 \\
679\end{array}$ & $K, P, \mathbf{S}$ \\
\hline \multirow[t]{2}{*}{$\mathrm{CF}_{2} \mathrm{Cl}_{2}(\mathrm{~F} 12)$} & $\begin{array}{c}875-950 \\
1060-1125\end{array}$ & $\begin{array}{l}1265-1490 \\
1141-1226\end{array}$ & $\begin{array}{l}1446 \\
1141\end{array}$ & $\mathbf{K}, \mathbf{P}, \mathbf{S}$ \\
\hline & $1125-1175$ & $728-821$ & 767 & \\
\hline \multirow[t]{2}{*}{$\mathrm{CF}_{3} \mathrm{Cl}(\mathrm{F} 13)$} & $\begin{array}{c}750-825 \\
1075-1125\end{array}$ & $\begin{array}{c}116-145 \\
1758-2311\end{array}$ & $\begin{array}{r}116 \\
1758\end{array}$ & $\mathbf{P}$ \\
\hline & $1175-1240$ & $2116-2767$ & 2116 & \\
\hline $\mathrm{CF}_{4}(\mathrm{~F} 14)$ & $\begin{array}{c}600-650 \\
1250-1300\end{array}$ & $\begin{array}{c}39-57 \\
3850-5472\end{array}$ & $\begin{array}{r}39 \\
5472\end{array}$ & $\begin{array}{l}P, S \\
S\end{array}$ \\
\hline $\mathrm{CHClF}_{2}\left(\mathrm{~F}_{22}\right)$ & $\begin{array}{c}780-840 \\
1080-1140 \\
1280-1340\end{array}$ & & $\begin{array}{l}219 \\
637 \\
101\end{array}$ & $\mathbf{N} / \mathbf{R}$ \\
\hline \multirow[t]{2}{*}{$C_{2} F_{6}(F 116)$} & $\begin{array}{c}880-740 \\
1080-1150\end{array}$ & & $\begin{array}{l}135 \\
975\end{array}$ & $\mathbf{P}$ \\
\hline & $1220-1280$ & Others & 3374 & \\
\hline \multirow{2}{*}{$\begin{array}{l}\mathrm{CCl}_{4} \\
\mathrm{CHCl}_{3}\end{array}$} & $730-810$ & $1214-1869$ & 1325 & $\mathbf{P}$ \\
\hline & $\begin{array}{c}740-820 \\
1190-1250\end{array}$ & $\begin{array}{l}797-1107 \\
129-190\end{array}$ & $\begin{array}{l}930 \\
129\end{array}$ & $\mathbf{P}$ \\
\hline $\mathrm{CH}_{3} \mathrm{CCl}_{3}$ & $\begin{array}{c}700-750 \\
1050-1110 \\
1360-1410\end{array}$ & & $\begin{array}{r}277 \\
154 \\
13\end{array}$ & $\mathbf{N} / \mathbf{R}$ \\
\hline $\mathrm{CHF}_{3}$ & $1110-1160$ & $2224-3540$ & 2693 & $\mathbf{P}, \mathbf{S}$ \\
\hline $\mathrm{CH}_{2} \mathrm{~F}_{2}$ & $1060-1120$ & $1230-1485$ & 1230 & $\mathbf{P}, \mathrm{S}$ \\
\hline $\mathrm{CBrF}_{3}$ & $\begin{array}{l}1060-1110 \\
1180-1240\end{array}$ & & $\begin{array}{l}1908 \\
1914\end{array}$ & $\mathbf{P}$ \\
\hline PAN & $\begin{array}{c}570-620 \\
760-820 \\
1130-1190 \\
1270-1330 \\
1700-1760\end{array}$ & & $\begin{array}{r}72 \\
726 \\
301 \\
301 \\
251 \\
531\end{array}$ & $\mathbf{N} / \mathbf{R}$ \\
\hline
\end{tabular}

*K: Kagann et al. [1983]; P: Pugh and Rao [1976]; N/R: measured values by $M$. Niki (Ford Motors, Dearborn, Mich.) and cited by Ramanathan et al. [1985]; and S: Smith et al. [1985].

trace gases that are considered in this report are shown in Tables $1 a$ and $1 b$.

\subsection{Greenhouse Gases With Weak Solar Absorption}

With the exception of $\mathrm{H}_{2} \mathrm{O}, \mathrm{O}_{3}$, and $\mathrm{NO}_{2}$, all other gases shown in Tables $1 a$ and $1 b$ have either weak or no absorption bands in the solar spectrum. Increasing the concentration of the gases with weak solar absorption subjects the troposphere to a net radiative heating accompanied by either a strong (for example, $\mathrm{CO}_{2}$ ) or a weak (for example, $\mathrm{CH}_{4}$ ) long-wave cooling of the middle to upper stratosphere.

2.1.1. $\mathrm{CO}_{2}$ : current understanding and recent findings. The best known example of tropospheric heating/stratospheric cooling is the radiative forcing due to doubling of $\mathrm{CO}_{2}$ (Figure 5). The significarit enhancement of the cooling rate from the middle stratosphere to lower mesosphere shown in Figure 5 is due to the increase in emission to space from the wings of the nonoverlapping Lorentzian lines within the $\mathrm{CO}_{2}$ $15-\mu \mathrm{m}$ band system. The vertical distribution of the cooling rate perturbation (Figure $5 a$ ) is largely governed by the vertical temperature gradient (the temperature increases with altitude from 15 to about $50 \mathrm{~km}$ and decreases above $50 \mathrm{~km}$ ). Since the $15-\mu \mathrm{m}$ Planck function (i.e., $\mathrm{CO}_{2}$ emission) increases exponentially with temperature, the cooling rate perturbation follows the temperature profile.

As opposed to the stratospheric effects, the $\mathrm{CO}_{2}$ increase enhances the tropospheric radiative heating (Figure $5 b$ ). The surface-troposphere radiative heating (flux change at the tropopause for average cloudiness) has a strong latitudinal gradient varying from about 4.5 to $5 \mathrm{~W} \mathrm{~m}^{-2}$ in the tropics to about $2 \mathrm{~W} \mathrm{~m}^{-2}$ in the polar region. The global average value of the surface-troposphere heating $(\Delta Q)$ is about $4.2 \mathrm{~W} \mathrm{~m}^{-2}$ (for a $\mathrm{CO}_{2}$ doubling), and $\Delta Q$ scales roughly as

$$
\Delta Q=c \ln F
$$

where $c$ is a constant and $F$ is the ratio of $\mathrm{CO}_{2}$ concentration to a reference value. For a doubling of $\mathrm{CO}_{2}$ the global average $\Delta Q$ consists of roughly $1.6 \mathrm{~W} \mathrm{~m}^{-2}$ owing to enhancement in downward emission from the stratosphere (mostly due to $\mathrm{CO}_{2}$ ) and of about $2.6 \mathrm{~W} \mathrm{~m}^{-2}$ owing to a decrease in the upward flux at the tropopause, and both of these quantities vary significantly with latitude (Figure 6).

In addition to the $15-\mu \mathrm{m}$ bands, $\mathrm{CO}_{2}$ has absotption features in the 7.6- $\mu \mathrm{m}$ and $10-\mu \mathrm{m}$ (two bands) region and also has several bands in the solar spectrum (Table 2). The 7.6- $\mu \mathrm{m}$ and $10-\mu \mathrm{m}$ bands have frequently been ignored by climate models. For $\mathrm{CO}_{2}$ doubling, the 7.6- $\mu \mathrm{m}$ bands have a negligible effect, and the two bands in the $10-\mu \mathrm{m}$ region contribute roughly 5 to $10 \%$ (of the $15-\mu \mathrm{m}$ greenhouse effect). The solar bands have negligible impact on the stratospheric heating rates and on the surface-troposphere radiative forcing. However, they have a nonnegligible impact on the partitioning of the forcing between the surface and the troposphere. For example, for a doubling of $\mathrm{CO}_{2}$ the increased $\mathrm{CO}_{2}$ solar absorption within the troposphere reduces the surface absorption of solar radiation by about $0.3 \mathrm{~W} \mathrm{~m}^{-2}$ and enhances the tropospheric solar absorption by about $0.4 \mathrm{~W} \mathrm{~m}^{-2}$ [Hansen et al., 1981]. In the 15- $\mu \mathrm{m}$ region, $\mathrm{H}_{2}$ also has strong absorption features, and the overlapping of $\mathrm{H}_{2} \mathrm{O}$ absorption with $\mathrm{CO}_{2}$ bands ameliorates the greenhouse effect. Most climate models include the overlapping effect of $\mathrm{H}_{2} \mathrm{O}$ lines but ignore the strong $\mathrm{H}_{2} \mathrm{O}$ continuum absorption (in the $15-\mu \mathrm{m}$ region) which was only discovered in the early 1970 s. Table 3 illustrates the influence of $\mathrm{H}_{2} \mathrm{O}-\mathrm{CO}_{2}$ overlap on the $\mathrm{CO}_{2}$ radiative forcing for midlatitude summer conditions, when the ameliorating effect of $\mathrm{H}_{2} \mathrm{O}$ overlap is expected to be large. The $\mathrm{H}_{2} \mathrm{O}$ absorption reduces the surface heating (i.e., enhanced $\mathrm{CO}_{2}$ downward emission) by an order of magnitude but ameliorates the surface-troposphere heating by only $15 \%$, half of which is due to the continuum absorption. The model results in Table 3 are for clear sky conditions, and the inclusion of clouds (accounted for in most climate models) ameliorates the surfacetroposphere heating by another 10 to $20 \%$.

In summary, the radiative forcing due to $\mathrm{CO}_{2}$ arises from a complex chain of processes, and it is reasonably straightforward to account for most of these processes. However, attempts (in the published literature) to oversimplify the radiative calculations have led to significant errors and misinterpretation of the greenhouse effects [e.g., Newell and Dopplick, 1979 ; Idso, 1980].

2.1.2. Gases with absorption bands in the 7. to 13- $\mu$ m region. The atmosphere is relatively transparent in this spectral region, as revealed dramatically in the spectral distribution of the long-wave emission to space measured by the Nimbus 3 infrared interferometer spectrometer (IRIS) instru- 
(a) STRATOSPHERE / MESOSPHERE

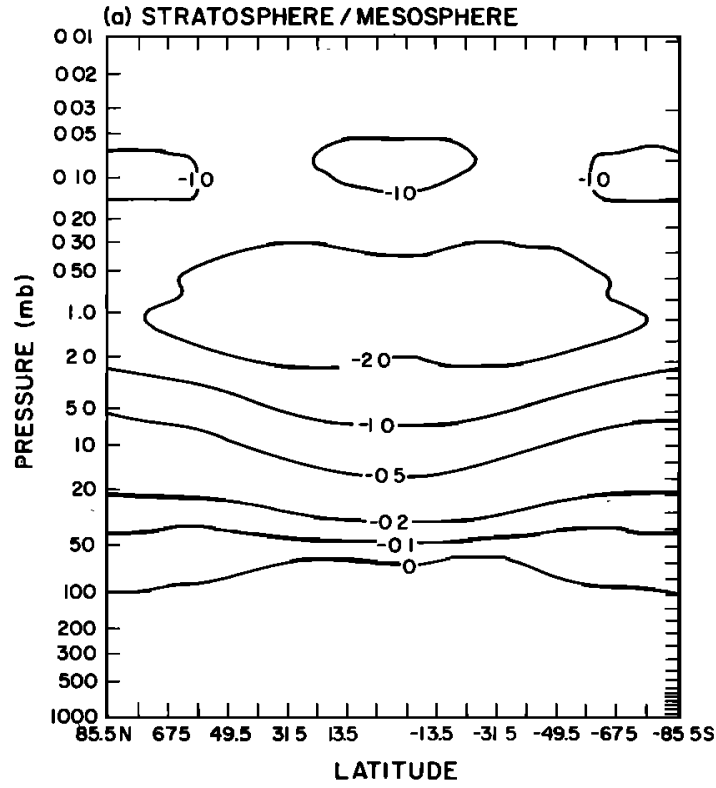

(b) LOWER ATMOSPHERE: $30^{\circ}$ N. LATITUDE

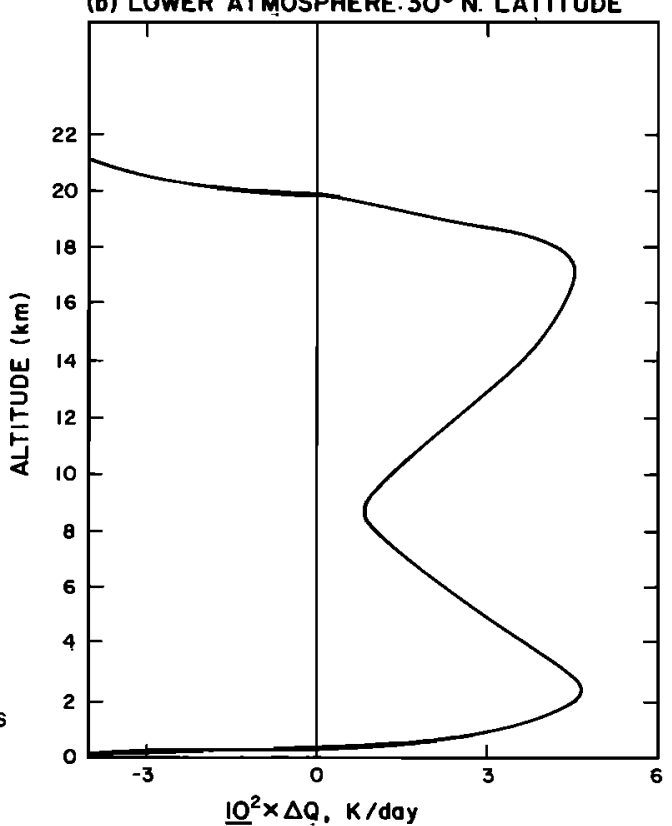

Fig. 5. Computed change in radiative heating rates for a doubling of $\mathrm{CO}_{2}$ : (a) stratosphere-mesosphere [Fels et al., 1980] and (b) troposphere and lower stratosphere [Ramanathan, 1981].

ment (Figure 7). The maximum emission by the planet occurs in the $7-$ to $13-\mu \mathrm{m}$ region where roughly $70-90 \%$ of the radiation emitted by the surface and clouds escapes to space. $\mathrm{CH}_{4}$, $\mathrm{N}_{2} \mathrm{O}$, and most other anthropogenic trace gases (in particular, the polyatomic trace gases) have strong absorption features in this spectral region and hence are effective in enhancing the greenhouse effect. $\mathrm{CH}_{4}$ and $\mathrm{N}_{2} \mathrm{O}$, in their present-day concentrations of 1.65 and 0.30 parts per million by volume (ppmv), respectively, contribute about $3.5 \mathrm{~W} \mathrm{~m}^{-2}$ to the radiative forcing of the surface-troposphere system, which is comparable to the greenhouse effect due to a doubling of $\mathrm{CO}_{2}$.

The vertical distributions of the forcing due to increases in $\mathrm{CH}_{4}, \mathrm{~N}_{2} \mathrm{O}$, and CFCs are shown in Figure 8. The corresponding radiative forcing of the surface-troposphere system and that of the surface alone are shown in Table 4 for comparison purposes. The model results shown in Figure 8 and Table 4 are clear-sky estimates computed with a tropical atmospheric profile. The tropical profile is chosen since CFC effects on atmospheric radiative heating rates are a maximum in the vicinity of the tropical tropopause (for example, see Dickinson et al. [1978]). The surface-troposphere radiative forcing for globally averaged conditions is also significantly smaller than the tropical clear-sky values shown in Table 4; for example, for $\mathrm{CO}_{2}$ doubling, the clear-sky tropical profile yields a value of $5.4 \mathrm{~W} \mathrm{~m}^{-2}$ (see Table 3 and also Kiehl and Ramanathan [1983, Table 3]) as opposed to about $4.2 \mathrm{~W} \mathrm{~m}^{-2}$ for globally averaged conditions.

The $\mathrm{CH}_{4}$ and $\mathrm{N}_{2} \mathrm{O}$ effects shown in Figure 8 are similar to those of $\mathrm{CO}_{2}$ in many respects. They all show tropospheric heating and stratospheric cooling. Furthermore, the surface radiative heating (i.e., downward emission at the surface) is only a small fraction of the total greenhouse effect, as in the case of $\mathrm{CO}_{2}$. However, the enhancements in stratospheric cooling rates for $\mathrm{CH}_{4}$ and $\mathrm{N}_{2} \mathrm{O}$ doubling are an order of magnitude smaller than that for a doubling of $\mathrm{CO}_{2}$.

The CFC effects differ significantly from $\mathrm{CH}_{4}, \mathrm{~N}_{2} \mathrm{O}$, and
$\mathrm{CO}_{2}$ in the following aspects: (1) the maximum in the local heating rate occurs at the tropopause and (2) the CFC surface heating (i.e., downward emission at the surface in Table 4) is almost equal to the surface-troposphere forcing, whereas for the other gases the surface heating is only a small fraction of the total effect. By scaling the CFC greenhouse effect of about $1.2 \mathrm{~W} \mathrm{~m}^{-2}$ at the tropopause for a 0 to 1 part per billion by volume (ppby) (each of F11 and F12) increase with that (5.4 W $\mathrm{m}^{-2}$; see Table 3) for a $\mathrm{CO}_{2}$ doubling, we see that the radiative forcing resulting from the addition of one molecule each of F11 and Fi2 is more than that due to the addition of $10^{4}$ molecules of $\mathrm{CO}_{2}$. The principal reasons for the extreme efficiency of CFCs are as follows: CFC band strengths are sev-

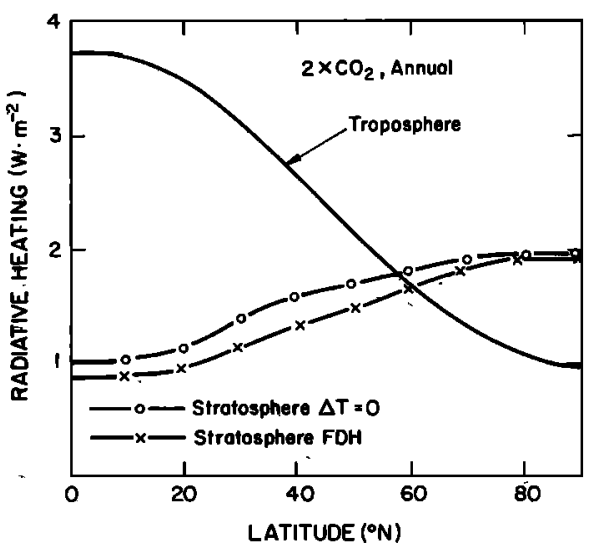

Fig. 6. Separate contributions from the troposphere and the stratosphere to the total heating of the surface-troposphere system, due to doubled $\mathrm{CO}_{2}$, for annual mean conditions. The stratosphere contribution is given by the increase in the downward radiative flux from the stratosphere. Stratospheric temperatures are held fixed as $\mathrm{CO}_{2}$ is increased for the $\Delta T=0$ curve, whereas they are allowed to change according to the fixed dynamical heating assumption for the fixed dynamical heating (FDH) curve. [Ramanathan et al., 1979]. 
TABLE 2. Long-Wave and Solar Bands of $\mathrm{CO}_{2}$

\begin{tabular}{|c|c|}
\hline $\begin{array}{l}\text { Spectral } \\
\text { Region, } \\
\mu \mathrm{m}\end{array}$ & Band Type \\
\hline $\begin{array}{l}12-18 \\
10 \\
7.6\end{array}$ & $\begin{array}{l}\text { Long-Wave Bands } \\
\text { Fundamental, isotopic, and hot bands } \\
\text { (total of } 76 \text { bands). } \\
\text { Two hot bands (9.4- and } 10.4-\mu \mathrm{m} \text { region). } \\
\text { Isotopic bands. }\end{array}$ \\
\hline Others & $\begin{array}{l}\text { Solar Bands } \\
\text { Fundamental, isotopic, and hot bands (see Dickinson } \\
\text { [1972] for a listing of the number of bands in each } \\
\text { spectral region). } \\
\text { There are numerous combination and overtone bands }\end{array}$ \\
\hline & $\begin{array}{l}\text { between } 1 \text { and } 3 \mu \mathrm{m} \text {. See Dickinson [1972] for } \\
\text { more details. }\end{array}$ \\
\hline
\end{tabular}

eral times stronger than those of $\mathrm{CO}_{2}$ (see Tables $1 a$ and $1 b$ ); CFC absorption increases linearly with its concentration, whereas the $\mathrm{CO}_{2}$ greenhouse effect scales logarithmically with the $\mathrm{CO}_{2}$ amount; and CFC absorption occurs in the atmospheric window (see WMO [1982] for further discussions).

\subsection{Greenhouse Gases With Strong Solar Absarption: $\boldsymbol{O}_{3}$}

On a global annual average, stratospheric $\mathrm{O}_{3}$ absorbs about $12 \mathrm{~W} \mathrm{~m}^{-2}$ of solar radiation and about $8 \mathrm{~W} \mathrm{~m}^{-2}$ of 9 - to $10-\mu \mathrm{m}$ radiation emitted by the surface-troposphere system [Ramanathan and Dickinson, 1979]. It also emits about $4 \mathrm{~W}$ $\mathrm{m}^{-2}\left(2.5 \mathrm{~W} \mathrm{~m} \mathrm{~m}^{-2}\right.$ up to space and $1.5 \mathrm{~W} \mathrm{~m}^{-2}$ down to the troposphere). Thus stratospheric $\mathrm{O}_{3}$ contributes to a net heating of the stratosphere which is balanced by long-wave cooling due to $\mathrm{CO}_{2}$ and $\mathrm{H}_{2} \mathrm{O}$. In effect, stratospheric $\mathrm{O}_{3}$ helps modulate the solar and long-wave fluxes to the troposphere [Ramanathan and Dickinson, 1979].

The largest impact of stratospheric $\mathrm{O}_{3}$ change is felt in the stratosphere itself (Figure 9). The solar heating rate perturbation peaks in the vicinity of the stratopause. With respect to the long-wave heating rate perturbation (Figure $9 b$ ), $\mathrm{O}_{3}$ reduction causes a decrease in the lower stratospheric heating rates (due to decreased absorption of surface emission) and an increase in the middle to upper stratosphere heating rates (due to decreased emission).

$A$ reduction in stratospheric $Q_{3}$ can modify the surface tem-

TABLE 3. Effects of 12- to 18- $\mu \mathrm{m} \mathrm{H}_{2} \mathrm{O}$ Absorption on the Radiative Forcing Due to $\mathrm{CO}_{2}$ Doubling for Clear Sky Tropical Atmosphere Conditions

Radiative
Forcing.
$\mathrm{W} \mathrm{m}^{-2}$ Comments

\begin{tabular}{lcl}
\hline & Surface-Troposphere Heating \\
$\mathrm{CO}_{2}$ only & 6.4 & Change in the net \\
$\mathrm{CO}_{2}+\mathrm{H}_{2} \mathrm{O}$ lines & 5.9 & long-wave flux at \\
$\mathrm{CO}_{2}+\mathrm{H}_{2} \mathrm{O}$ lines + continuum & 5.4 & the tropopause.
\end{tabular}

\begin{tabular}{lrl} 
& Surface Heating & \\
$\mathrm{CO}_{2}$ only & 6.9 & Increase in the \\
$\mathrm{CO}_{2}+\mathrm{H}_{2} \mathrm{O}$ lines & 3.6 & downward emission. \\
$\mathrm{CO}_{2}+\mathrm{H}_{2} \mathrm{O}$ lines + continuum & 0.4 & \\
\hline
\end{tabular}

Fṛom Kiehl and Ramanathan [1983].

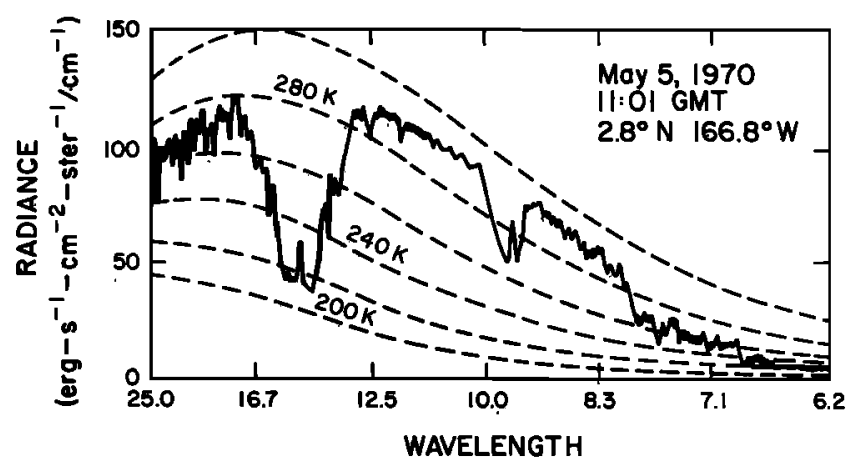

Fig. 7. Sample spectra from the IRIS instrument onboard Nimbus 3 satellite. The dashed lines indicate the effective radiation temperature for different wavelengths [Hanel et al., 1972].

perature via two competing processes: more solar radiation is transmitted to the surface-troposphere system, thereby contributing to a surface warming; on the other hand, the cooler stratosphere (owing to decreased solar and long-wave absorption) emits less to the troposphere, which would tend to cool the surface. The solar warming and the long-wave cooling effects are comparable in magnitude, and the magnitude as well as the sign of the net effect depends very critically on the magnitude of the stratospheric temperature change which in turn depends strongly on latitude and season.

The magnitude of the long-wave cooling effect depends on the altitude of $\mathrm{O}_{3}$ reduction, whereas the magnitude of the solar warming effect depends solely on the reduction in total column amount. Consequently, changes in stratospheric $\mathrm{O}_{3}$ can have different effects on the surface temperature, depending on the vertical distribution of the $\mathrm{O}_{3}$ change. This dependence is revealed in Figure 10, which shows the computed change in surface-troposphere radiative heating for two different profiles of $\mathrm{O}_{3}$ change. While the uniform $\mathrm{O}_{3}$ reduction leads to a net radiative cooling, the nonuniform $\mathrm{O}_{3}$ change profile (denoted by CFM in Figure 10b) leads to a net increase in the heating. For the CFM perturbation most of the decrease in $\mathrm{O}_{3}$ occurs in the upper stratosphere and hence the reduction in long-wave emission (due to stratospheric cooling) is not "felt" by the troposphere with the result that the solar warming dominates over the long-wave cooling effect.

Since the net effect on tropospheric radiative forcing is obtained as a difference between solar and long-wave effects, it depends strongly on latitude and season. In middle to higher latitudes, even the sign of the effect depends on season (for example, see the CFM curve in Figure 10).

Although the troposphere contains only about $10 \%$ of the total $\mathrm{O}_{3}$, the long-wave opacity of present tropospheric $\mathrm{O}_{3}$ amounts is nearly the same as that of present stratospheric $\mathrm{O}_{3}$ amounts (owing to the pressure broadening effects on the $\mathrm{O}_{3}$ 9.6- $\mu \mathrm{m}$ band line shape). Furthermore, both solar and longwave effects of tropospheric $\mathrm{O}_{3}$ change influence the surface temperature in the same direction, in contrast to the opposing solar and long-wave radiative effects induced by stratospheric $\mathrm{O}_{3}$ change. As a result, surface temperature is significantly more sensitive to changes in tropospheric $\mathrm{O}_{3}$ than to stratospheric $\mathrm{O}_{3}$ changes. In fact, for a uniform $\mathrm{O}_{3}$ change, tropospheric $\mathrm{O}_{3}$ change is about 2 to 3 times as effective as stratospheric $\mathrm{O}_{3}$ change in altering the radiative forcing (for example, see Table 5).

The strong dependence of the computed surface temper- 


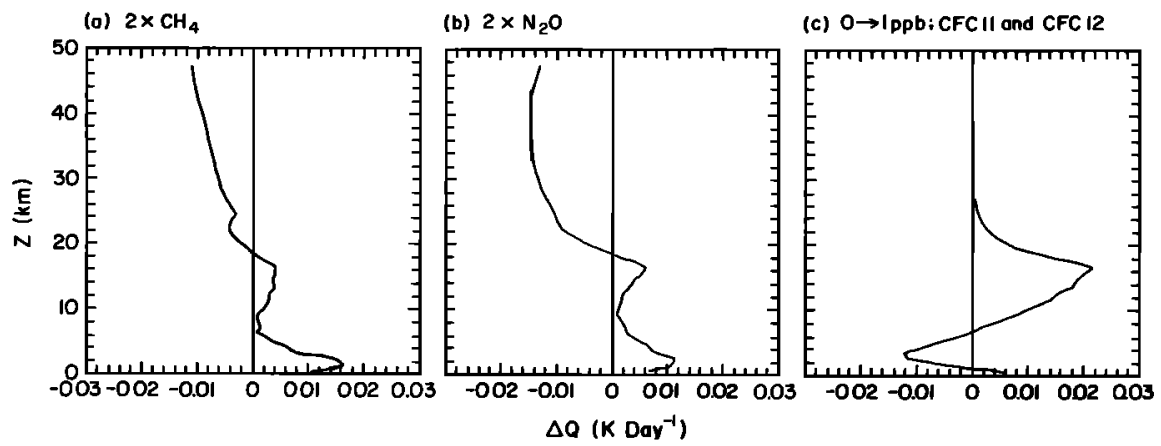

Fig. 8. Computed change in radiative heating rates $(\Delta Q)$ due to trace gas increase The calculations are for clear-sky conditions and employ a tropical profile. The results cited refer to calculations performed by J. T. Kiehl employing the narrow-band model described by Ramaswamy and Kiehl [1985].

ature change to the altitude and latitude of $\mathrm{O}_{3}$ perturbation is summarized in Figure 11 (adapted from Wang et al. [1980]). This figure shows the computed surface temperature change (per (cm atm) sTP $_{\text {of }} \mathrm{O}_{3}$ change) as a function of the altitude at which $\mathrm{O}_{3}$ is perturbed. For both the tropical and the midlatitude profiles, the computed surface temperature change is most sensitive to ozone change (on a per molecule basis) within the upper troposphere and lower stratosphere. The larger sensitivity of the tropical profile is mainly due to the warmer tropical surface temperature and the colder tropical tropopause temperature, both of which tend to maximize the greenhouse effect of $\mathrm{O}_{3}$.

\subsection{Additiveness of the Greenhouse Effects}

The question to be addressed here is, would the computed change in tropospheric radiative forcing due to the simultaneous addition of two or more gases to the atmosphere be the same as that of summing up the effects of adding each gas separately? This question arises because the absorption features of several gases appear in the same spectral region. For example, the $\mathrm{CF}_{4}, \mathrm{CH}_{4}$, and $\mathrm{N}_{2} \mathrm{O}$ bands occur in the 6- to $8-\mu \mathrm{m}$ region; $\mathrm{N}_{2} \mathrm{O}$ bands in the $15-\mu \mathrm{m}$ region overlap with $\mathrm{CO}_{2}$ bands; $\mathrm{CFC}$ bands overlap with $\mathrm{O}_{3}$ bands; etc. To a large extent, model calculations show that the error involved in the additive assumption is of the order of $10 \%$ (V. Ramanathan, unpublished calculations, 1986).

The above conclusion becomes invalid once one or more of the added gases alters a radiatively active constituent through chemical interactions. For example, both $\mathrm{CFCs}$ and $\mathrm{CH}_{2}$ influence $\mathrm{O}_{3}$ through chemistry. $\mathrm{CH}_{4}$ is estimated to lead to an increase in $\mathrm{O}_{3}$ in the upper troposphere and lower stratosphere, whereas an increase in CFCs would lead to a decrease in $\mathrm{O}_{3}$ in the stratosphere. Simultaneous addition of $\mathrm{CH}_{4}$ and CFCs may not produce the same change in the vertical profile of $\mathrm{O}_{3}$ as that obtained by superposition of the individual $\mathrm{O}_{3}$ changes produced by $\mathrm{CH}_{4}$ and CFCs. Since the tropospheric effects depend on the vertical distribution of the $\mathrm{O}_{3}$ perturbation, the validity of the additiveness assumption needs to be examined in the case of trace gases that chemically impact other radiatively active gases.

\subsection{Effects of Aerosols}

Stratospheric aerosols of volcanic origin undergo episodic variations, while tropospheric aerosols can undergo episodic or secular variations. It is necessary to understand the nature and magnitude of the "signature" of aerosols on the observed trends of surface-troposphere-stratosphere temperature before we can identify the role of trace gases on long-term (decadal) climate trends. The above necessity is the primary motivation for including a brief discussion on aerosols in the present study.

A detailed description of our current understanding of aerosol effects on climate can be found in the work by the World Climate Research Programme (WCP) [1983]. Aerosols can impact climate either directly by absorption and scattering of solar and long-wave radiation or indirectly by altering optical properties of clouds [Twomey et al., 1984]. The aerosolclimate problem is so complicated that after decades of research it is still difficult to make any general statements about whether aerosols cool or warm the climate. However, the direct radiative effects are relatively better understood than the indirect effects [Lenoble, 1984], and hence we will focus on the direct radiative effects of aerosols. With respect to climate change, aerosols of volcanic origin in the stratosphere and of anthropogenic origin in the troposphere have the potential for influencing temperature trends within the stratosphere and troposphere on time scales ranging from a few years to several decades.

The visible optical depth of the background stratospheric aerosols is of the order of 0.01 or less and hence has a negligible impact on climate [WCP, 1983]. The background tropospheric aerosol is estimated (by climate models) to cause a global surface cooling of about 1 to $3 \mathrm{~K}$ [see $W C P, 1983$, Table 2.2]. However, small changes in the assumed optical properties of aerosols (for example, single scattering albedo

TABLE 4. Surface-Troposphere Radiative Forcing Due to Increase in $\mathrm{CH}_{4}, \mathrm{~N}_{2} \mathrm{O}$, and CFCs for Clear-Sky Tropical Profile

\begin{tabular}{lcccc}
\hline & $2 \times \mathrm{N}_{2} \mathrm{O}$ & $2 \times \mathrm{CH}_{4}$ & $\begin{array}{c}\mathrm{CFC} \mathrm{11} \text { and } 12 \\
(0-2 \mathrm{ppb})\end{array}$ & $2 \times \mathrm{CO}_{2}{ }^{*}$ \\
\hline $\begin{array}{l}\text { Surface-troposphere } \\
\text { forcing } \dagger\end{array}$ & 0.7 & 0.9 & 1.2 & 5.38 \\
\begin{tabular}{l} 
Surface forcing \\
\hline
\end{tabular} & 0.12 & 0.15 & 1 & 0.4 \\
\hline
\end{tabular}

From Ramaswamy and Kiehl [1985]. Units are in watts per square meter.

*The $\mathrm{CO}_{2}$ results are taken from Kiehl and Ramanathan [1983]. The values given here are taken from their narrow-band Malkmus model results [see Kiehl and Ramanathan, 1983, Table 3].

†Downward stratospheric emission contributes about $10 \%$ for $\mathrm{N}_{2} \mathrm{O}$ and about $2 \%$ for $\mathrm{CH}_{4}$ and CFCs. 
(a) $8 \mathrm{~J}_{\mathrm{SW}}, \frac{1}{2} \mathrm{O}_{3}-$ CONTROL

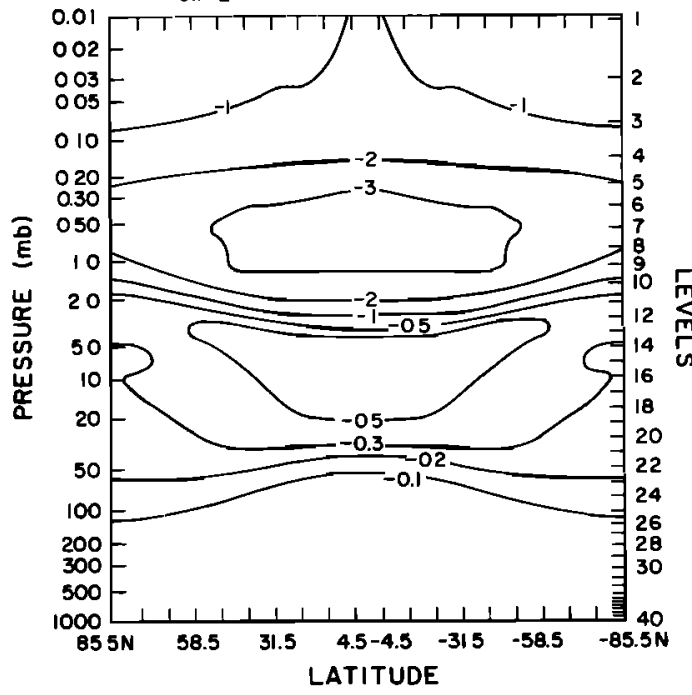

(b) $8 \mathrm{Q}_{96}, \frac{1}{2} \mathrm{O}_{3}-\mathrm{CONTROL}$

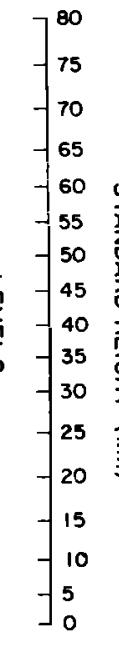

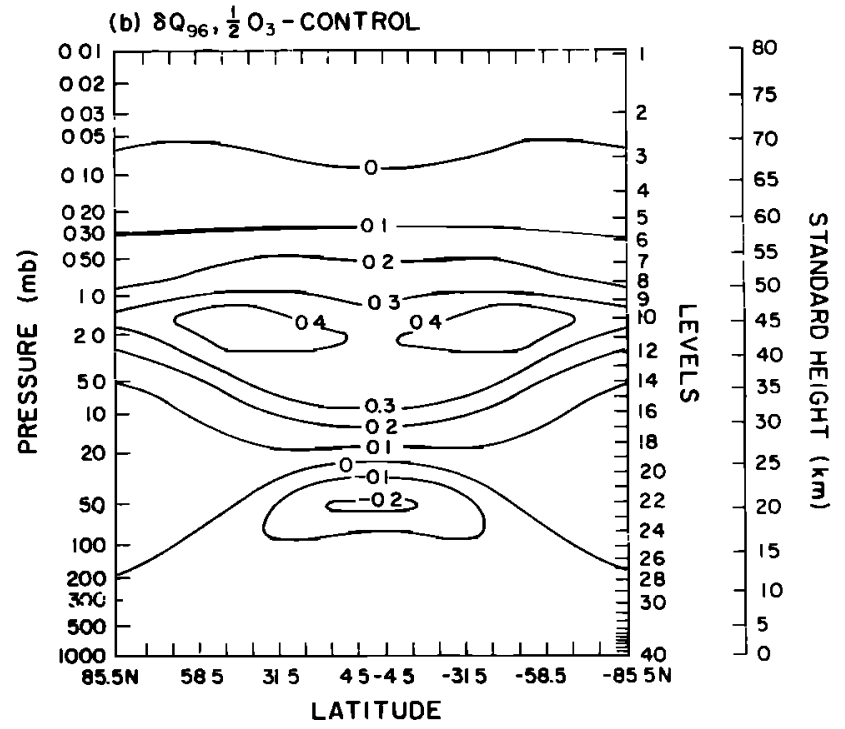

Fig. 9. Radiative drives (in Kelvins per day) for the ozone reduction experiments: (a) $\delta J_{\mathrm{sw}}$, the change in shortwave heating due to a $50 \%$ ozone reduction and $(b) \delta Q_{9.6}$, the change in $9.6-\mu \mathrm{m} \mathrm{O}_{3}$ band heating rate due to a $50 \%$ ozone reduction, with the temperatures in all cases held fixed at the control values [Fels et al., 1980].

and/or backscattered fraction; also see Lenoble [1984]) can change the computed effort from cooling to warming.

The stratospheric volcanic aerosols have been shown to affect the tropospheric climate in the following way. Aerosols produce two competing effects: (1) the scattering and absorption of solar radiation by the aerosols reduce the solar radiation reaching the troposphere, and (2) they increase the atmosphere's long-wave opacity. By decreasing the direct solar radiation and increasing the scattered radiation, the aerosol contributions can cool the troposphere. The increased longwave opacity and solar absorption can also heat the stratosphere. In order to account fully for aerosol effects upon climate, it is necessary to follow the cloud dispersion, the oxidation of $\mathrm{SO}_{2}$, the change in the size distribution, the geographical location, and the height and vertical structure of the aerosol cloud. In order to use this information effectively in a model, it is also necessary to know the aerosol refractive index [Reck and Hummel, 1981], from which the aerosol extinction, the single scattering albedo, and the asymmetry factor may be calculated.
One of the best documented and better understood effects of volcanic aerosols is their effect on stratospheric temperatures. Stratospheric temperature statistics recorded over the last two decades clearly reveal the low-latitude warming in the lower stratosphere following the eruption of Agung in 1963 and El Chichon in 1982 [WCP, 1983]. In the special case of the effects of the El Chichon eruption of April 4, 1982 [McCormick et al., 1984; Michalsky et al., 1984], isolation of its stratospheric signal from the thermal effects of the El Niño event and the quasi-biennial oscillation indicates that a temperature increase of $1^{\circ}-3^{\circ} \mathrm{C}$ at 30 mbars occurred between the equator and $35^{\circ} \mathrm{N}$ latitude [Labitzke et al., 1983; Quiroz, 1983]. Harshvardhan et al. [1983] used a nine-layer zonally averaged energy balance model with ice albedo feedback to estimate that the maximum surface cooling should have been $0.3^{\circ}-$ $0.4^{\circ} \mathrm{C}, 2.5$ years following the eruption. They expected the largest zonal temperature change to occur around $70^{\circ} \mathrm{N}$, with a value $0.5^{\circ}-0.6^{\circ} \mathrm{C}$. Their model also predicted an increase in the reflected solar radiation at the top of the atmosphere of about 3-4 $\mathrm{W} \mathrm{m}^{-2}$.
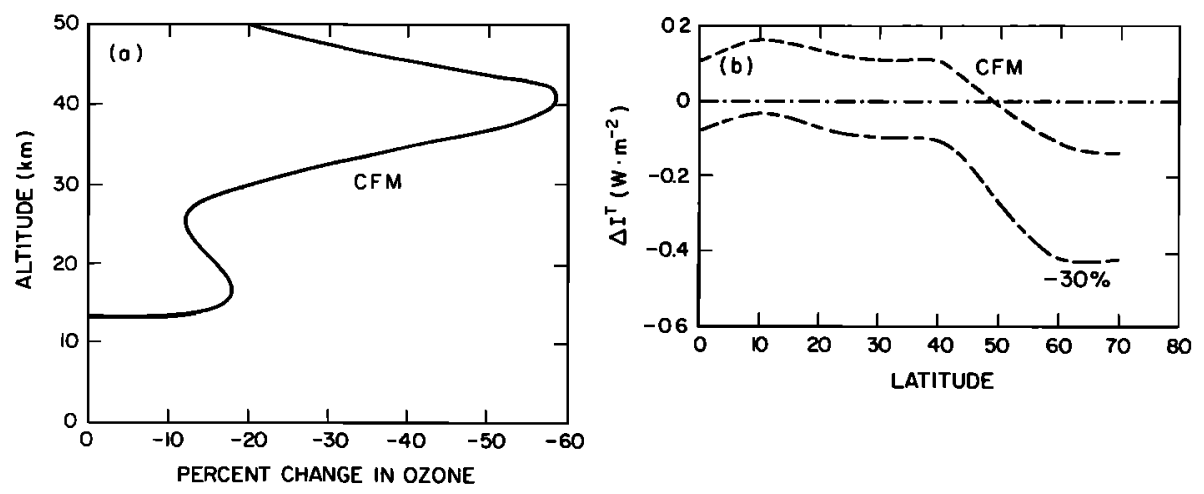

Fig. 10. Dependence of computed change in the net radiative flux at the tropopause to assumed vertical profile of $\mathrm{O}_{3}$ change. (a) The CFM profile is similar to the profile yielded by photochemical models for CFC increases. (b) The computed change in the net flux at the tropopause for the CFM profile and for a $30 \%$ uniform $\mathrm{O}_{3}$ reduction is shown [Ramanathan and Dickinson, 1979]. 
TABLE 5. Computed Surface-Troposphere Radiative Forcing Due to Uniform Reduction in $\mathrm{O}_{3}$ for Globally Averaged Conditions With Average Clouds

\begin{tabular}{|c|c|c|}
\hline $\mathrm{O}_{3}$ Perturbation & $\begin{array}{l}\text { Radiative } \\
\text { Forcing, } \\
\text { W m }^{-2}\end{array}$ & Reference \\
\hline$-25 \%$ in the total column & -0.6 to -0.7 & $\begin{array}{l}\text { Inferred from } \\
\text { Hansen et al. [1981]† }\end{array}$ \\
\hline & -0.1 to -0.2 & $\begin{array}{l}\text { Ramanathan and } \\
\text { Dickinson }[1979] \dagger\end{array}$ \\
\hline$-25 \%$ in the troposphere & -0.4 to -0.5 & Fishman et al. [1979] \\
\hline
\end{tabular}

*The values cited here account for stratospheric temperature changes to the imposed perturbations.

†These authors give results for surface temperature change and the radiative forcing was inferred by multiplying the temperature change with their model sensitivity (i.e., $\lambda$ as given by (1) defined in section 3.2.1) which is about $1.4 \mathrm{~W} \mathrm{~m}^{-2} \mathrm{~K}^{-1}$.

Episodic aerosol disturbances in the troposphere have also been shown to lead to regional climatic effects. The most important of these disturbances are arctic haze [Porch and $\mathrm{Mc}$ Cracken, 1982], Saharan dust [e.g., Fouquart et al., 1984], and urban aerosols [Galindo, 1984]. Among these disturbances, arctic haze may turn out to be an important issue for the trace gas-climate problem for several reasons. First, observations indicate that arctic haze contains large amounts of anthropogenic compounds like soot and sulfuric acid [Blanchet and List, 1984]. Second, it has been shown recently [Wilkness and Larson, 1984] that continental air masses (containing soot and other anthropogenic gases) can be transported over very long distances (for example, from Asia to the Arctic). Hence the arctic haze can exhibit a secular trend in the future. Third, the arctic haze has a substantial impact on the springtime solar heating rates [Porch and MacCracken, 1982]. Under clear-sky conditions the haze layer can enhance the heating rate by as much as $\mathbf{5 0} \%$. Since the trace gas effects on tropospheric climate are also expected to be large in the arctic region (see section 5 and 6), the potential effects of the haze on arctic climate can make it difficult to infer the trace gas effects.

In summary, aerosols can produce a sizable "noise" in meteorological data which makes it very difficult to establish a direct relationship between trace gas increases and climate change. Perhaps the best hope for assessing aerosol effects is to monitor the albedo of the planet from satellites with a high degree of precision (within $0.1 \%$ ).

\subsection{Current Status in Trace Gas Radiative Treatment}

Numerous approximations are invoked within climate models to simplify the treatment of the radiative effects of trace gases (for example, the use of band models). For example, an international study entitled "The Intercomparison of Radiation Codes Used in Climate Models (ICRCCM)" undertook the task of comparing clear-sky long-wave fluxes and cooling rates computed by the about $\mathbf{4 0}$ radiation models including line-by-line, narrow-band, and broadband models (see the appendix for further discussion of the band models). The results of this study have been published as a World Climate Research Programme report by Luther and Fouquart [1984], and this report will be referred to as ICRCCM (1984). The principal findings of the ICRCCM (1984) study, which focused on clear-sky long-wave calculations for $\mathrm{H}_{2} \mathrm{O}, \mathrm{CO}_{2}$, and $\mathrm{O}_{3}$ are given below.
(1) The line-by-line models are in very good agreement with each other (within $1 \%$ in the computed fluxes). (2) The radiation codes used in climate models differ significantly from each other. For example, the net radiative flux change (for clear-sky mid-latitude summer conditions) at the tropopause due to $\mathrm{CO}_{2}$ doubling (i.e., the radiative forcing of $\mathrm{CO}_{2}$ doubling) yielded by the models ranged from 4.5 to $7.5 \mathrm{~W} \mathrm{~m}^{-2}$. To give another example, the range in the computed downward flux at the surface for a mid-latitude summer atmosphere (with only water vapor) is about $60 \mathrm{~W} \mathrm{~m}^{-2}$. (3) Because of large uncertainties in $\mathrm{H}_{2} \mathrm{O}$ line shapes and in the physics of the $\mathrm{H}_{2} \mathrm{O}$ continuum, there is an urgent need to validate lineby-line calculations with accurate laboratory data and with flux measurements in the atmosphere.

Since $\mathrm{H}_{2} \mathrm{O}, \mathrm{CO}_{2}$, and $\mathrm{O}_{3}$ are discussed in great detail in the ICRCCM (1984) study, the present discussion will focus on the other trace gases listed in Table 1. Climate models generally employ narrow-band or broadband models for $\mathrm{CH}_{4}$ and $\mathrm{N}_{2} \mathrm{O}$ and employs various versions of the optically thin approximations for all other gases in Table 1.

The validity of the optically thin approximation is discussed in detail in the work by $W M O$ [1982] (see the appendix by $R$. D. Cess in that report). For concentrations of CFCs (and others in Table 1) of several parts per billion by volume or less, the optically thin approximation when employed in conjunction with the exponential sum-fitting method has been shown [Ramanathan et al., 1985] to yield the same accuracy as the more detailed narrow-band model. The next step is to assess the accuracy of the approaches used in narrow-band and broadband models.

The effect of simplified model approaches can be evaluated by intercomparing models of varying complexity. This technique for evaluating models is illustrated in the Appendix for the $v_{4}$ band of $\mathrm{CH}_{4}$ (located at $1300 \mathrm{~cm}^{-1}$ ). The following is a summary of the analyses given in the appendix:

1. It is possible to define and derive a self-consistent narrow-band or broadband model that agrees excellently with line-by-line calculations both for homogeneous and for inhomogeneous optical paths (i.e., atmospheric path).

2. The choice of spectral interval for the narrow-band model is quite arbitrary. The spectral interval has to be chosen by comparing with line-by-line calculations.

3. Line half-width and its temperature dependence are

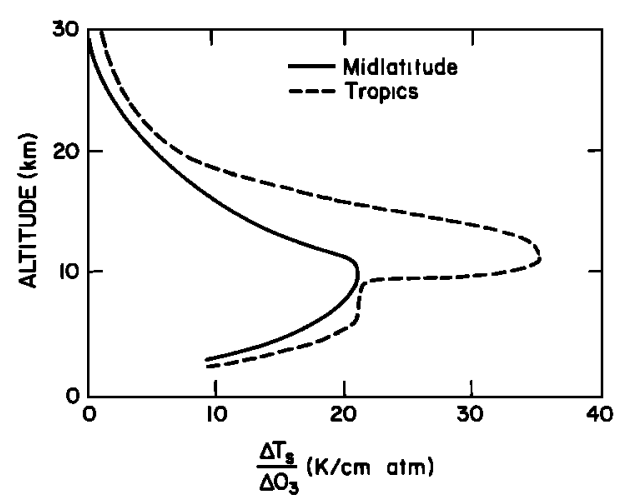

Fig. 11. Computed change in surface temperature (per unit local $\mathrm{O}_{3}$ change) as a function of altitude at which $\mathrm{O}_{3}$ is perturbed. The surface temperature sensitivity curve is shown for mid-latitude (solid curve) and tropical (dashed curve) atmosphere conditions [Wang et al., 1980]. 
available for only a minor fraction of the several thousand lines within each band. The lack of this data is a major source of uncertainty in line-by-line calculations.

For CFCs and all other gases except $\mathrm{CH}_{4}$ and $\mathrm{N}_{2} \mathrm{O}$, the relevant narrow-band model parameters are unavailable. Even the integrated band strengths are unavailable for many potentially important gases such as F113 and F114. Furthermore, for many of the gases the hot bands (i.e., bands for which the lower vibrational states is an excited state) overlap strongly with the fundamental bands (for example, Varanasi and $\mathrm{Ko}$ [1977] for F11 and F12). In such instances it is important to determine the strengths of the hot bands for accurate modeling of the opacities in band models.

\section{THEORY AND MODELS}

\subsection{Stratospheric Response to Perturbations}

The study of climatic impacts within the stratosphere owing to added trace constituents is of special interest for several reasons. First, for reasonable projections of future trace constituent distributions, the expected temperature changes in the upper stratosphere are nearly an order of magnitude greater than the expected surface changes. Second, these expected temperature changes are essentially independent of ocean temperature changes and cloud feedback effects. Both processes are a source of considerable uncertainty in assessing tropospheric climate change.

Climate change in the stratospheric is also different because temperature change there is coupled directly with photochemical processes. The strongest link is with the temperature dependence of the equilibrium ozone. For example, the cooling effect of increasing $\mathrm{CO}_{2}$ in the upper stratosphere superficially involves virtually no chemistry. However, as temperatures drop, ozone amounts increase, leading to a local heating effect. This is an important negative feedback. In addition, increases of the trace gases, particularly $\mathrm{CH}_{4}, \mathrm{H}_{2} \mathrm{O}, \mathrm{N}_{2} \mathrm{O}$, and chlorofluorocarbons, tend to lead to $\mathrm{O}_{3}$ decreases (and cooling effects) in the upper stratosphere. However, such local decreases of $\mathrm{O}_{3}$ affect the incoming solar ultraviolet radiation such that greater penetration into the lower stratosphere would be allowed. This acts to increase local heating there but more importantly, increases production of $\mathrm{O}_{3}$ below. This process produces a very significant "self-healing" effect on the total $\mathrm{O}_{2}$ column while leading to significant changes in the shape of the ozone profile. This, in turn, affects the local temperature.

The almost bewildering array of interactive feedback processes in the stratosphere implies that they can be understood only through careful, self-consistent modeling of the radiativephotochemical-dynamical system. Ultimately, this modeling must be done with fully interactive, time-dependent, threedimensional models.

For a number of reasons, such complete models remain impractical today. The most well-known reason is the tremendous computational requirements for a fully comprehensive model. However, even if such resources were now available, the current strategy of using a hierarchy of models ranging from the very simple to the very complex would still be the appropriate one. This is because there remains significant uncertainties in our understanding of many aspects of the radiative-photochemical-dynamical system. Useful reductions of such uncertainties require a wide range of considerably more focused research activities. Without improved understanding and modeling capability in all components of the problem, the power of more comprehensive modeling treatment tends to be diminished.

These difficulties are amplified by the very serious uncertainties in the projected changes in atmospheric trace constituent amounts. In order to explore such problems, typically, a generous range of possibilities (scenarios) is considered.

This situation has led to a wide variety of modeling approaches, all of which work to reduce the complexity of the problem and emphasize various sets of scientific questions. Some of these modeling approaches are surveyed below.

3.1.1. Role of radiative-photochemical-diffusive models. The simplest approach that comes close to allowing an understanding of the complex interactions among radiation, photochemical, and transport processes is the so-called onedimensional model. These models allow no horizontal variations and thus may logically be considered to represent globally averaged (in the horizontal) conditions. Historically, however, they often have been used to represent local conditions, usually at some appropriate "midpoint" latitude such as $30^{\circ} \mathrm{N}$. Historically, the one-dimensional models have usually considered only photochemical problems, with the required transport being parameterized by carefully chosen but empirical "eddy" diffusion coefficients [e.g., McElroy et al., 1974; Hunten, 1975].

Such one-dimensional models have been shown to be very powerful tools for understanding complex chemical feedback in spite of their simplicity. Moreover, they have served as the basic tool for most of the previous assessments of the expected impacts on stratospheric ozone changes due to various anthropogenic activities [e.g., National Research Council, 1979]. Typically, these models have prescribed temperatures and thus have only indirect implications for stratospheric climate changes.

More recently, some investigators have begun efforts to couple these chemically oriented one-dimensional models with the Manabe and Wetherald [1967] type radiative-convective one-dimensional climate models. These include Luther et al. [1977] and Boughner [1978].

To date, the main concern has been with including the effects of climatic feedback on calculated ozone changes. As the effects of radiatively important trace species other than $\mathrm{CO}_{2}$ become the object of more serious climatic attention, the inclusion of photochemical feedbacks in the climate system will gain more research attention. However, in such cases the limitations of the one-dimensional model framework will become more severe. This is particularly so for the calculation of chemical-climatic feedbacks through stratospheric water, a trace substance whose spatial distribution seems to be fundamentally dependent upon three-dimensional processes.

3.1.2. Two-dimensional effects. In both climatic and chemical problems there are many physical processes that at best are poorly represented in one-dimensional models. The next logical step is to construct a two-dimensional model in the meridional-vertical plane. This allows inclusion of many important sun angle dependent processes. Most models in this category have prescribed transport processes in various combinations of zonally symmetric and eddy mechanisms.

In the past the main concern has been with the problem of self-consistent prescription of mean and eddy transport processes. Recently, conceptual progress (R. A. Plumb and J. D. 
Mahlman, unpublished manuscript, 1986] and semiempirical successes [e.g., Garcia and Solomon, 1983; Ko et al., 1985; Guthrie et al., 1984] have been achieved. This progress has been mainly in the "transport-chemistry only" models in which the transport does not really change as the constituents or the climate of the stratosphere change.

Early attempts to produce self-consistent dynamical response in two-dimensional models were given by Vupputuri [1978] and Pyle and Rogers [1980]. In these models the eddy fluxes are essentially specified (usually through local eddy diffusion coefficients), but the meridional circulation is calculated self-consistently in response to these fluxes. In a more fundamental sense, these models are not really climate models either, since the fundamental eddy forcing remains prescribed through large changes in constituents. They might, however, capture an important part of the two-dimensional "nondynamical" part of the climatic response to trace constituent changes. Such models can yield temperature changes that are very close to the "fixed dynamical heating" (FDH) limit described in the next section.

3.1.3. Three-dimensional and dynamical effects. Since it is clear that both chemical and dynamical processes are inherently three-dimensional, it is inevitable that threedimensional climate-chemical models will play an increasing role in analysis of such trace gas-climate problems. However, even as much models are employed, they can provide information which at times may show ways in which full threedimensional processes may not have to be modeled explicitly once they are well understood. For example, the work of $\mathrm{Mahl}$ man et al. [1986] indicates that all long-lived stratospheric gases exhibit predictable structure, provided that the complete three-dimensional structure is solved for one of them and the chemistry of each of the gases of interest is known. In this context it is likely that full three-dimensional solutions will not be required for each of the ever growing list of radiatively active gases that may influence climate.

In the context of predicting stratospheric climate change, it is of interest to inquire whether or not three-dimensional models are really required. The answer to this probably can be supplied only with a properly posed three-dimensional model. An early attempt in this regard was offered by Fels et al. [1980]. They pointed out that there are two possible extremes of stratospheric climatic responses to changes in trace constituents. These are (1) "dynamical adjustment" and (2) "radiative adjustment." For dynamical adjustment the net dynamical heating (sum of adiabatic heating mechanisms in the thermodynamic equation) adjusts so that the temperature doesn't change. For radiative adjustment (see also Fels and Kaplan [1975] and Ramanathan and Dickinson [1979]) the temperature changes so that the net dynamical heating doesn't change.

Since the net dynamical heating is a function of the degree to which the stratosphere is dynamically forced, radiative adjustment means in this context that no further changes in dynamical forcing occur as a result of changing trace constituents. This is why Fels et al. [1980] refer to this as the fixed dynamical heating limit. The attractive feature of the FDH limit (if valid) is that in principle, climatic calculations can be performed with purely radiative models. However, this requires that such radiative models perturb about realistic atmospheric structure (either real or modeled). The experiments of Fels et al. [1980] suggest strongly that middle and high latitudes of the stratosphere are rather well described by the FDH limit. For tropical wind systems, however, considerable dynamical adjustment is expected. They offer a mechanistic model that explains why significant dynamical adjustment is expected mainly in the tropics.

The calculations of Fels et al. [1980] pertain to annual mean conditions and may not necessarily reflect the validity of the FDH model for other seasons (in particular, the winter polar regions where dynamical processes play a crucial role in maintaining the thermal structure). Nevertheless, it seems safe to conclude that on an annual mean basis the stratospheric temperature response to radiative heating perturbations is governed to a large extent by long-wave radiative adjustment processes.

\subsection{Troposphere Response and the Role of Feedbacks}

One of the fundamentally important concepts which has emerged out of the numerous one-, two-, and threedimensional climate model studies is that the surface temperature change is largely determined by the radiative forcing of the surface-troposphere system (i.e., net flux change at the tropopause). The computed surface temperature change is neither strongly dependent on the vertical distribution of the radiative heating within the troposphere nor strongly dependent on the manner in which the radiative heating is partitioned between the surface and the troposphere. The reason for the insensitivity of the computed surface temperature change to the vertical heating distribution has been explained in the introduction to section 2 .

The model results that helped forge this concept are numerous, and only a few examples will be given below: (1) The radiative forcing of the surface-troposphere system due to a $2 \%$ increase in solar insolation and due to a $\mathrm{CO}_{2}$ doubling agree within about $10 \%$. But the partitioning of this forcing in terms of surface forcing and tropospheric forcing is vastly different. Yet, almost all climate model studies, including the general circulation model studies [e.g., Wetherald and Manabe, 1975; Hansen et al., 1984], show that the computed surface temperatures change for the $2 \%$ solar radiation increase is within $10 \%$ of that due to $\mathrm{CO}_{2}$ doubling. (2) Likewise, as shown in section 2 , the vertical distribution of the radiative heating due to $\mathrm{CFCs}$ and $\mathrm{CH}_{4}$ or $\mathrm{CO}_{2}$ are drastically different. Yet, the computed surface temperațure change due to the individual gases scales almost linearly with respect to their radiative forcing of the surface-troposphere system. The conclusions derived from these studies apply only to small deviations from the observed climate and should not be generalized to large perturbations.

Three different types of climate models have been used to compute the climate change due to trace gas perturbations: energy balance models (EBMs), radiative-convective models (RCMs), and general circulation models (GCMs).

3.2.1. Energy balance models: the zero climate feedback limit. The concept of surface-troposphere radiative forcing is particularly useful for inferring the role of feedback processes, since it enables the problem to be formulated in terms of a zero-dimensional climate model. Denoting the perturbation in surface-troposphere radiative heating (i.e., the radiative forcing) as $\Delta Q$, the surface temperature change $\Delta T_{s}$ can be related to $\Delta Q$ by the relation [Dickinson, 1985]

$$
\Delta T_{s}=\Delta Q / \lambda
$$


where $\lambda$ is referred to as the climate feedback parameter. The net (solar plus long-wave) radiative forcing, $\Delta Q$, is the net (down minus up) radiative flux change at the tropopause due to the trace gas change. The change in the net flux is computed by holding the surface and tropospheric temperatures fixed at the reference value but allowing the stratospheric temperatures to come to equilibrium with the radiative heating perturbation. These subtle requirements of computing $\Delta Q$ have been ignored at times (in the literature) with catastrophic errors. For example, (1) has been applied by estimating $\Delta Q$ at the surface, which tends to underestimate $\Delta T_{s}$ by a factor of 2 to 4 [see Ramanathan, 1981] or by estimating $\Delta Q$ at the top of the atmosphere without allowing the stratosphere to come to equilibrium, which tends to underestimate $\Delta T_{s}$ by a factor of 2 (see the discussions by Schneider [1975]).

In general, $\lambda$ estimated by the hierarchy of simple and sophisticated climate models lies in the range of

$$
1<\lambda<4 \mathrm{~W} \mathrm{~m}^{-2} \mathrm{~K}^{-1}
$$

For the simplest case in which the earth-atmosphere system radiates as a blackbody with an effective radiating temperature of $254 \mathrm{~K}, \lambda=4 \sigma \dot{T}^{3}\left(=3.7 \mathrm{~W} \mathrm{~m}^{-2} \mathrm{~K}^{-1}\right)$. For this case a doubling of $\mathrm{CO}_{2}$ (note that $\Delta Q \approx 4.2 \mathrm{~W} \cdot \mathrm{m}^{-2}$ ) would yield a surface warming of about $1.1 \mathrm{~K}$. This simple model implicitly assumes that the troposphere and surface are coupled so that the same temperature change occurs in the troposphere or at the surface, i.e., the lapse rate is assumed to be an invariant of climate. More importantly, this model ignores all climate feedback processes involving temperature, humidity, clouds, and others. The only feedback this model includes is the negative feedback between temperature and long-wave emission [Dickinson, 1982]. Hence the climate response obtained from a model with fixed lapse rate, fixed atmospheric composition, and fixed planetary albedo is referred to as the zero climate feedback case, and the change in surface temperature for this case is denoted by $\left(\Delta T_{s}\right)_{0}$.

The EBM given by (1) imposes the energy balance at the top of the tropopause. There are also surface energy balance models (SEBMs) which solve for $\Delta T_{s}$ by imposing surface energy balance. A recent review by Schlesinger and Mitchell [1985] shows that a wide range of values for $\lambda$ may be obtained ( 0.3 to $10 \mathrm{~W} \mathrm{~m}^{-2} \mathrm{~K}^{-1}$ ) for SEBMs, depending upon modeling assumptions. In several cases where the $\lambda$ is outside the range of 1 to $4 \mathrm{~W} \mathrm{~m}^{-2} \mathrm{~K}^{-1}$, the cause has been traced to the assumptions that violated the first law of thermodynamics [Cess and Potter, 1984].

There are also one-dimensional (latitude) and twodimensional (latitude and altitude) EBMs which have played an important role in illustrating the magnitude of several climate feedbacks. The one-dimensional EBMs are reviewed by North et al. [1981], and the two-dimensional models are described by Peng et al. [1982] and Gutowski et al. [1985].

3.2.2. Radiative-convective models. Radiative-convective models determine the equilibrium vertical temperature distribution for an atmospheric column and its underlying surface for given insolation and prescribed atmospheric composition and-surface albedo. An RCM includes submodels for the transfer of solar and long-wave radiation, the turbulent heat transfer between the earth's surface and the atmosphere, the vertical redistribution of heat within the atmosphere by dry or moist convection, the atmospheric water vapor content, and cloud amount. The radiative transfer models used in RCMs are frequently identical to those used in GCMs. The vertical heat redistribution by convective atmospheric motions is modeled as an adjustment whereby the temperature lapse rate of the atmosphere is prevented from exceeding some given value. The amount of water vapor is determined in RCMs either by prescribing the absolute humidity or the relative humidity; in the latter case the amount of water vapor increases (decreases) with increasing (decreasing) temperature. Finally, the fractional cloudiness and the temperature or altitude of the cloud tops are either prescribed or predicted.

The zero climate feedback limit in the RCM is obtained by prescribing the lapse rate, absolute humidity, and planetary albedo and by holding them fixed as surface and atmospheric temperatures vary. The computed surface temperature change for the zero climate feedback case, $\left(\Delta T_{s}\right)_{0}$, generally ranges from $1.2 \mathrm{~K}$ [Hansen et al., 1984] to $1.3 \mathrm{~K}$ [Manabe and Wetherald, 1967; Ramanathan, 1981]. Both of these values are reasonably close to the value of $1.1 \mathrm{~K}$ obtained from the zero-dimensional EBM (section 3.2.1). Hence $\left(\Delta T_{s}\right)_{0}$ is a nearly model-independent parameter and is a useful measure of the radiative forcing due to a given change in atmospheric composition.

To indicate the importance of the climate feedback processes listed in Table 6, we introduce a climate feedback factor $F$ which is defined as

$$
F=\Delta T_{s} /\left(\Delta T_{s}\right)_{0}
$$

where $\Delta T_{s}$ is the change in surface air temperature with the feedback. The $\left(\Delta T_{s}\right)_{0}, \Delta T_{s}$, and $F$ obtained for $\mathrm{CO}_{2}$ doubling with various hypothesized feedbacks are shown in Table 6.

TABLE 6. Feedback Analysis Using the Oregon State University

\begin{tabular}{|c|c|c|c|}
\hline $\begin{array}{l}\text { Feedback } \\
\text { Mechanism }\end{array}$ & $\underset{{ }^{\circ} \mathrm{C}}{T_{s}\left(1 \times \mathrm{CO}_{2}\right)}$ & $\begin{array}{c}\Delta T_{s}, \\
{ }^{\circ} \mathrm{C}\end{array}$ & $F^{*}$ \\
\hline None $\left[\left(\Delta T_{s}\right)_{0}\right] \dagger$ & 15.28 & 1.35 & \\
\hline Water vapor $\ddagger$ & 14.53 & 1.94 & 1.4 \\
\hline Lapse rates & 9.53 & 0.88 & 0.7 \\
\hline Cloud temperature\| & 15.28 & 1.73 & 1.3 \\
\hline Cloud cover & 15.28 & 1.38 & 1.0 \\
\hline Cloud optical depth $\rceil$ & 15.28 & 1.39 & 1.0 \\
\hline Surface albedo** & 15.43 & 1.56 & 1.2 \\
\hline $\begin{array}{l}\text { Water vapor } \ddagger \text { and } \\
\text { lapse rate§ }\end{array}$ & 9.38 & 1.19 & 0.9 \\
\hline Cloud temperature $\|$ & 14.20 & 2.79 & 2.1 \\
\hline Cloud cover $\ddagger \ddagger$ & 15.12 & 1.81 & 1.3 \\
\hline Cloud optical depth $T$ & 15.39 & 1.70 & 1.3 \\
\hline Surface albedo** & 14.58 & 2.39 & 1.8 \\
\hline $\begin{array}{l}\text { Water vapor, } \ddagger \\
\text { cloud temperature,\| } \\
\text { and surface albedo** }\end{array}$ & 14.14 & 3.85 & \\
\hline
\end{tabular}
Two-Layer RCM

From M. E. Schlesinger (private communication, 1986).

${ }^{*} F=\Delta T_{\mathrm{s}} /\left(\Delta T_{\mathrm{s}}\right)_{0}$.

$\dagger\left(\Delta T_{s}\right)_{0}$ is calculated by the RCM without feedbacks.

IWith the fixed relative humidity profile of Manabe and Wetherald [1967].

$\S$ With the moist adiabatic lapse rate.

WWith fixed cloud temperature prescribed equal to that of the 1 $\times \mathrm{CO}_{2}$ simulation with no feedback.

fWith variable optical depth $\tau$ prescribed similarly to that of $W$ ang et al. [1981] and cloud albedo, absorptivity, and transmissivity parameterized in terms of $\tau$, following Stephens et al. [1984].

${ }^{* *}$ With variable surface albedo prescribed as by Wang and Stone [1980].

¥With variable cloud cover prescribed similarly to that of Wang et al. [1981] and cloud albedo, absorptivity, and transmissivity. 
The water vapor feedback (second row in Table 6) is one of the better understood feedback processes and was introduced in the RCM by Manabe and Wetherald [1967] on the basis of the fact that the observed zonally averaged relative humidity is quite insensitive to seasonal changes in temperatures. With fixed relative humidity the water vapor amount increases with an increase in surface temperature according to the ClausiusClapeyron relation. Since $\mathrm{H}_{2} \mathrm{O}$ is the most important greenhouse constituent, the $\mathrm{H}_{2} \mathrm{O}-T_{s}$ feedback increases computed $\Delta T_{s}$ by roughly 50 to $80 \%$, depending on the model [see Manabe and Wetherald, 1967] (see also the review paper by Ramanathan and Coakley [1978] and $F$ in Table 6). The increased solar absorption by $\mathrm{H}_{2} \mathrm{O}$ contributes roughly $10 \%$ to the $\mathrm{H}_{2} \mathrm{O}-T_{\mathrm{s}}$ feedback.

Other parameters such as lapse rate, cloud top temperature, and cloud cover will have a significant impact on $\lambda$. The numbers in Table 6 indicate the potential importance of these feedbacks. However, the magnitude and even the sign in some instances (for example, clouds) of these feedbacks are not well known.

Another important feedback concerns the snow and ice albedo feedback. With an increase in surface temperature, snow and ice cover will melt, which may lead to a decrease in the areal extent of snow and ice cover; this will lead to a decrease in surface albedo and a corresponding increase in the absorbed solar radiation. This positive feedback has been the subject of scores of EBM, RCM, and GCM studies. Generally, according to Dickinson [1985], several models have converged to the conclusion that the ice albedo feedback amplifies global average $\Delta T_{s}$ by about $15 \%$ (also see last column of Table 6); note, however, that the magnitude of amplification by any one feedback depends on the other feedbacks included. It should also be noted that the ice albedo feedback has a significant impact on polar surface temperature change.

3.2.3. General circulation models. The principal prognostic variables of an atmospheric GCM are the temperature, horizontal velocity, and surface pressure, which are governed by the thermodynamic energy equation, the horizontal momentum equation, and the surface pressure tendency equation, respectively. With the mass continuity equation and the hydrostatic approximation and appropriate boundary conditions, these equations form a closed system for an adiabatic and frictionless atmosphere. But the general circulation of the atmosphere is the large-scale, thermally driven field of motion in which there are interactions between the heating and motion fields. Therefore several additional prognostic variables, with corresponding governing equations and appropriate boundary conditions, must be added to simulate the heating. Of these the most important is the water vapor, which is governed by the water vapor continuity equation. Because the atmosphere is largely heated by the underlying surface through the exchange of sensible and latent heat, and because snow lying on the ground can have a large influence on the surface albedo, the ground temperature, soil moisture, and mass of snow on the ground are prognostic variables, governed by energy, water, and snow budget equations for the ground. In addition to the prognostic variables, GCMs have many diagnostic variables, among which clouds may be one of the most important.

The equilibrium changes in surface air temperature $\Delta T_{s}$ simulated by seven selected GCMs for a doubled $\mathrm{CO}_{2}$ concentration are presented in Table 7. The first five studies were
TABLE 7. Surface Air Temperature Change Induced by a Doubled $\mathrm{CO}_{2}$ Concentration as Simulated by Selected General Circulation Models

\begin{tabular}{ll}
\hline \multicolumn{1}{c}{ Reference } & $\Delta T_{\mathbf{s}}, \mathbf{K}$ \\
\hline Manabe and Wetherald [1975] & 2.9 \\
Manabe and Wetherald [1980] & 3.0 \\
Schlesinger [1983] & 2.0 \\
Washington and Meehl [1983] & 1.3 \\
Washington and Meehl [1984] & 3.5 \\
Hansen et al. [1984] & $4.2^{*}$ \\
S. Manabe and R. T. Wetherald $\dagger$ & 4.0 \\
\hline
\end{tabular}

*This version of the Hansen et al. GCM has less sea ice than observed. They also report results with an alternate version of the GCM which was roughly $15 \%$ more sea ice than observed, and this "alternate" version yielded a $\Delta T_{\mathrm{s}}$ of $4.8 \mathrm{~K}$.

†Unpublished study. See Schlesinger and Mitchell [1985].

performed with atmospheric GCMs coupled to a swamp ocean model which has zero heat capacity and no horizontal or vertical heat transports. These coupled atmospheric GCM/swamp ocean models are run without a seasonal insolation cycle to prevent the freezing of the ocean in the latitudes of the polar night. The last three studies were performed with atmospheric GCMs coupled to a fixed-depth mixed layer ocean model which has heat capacity, prescribed horizontal heat transports (zero except in the work by Hansen et al. [1984]), and no vertical heat transports. These coupled atmospheric GCM fixed-depth mixed layer ocean models are run with the seasonal insolation cycle.

Table 7 shows that the models without the seasonal insolation cycle give surface air temperature warmings of 1.3 to 3.0 $\mathrm{K}$ for a doubling of $\mathrm{CO}_{2}$, while the models with the seasonal insolation cycle give annual average warmings of 3.5 to $4.2 \mathrm{~K}$ (also see footnotes in Table 7). It is difficult to identify the specific causes for the wide range of surface air temperature warming simulated by the models with a swamp ocean, because these models differ in geographical domain, land/ocean distribution, and orography as well as in their treatment of clouds, snow, and sea ice [Schlesinger, 1984]. It is therefore surprising, but gratifying, that the three simulations with the atmospheric GCM/fixed-depth mixed layer ocean model having a global domain, realistic land/ocean distributions and orography, and interactive clouds produce comparable global mean surface air temperature warmings.

3.2.4. Importance of cloud feedback. One of the least understood and potentially important feedbacks is the feedback involving clouds. The issues to be addressed are threefold. The first concerns the response of cloud cover, cloud base, and cloud tops to temperature changes; the second concerns the change in cloud radiative properties (i.e., albedo and emissivity); and the last is the relationship between the above changes and the radiative forcing due to the clouds. The limited number of studies on this tough problem have led to the following conflicting inferences. Empirical studies using satellite radiation budget data in conjunction with cloud cover data have indicated that even if cloud cover changes substantially, the radiative changes would be negligible [Cess, 1976]. Similar empirical studies, but using different satellite data sets [see Cess et al., 1982], have suggested that an increase (decrease) in clouds would lead to a large radiative cooling (heating). The implication of these studies is that an increase (decrease) of global average clouds by about $4 \%$, i.e., from $50 \%$ 
THE VALIDITY OF THE FIXED DYNAMICAL HEATING (FDH) ASSUMPTION
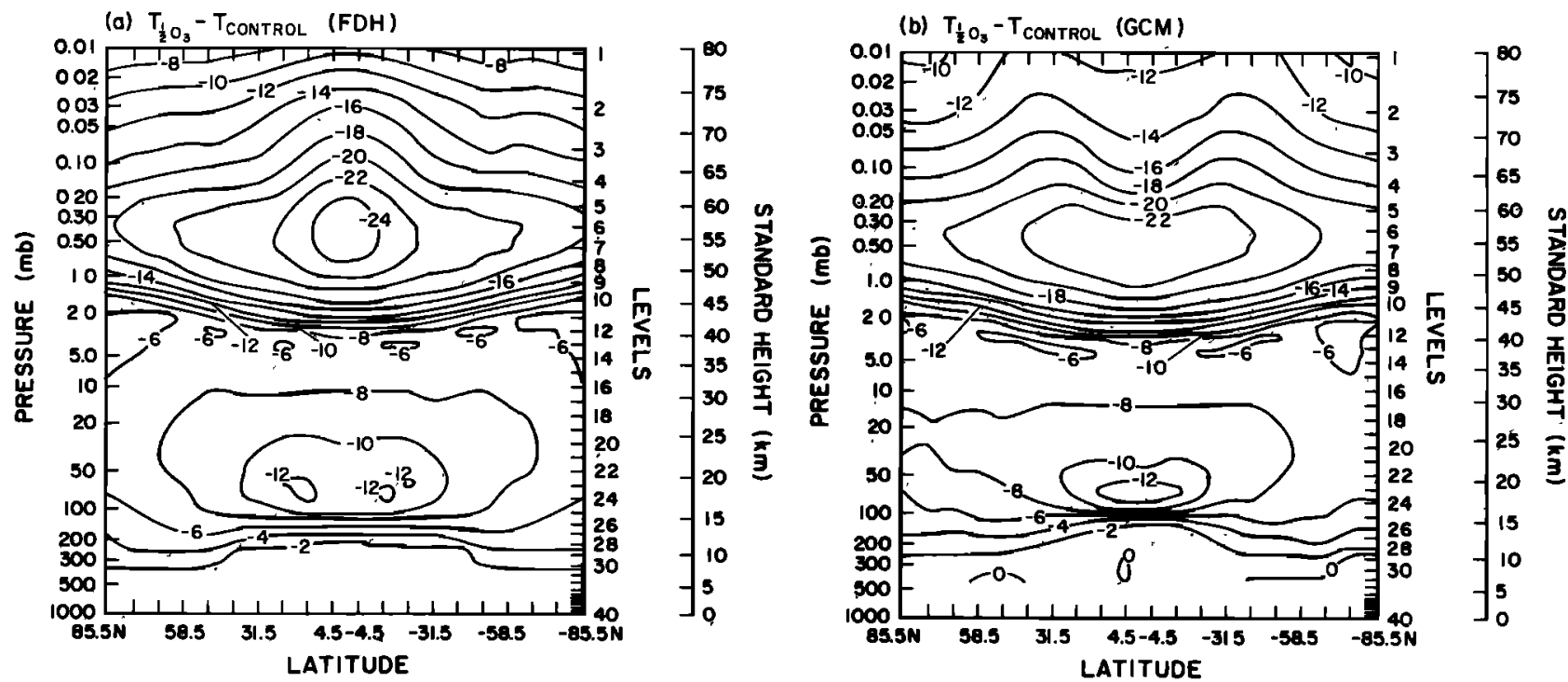

Fig. 12. Temperature change due to $50 \%$ ozone reduction as simulated by (a) the FDH model and (b) the GCM [Fels et al., 1980].

to $54 \%$ (or decrease to $46 \%$ ), would be sufficient to ameliorate (amplify) the $\mathrm{CO}_{2}$ effect by a factor of 2 or more. Recent GCM studies [Hansen et al., 1984; Washington and Meehl, 1984], on the other hand, indicate that cloud leedback amplifies the $\mathrm{CO}_{2}$ warming by about 25 to $50 \%$.

The GCM studies have largely ignored the so-called cloud optics feedback [Charlock, 1982; Somerville and Remer, 1984]. In this feedback the cloud liquid water increases with an increase in $T_{s}$ such that the cloud albedo increases with an increase in $T_{s}$. The increase in cloud albedo provides a negative feedback. RCM calculations [Charlock, 1982; Somerville and Remer, 1984] suggest that the cloud optics feedback may reduce $\Delta T_{s}$ by a factor of 1.5 to 2 .

The fundamental difficulty in the way of realistic attack on the cloud problem is the fact that the processes that govern cloud formations and their radiative effects occur on scales ranging from several meters to several tens of kilometers. Theoretical, modeling, and observational breakthroughs are needed to bridge the gap between the spatial scales of climate models and the scales of cloud formation. In the interim we have to acknowledge the potentially large source of uncertainty in model estimates of climate sensitivity and explore imaginative ways of verifying model sensitivity with observations.

\subsection{Implications of $\mathrm{H}_{2} \mathrm{O}$-Climate Feedback}

Most climate models and, in particular, all of the GCMs indicate that an increase in tropospheric water vapor content will accompany the greenhouse warming of trace gases. The increase in $\mathrm{H}_{2} \mathrm{O}$ is a strong function of latitude and altitude ranging from 5 to $15 \%$ in the low latitudes to as much as $50 \%$ in the polar regions (for example, see Washington and Meehl [1984]). As described earlier (section 3.2), this $\mathrm{H}_{2} \mathrm{O}$ feedback amplifies the surface warming by about 50 to $80 \%$. In addition to providing the positive climate feedback, the increase in troposperic $\mathrm{H}_{2} \mathrm{O}$ has important implications to tropospheric chemistry [Hameed et al., 1980; Callis et al., 1983; WMO, 1982].

The increase in $\mathrm{H}_{2} \mathrm{O}$ can lead to increased production of tropospheric $\mathrm{OH}$ which, in turn, may lead to enhanced oxidation of $\mathrm{CH}_{4}, \mathrm{CO}$, and $\mathrm{O}_{3}$ (see Figure 4), and possibly other chemicals. Since $\mathrm{OH}$ plays a dominant role as a cleansing agent of tropospheric pollutants, surface-troposphere temperature changes (through the $\mathrm{H}_{2} \mathrm{O}$ feedback) can have substantial influence on the concentration of other greenhouse gases (for example, $\mathrm{O}_{3}$ and $\mathrm{CH}_{4}$ ) in the troposphere. The nature and magnitude of this climate-chemistry feedback is discussed in section 4.

The second important role of $\mathrm{H}_{2} \mathrm{O}$ feedback concerns the interactions between low-latitude tropopause temperatures and stratospheric $\mathrm{H}_{2} \mathrm{O}$. The direct radiative forcing of trace gases such as CFCs and $\mathrm{O}_{3}$ are particularly large in the vicinity of the tropical tropopause (Figures 8 and 9). Furthermore, GCM results reveal a large change in tropical tropopause temperatures in response to $\mathrm{O}_{3}$ change (Figure 12) or to CFCs [Dickinson et al., 1978]. Since the stratospheric $\mathrm{H}_{2} \mathrm{O}$ concentration is believed to depend critically on this temperature, substantial cooling (or warming) of the tropopause may lead to substantially drier (or wetter) stratosphere.

Large changes in stratospheric water vapor have important radiative and chemical consequences. For example, a doubling of stratospheric $\mathrm{H}_{2} \mathrm{O}$ from 3 to $6 \mathrm{ppm}$ can lead to a $0.6 \mathrm{~K}$ surface warming [Wang et al., 1976]. Since $\mathrm{H}_{2} \mathrm{O}$ is a controlling factor in stratospheric $\mathrm{HO}_{x}$ chemistry [Liu et al., 1976], altered stratospheric $\mathrm{H}_{2} \mathrm{O}$ can also influence stratospheric concentrations of $\mathrm{O}_{3}$ and $\mathrm{CH}_{4}$.

\section{EfFects on Atmospheric and Surface Temperatures}

Most of the trace gases that have been detected in the atmosphere are listed in Table 8 together with information pertinent to their presently known sources, sinks, lifetimes, and present concentrations. The direct greenhouse effects of these gases will be discussed first, to be followed by discussion of the effects arising from chemical perturbations. 


\subsection{Direct Effects}

Most of the gases shown in Table 8 have absorption features in the long-wave spectrum (see Tables $1 a$ and $1 b$ ). Many of the gases shown in Table 8 have a substantial surface warming effect at $1 \mathrm{ppbv}$ level (see Figure 13). For reference purposes, Figure 13 also shows the surface warming due to uniform increases in tropospheric $\mathrm{O}_{3}$ between 0 and $12.5 \mathrm{~km}$, $\mathrm{CH}_{4}$, and $\mathrm{N}_{2} \mathrm{O}$. All of the gases shown in Figure 13 have strong absorption features in the window region of 7-13 $\mu \mathrm{m}$. Bands of gases such as $\mathrm{CF}_{4}$ occur in the same wavelength as $\mathrm{CH}_{4}$ and $\mathrm{N}_{2} \mathrm{O}$ bands. Because of this band overlap, $\mathrm{CF}_{4}$, in spite of having the strongest band (band strength of about $5000 \mathrm{~cm}^{-2} \mathrm{~atm}^{-1}$; see Table $1 b$ ) of the gases shown in Figure 8 , does not have as large a surface warming as some of the other CFCs. The direct greenhouse effects have also been estimated by numerous recent studies [e.g., Brühl and Crutzen, 1984; Wang and Molnar, 1985; Ramanathan et al., 1985; Owens et al., 1985; Dickinson and Cicerone, 1986].

The radiative-convective model results for $\Delta T_{s}$ due to increases in CFCs, $\mathrm{CH}_{4}$, and $\mathrm{N}_{2} \mathrm{O}$ have differed significantly among models. Recent studies [Ramanathan et al., 1985; Owens et al., 1985] have attempted to clarify the sources for the discrepancy. For CFCs most of the differences were traced to the use of different spectroscopic data and to differences in model sensitivity. When these results were scaled to the same model sensitivity of $\Delta T_{s}=2 \mathrm{~K}$ for a doubling of $\mathrm{CO}_{2}$ and to the most recent CFC band strengths of Kagann et al. [1983], all of the models [Ramanathan, 1975; Reck and Fry, 1978; Lacis et al., 1981; Brühl and Crutzen, 1984; Ramanathan et al., 1985] except the Owens et al. [1985] and the Wang and Molnar [1985] models yield a surface warming of 0.55 to 0.6 $\mathrm{K}$ for a 0 to $2 \mathrm{ppbv}$ increase in each of F11 and F12. The Owens et al. and Wang and Molnar models yield a $\Delta T_{s}$ of 0.45 $\mathrm{K}$. A similar scaling procedure of model sensitivity (i.e., $\Delta T_{s}=$ $2 \mathrm{~K}$ for $\mathrm{CO}_{2}$ doubling) for doubling of $\mathrm{CH}_{4}$ and $\mathrm{N}_{2} \mathrm{O}$ shows a spread of about 0.2 to $0.3 \mathrm{~K}$ for doubling of $\mathrm{CH}_{4}$ and about 0.35 to $0.45 \mathrm{~K}$ for doubling of $\mathrm{N}_{2} \mathrm{O}$ [see Owens et al., 1985, Table 9]. These differences strongly suggest the need for an ICRCCM (1984) type intercomparison study for the trace gases shown in Figure 13.

It is important to note that increasing levels of these gases are essentially additive and have the potential to add directly and significantly to the greenhouse effect of the present-day atmosphere. Furthermore, several of the important gases shown in Table 8 (for example, F13, F116, F13B1, and CF $_{4}$ ) have lifetimes in excess of 100 years, and hence if their use increases in the future, these gases have the potential for a substantial impact on climate on time scales of several hunderd years.

\subsection{Indirect Effects}

In addition to the direct effects many of the trace gases perturb temperatures indirectly through physical or chemical mechanisms that cause the distributions or concentrations of other optically active constituents to be changed. The nature of some of the interactions leading to these indirect effects were shown in Figure 4. Most well known of these is perhaps the stratospheric destruction of $\mathrm{O}_{3}$ due to reaction with chlorine and chlorine oxides formed as a result of stratospheric photolysis of chlorine-bearing compounds (for example, $\mathrm{CF}_{2} \mathrm{Cl}_{2}, \mathrm{CFCl}_{3}, \mathrm{CCl}_{4}$, and $\mathrm{CH}_{3} \mathrm{Cl}$ ). The altered atmospheric $\mathrm{O}_{3}$ levels will affect both the tropospheric and stratospheric radiative budgets at both solar and infrared wavelengths. Furthermore, temperature changes can perturb chemistry through the $\mathrm{H}_{2} \mathrm{O}$ feedback (section 3.) These and other examples are discussed in the following paragraphs.

4.2.1. $\mathrm{H}_{2} \mathrm{O}$-temperature feedback effects on tropospheric chemistry. As was discussed in section 3.3, climate models including GCMs indicate that an increase in tropospheric humidity accompanies the computed surface-troposphere warming (due to the greenhouse effect of trace gases). For example, a $2 \mathrm{~K}$ tropospheric warming in the $\mathrm{RCM}$ (due to $\mathrm{CO}_{2}$ doubling) leads to an increase of $\mathrm{H}_{2} \mathrm{O}$ that ranges from about 10 to $30 \%$ (Figure 14). The increase in $\mathrm{H}_{2} \mathrm{O}$ can lead to enhanced OH production through the reaction [Hameed et al., 1980]

$$
\mathrm{O}\left({ }^{1} D\right)+\mathrm{H}_{2} \mathrm{O} \rightarrow 2 \mathrm{OH}
$$

which also acts as a direct loss reaction for ozone as $O\left({ }^{1} D\right)$ is in instantaneous equilibrium with $\mathrm{O}_{3}$. Further loss of ozone may take place through the reactions

$$
\begin{gathered}
\mathrm{OH}+\mathrm{O}_{3} \rightarrow \mathrm{HO}_{2}+\mathrm{O}_{2} \\
\mathrm{HO}_{2}+\mathrm{O}_{3} \rightarrow \mathrm{OH}+2 \mathrm{O}_{2}
\end{gathered}
$$

However, at high $\mathrm{NO}_{x}$ level, ozone is efficiently produced through the catalytical cycle:

$$
\begin{gathered}
\mathrm{HO}_{2}+\mathrm{NO} \rightarrow \mathrm{NO}_{2}+\mathrm{OH} \\
\mathrm{NO}_{2}+h v \rightarrow \mathrm{NO}+\mathrm{O} \\
\mathrm{O}+\mathrm{O}_{2}+M \rightarrow \mathrm{O}_{3}+M
\end{gathered}
$$

The main source for $\mathrm{HO}_{2}$ is $\mathrm{OH}$ reacting with $\mathrm{CO}$ (see discussions later under the $\mathrm{CO}$ section) rather than (R2). Hence (R4) to (R6) lead to a net $\mathrm{O}_{3}$ production. However, because of the large observed variations in tropospheric NO levels, with extremely low values in some remote region, one could expect either ozone production or ozone destruction as a result of $(\mathrm{R} 1)$ to $(\mathrm{R} 6)$.

Tropospheric $\mathrm{CH}_{4}$ levels may also be reduced by the reaction

$$
\mathrm{CH}_{4}+\mathrm{OH} \rightarrow \mathrm{CH}_{3}+\mathrm{H}_{2} \mathrm{O}
$$

For a doubling of $\mathrm{CO}_{2}$ the one-dimensional latitudinal energy balance model [Hameed and Cess, 1983], with a $\Delta T_{s}$ of $3.1 \mathrm{~K}$, shows a decrease in tropospheric $\mathrm{O}_{3}$ and $\mathrm{CH}_{4}$ of $11 \%$ and $17 \%$, respectively; the radiative-convective model, with a $\Delta T_{s}$ of $2 \mathrm{~K}$, computes a decrease of 5-7\% for tropospheric $\mathrm{O}_{3}$ and $9-14 \%$ for $\mathrm{CH}_{4}$. Because of the nonlinearities in the $\mathrm{H}_{2} \mathrm{O}-\mathrm{T}$ coupling and other nonlinearities in the chemistry, simultaneous perturbations may exacerbate the effect (for example, see Figures 15 and 16). For example, a doubling of $\mathrm{CO}_{2}$ with a CFC increase (due to steady state injection of $\mathrm{F} 11$ and $F 12$ at the 1977 emission rate) results in a computed decrease of about $16 \%$ for $\mathrm{O}_{3}$ (see Figure 15) and about $26 \%$ for $\mathrm{CH}_{4}$ [Callis et al., 1983].

The $\mathrm{O}_{3}$ and $\mathrm{CH}_{4}$ changes resulting from the $\mathrm{H}_{2} \mathrm{O}-\mathrm{T}$ coupling have a negative feedback effect on the computed $\Delta T_{s}$. For a $\mathrm{CO}_{2}$ doubling, the computed surface warming decreases by about $10 \%$ with the inclusion of the decreases in $\mathrm{O}_{3}$ and $\mathrm{CH}_{4}$ [Hameed and Cess, 1983]. All of the results described above depend very strongly on the assumed background levels of $\mathrm{NO}_{x}$ [Hameed et al., 1979] (also see Figures 15 and 16), since the ozone formation as described above as well as the 


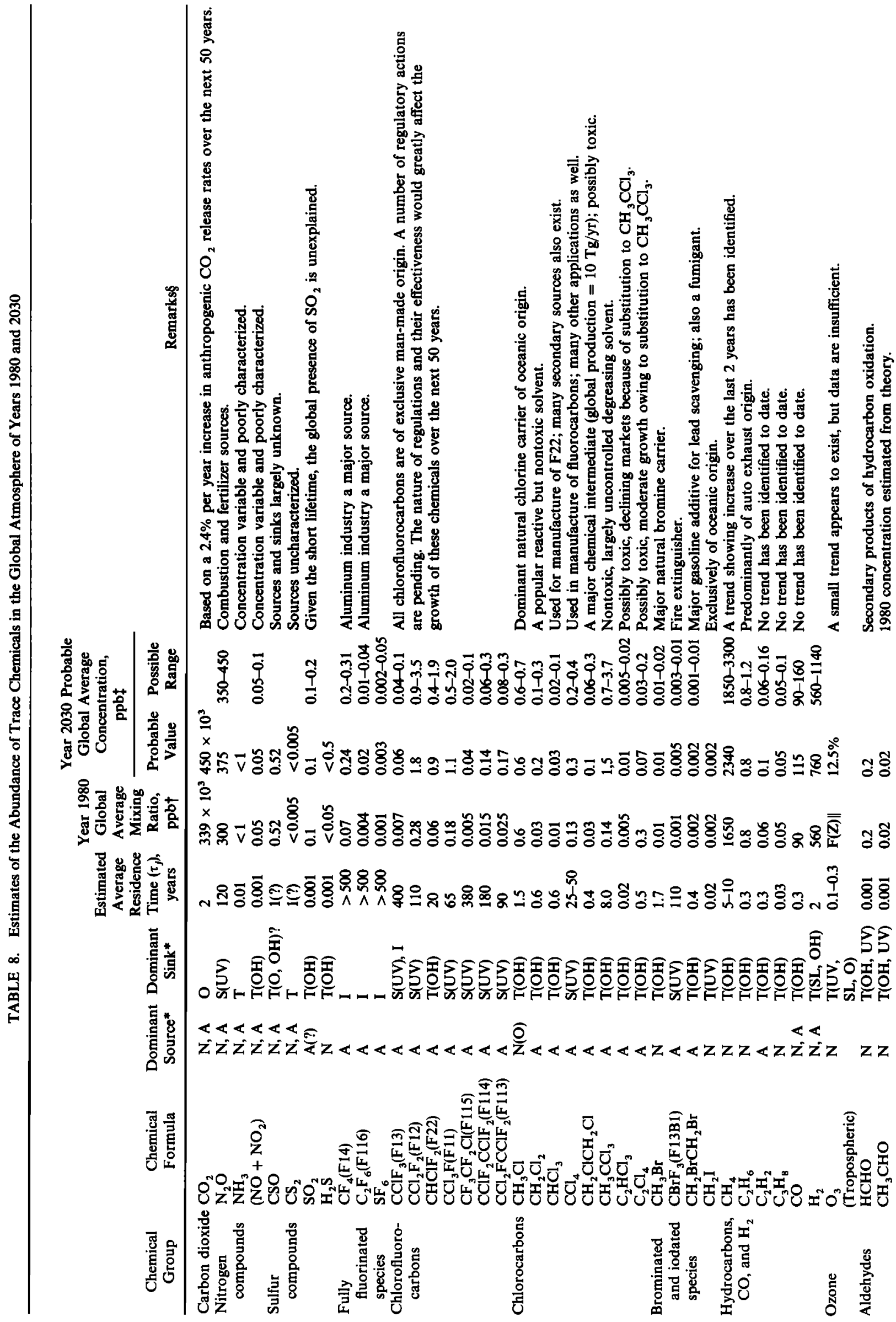


products in the methane oxidation scheme depend on NO concentrations.

4.2.2. Effects of $\mathrm{CO}_{2}$. Carbon dioxide does not react chemically to any significant degree in the troposphere or stratosphere. However, the stratospheric temperature decrease that is computed to result from a $\mathrm{CO}_{2}$ increase [Manabe and Wetherald, 1967] will alter the reaction rates and can lead to stratospheric $\mathrm{O}_{3}$ increases [Boughner and Ramanathan, 1975]. The $\mathrm{O}_{3}$ increase can, in turn, have a negative feedback on the $\mathrm{CO}_{2}$-induced stratospheric cooling. Numerous coupled onedimensional model studies [Boughner, 1978; Owens at al., 1985] have estimated this feedback. For a doubling of $\mathrm{CO}_{2}$ the model calculations generally indicate a column $\mathrm{O}_{3}$ increase of 2 to $6 \%$ [see Owens et al., 1985, Table 6]. This $O_{3}$ increase is mainly concentrated above $20 \mathrm{~km}$ where the hanced solar heating (due to $\mathrm{O}_{3}$ increase) reduces the stratospheric cooling due to a $\mathrm{CO}_{2}$ increase by about $20 \%$ [Owens et al., 1985, Figure 7]. The effect of the $\mathrm{O}_{3}-T$ feedback on surface temperature is negligible.

4.2.3. Effects of $\mathrm{CH}_{4}$. Atmospheric measurements have established that tropospheric concentrations of $\mathrm{CH}_{4}$ have been increasing [Fraser et al., 1981, 1983; Rasmussen and Khalil, 1981; Blake et al., 1982; Blake and Rowland, 1985]. Khalil and Rasmussen [1985] present data suggesting a change of 12 to $30 \mathrm{ppbv} \mathrm{yr}^{-1}$ (0.7 to $1.8 \%$ per year) during years unaffected by the El Niño southern oscillation (ENSO). During the ENSO years the $\mathrm{CH}_{4}$ levels but recovered rapidly after the event.

Over longer periods of time, Rinsland et al. [1985], analyzing historical spectra, have inferred a mean annual $\mathrm{CH}_{4}$ increase over a 30-year period of $1.1 \%$ per year within the troposphere in Europe. By analyzing air trapped in polar ice, Craig and Chou [1982] and Rasmussen and Khalil [1984] have extended this record further back in time and have shown that atmospheric $\mathrm{CH}_{4}$ has been increasing for several centuries and that recent levels are more than double the $0.7 \mathrm{ppmv}$ that existed prior to this long-term increase.

The observed $\mathrm{CH}_{4}$ increases represent the net effect due to changes in $\mathrm{CH}_{4}$ sources and/or sinks. The major sink for atmospheric $\mathrm{CH}_{4}$ is by (R7), with the hydroxyl radical $\mathrm{OH}$. There is also a minor uptake by dry soils [Seiler and Conrad, 1987]. The sources of $\mathrm{CH}_{4}$ are thought to be about $60 \%$ biogenic and $40 \%$ abiogenic [Seiler and Conrad, 1987]. The causes for the global net increase within time of $\mathrm{CH}_{4}$ are thought to be related to increasing levels of a variety of activities associated with global population growth (for example, see Crutzen [1987]). However, we cannot, with certainty, determine the relative importance of the various sources which contribute to this net increase [World Meteorological Organization (WMO), 1985]. Neither can we predict, with confidence, the future levels of $\mathrm{CH}_{4}$, though increase with time soms likely.

What is certain, however, is that $\mathrm{CH}_{4}$ and $\mathrm{OH}$ levels are closely coupled through (R7) [Chameides et al., 1977; Callis at al., 1983; Owens et al., 1985; Levine et al., 1985; Thompson and Cicerone, 1986]. As the methane oxidation by $\mathrm{OH}$ (reaction (R7)) is the main loss for $\mathrm{OH}$ in the free troposphere, increases in the release rate of methane lead to a decrease in $\mathrm{OH}$ and thereby to a further increase in methane levels. With continued increases in methane in the future, this positive feedback mechanism could become increasingly important. Recent twodimensional model studies [Isaksen and Hov, 1985] suggest 


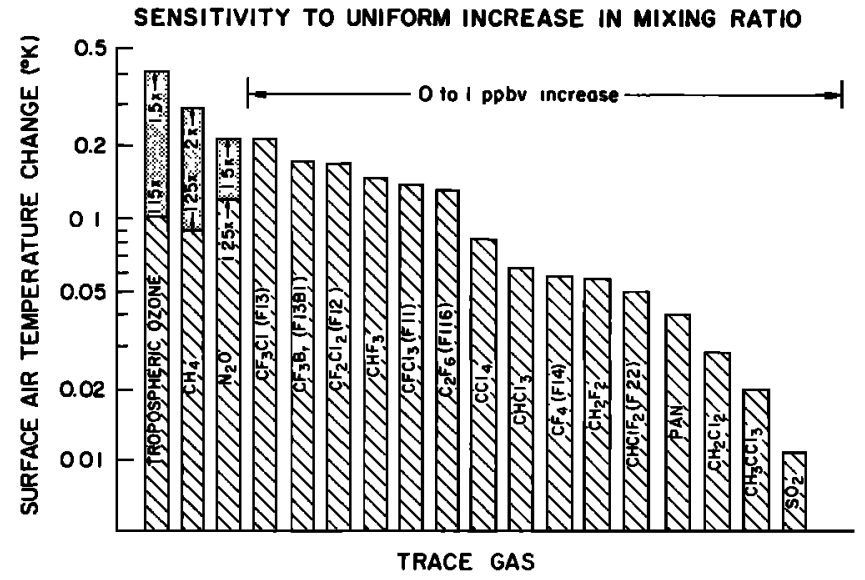

Fig. 13. Computed surface air temperature change due to a 0 to 1 ppbv increase in trace gas concentrations. Tropospheric $\mathrm{O}_{3}, \mathrm{CH}_{4}$, and $\mathrm{N}_{2} \mathrm{O}$ increases are also shown for comparison. For these three gases the factor of increase is indicated in the figure. For example, for tropospheric $\mathrm{O}_{3}$ the bottom part of the shaded region is the temperature change due to a uniform increase in $\mathrm{O}_{3}$ from 0 to $12 \mathrm{~km}$ by a factor of 1.15 (from the one-dimensional) radiative-convective model results of Ramanathan et al. [1985]).

that this feedback may account for $30 \%$ of the methane increase at present. However, since the magnitude of this leedback depends on the assumed emission of $\mathrm{NO}_{x}$, the contribution of this feedback to the observed $\mathrm{CH}_{4}$ increase is highly model dependent (P. J. Crutzen, private communication, 1986). A reduction of tropospheric $\mathrm{OH}$ levels due to a $\mathrm{CH}_{4}$ increase will also lead to reduction of the rate of scavenging (by $\mathrm{OH}$ ) of $\mathrm{CH}_{2} \mathrm{~F}_{2}, \mathrm{CHClF}_{2}, \mathrm{CH}_{2} \mathrm{Cl}_{2}, \mathrm{CH}_{3} \mathrm{CCl}_{3}$, and $\mathrm{SO}_{2}$,

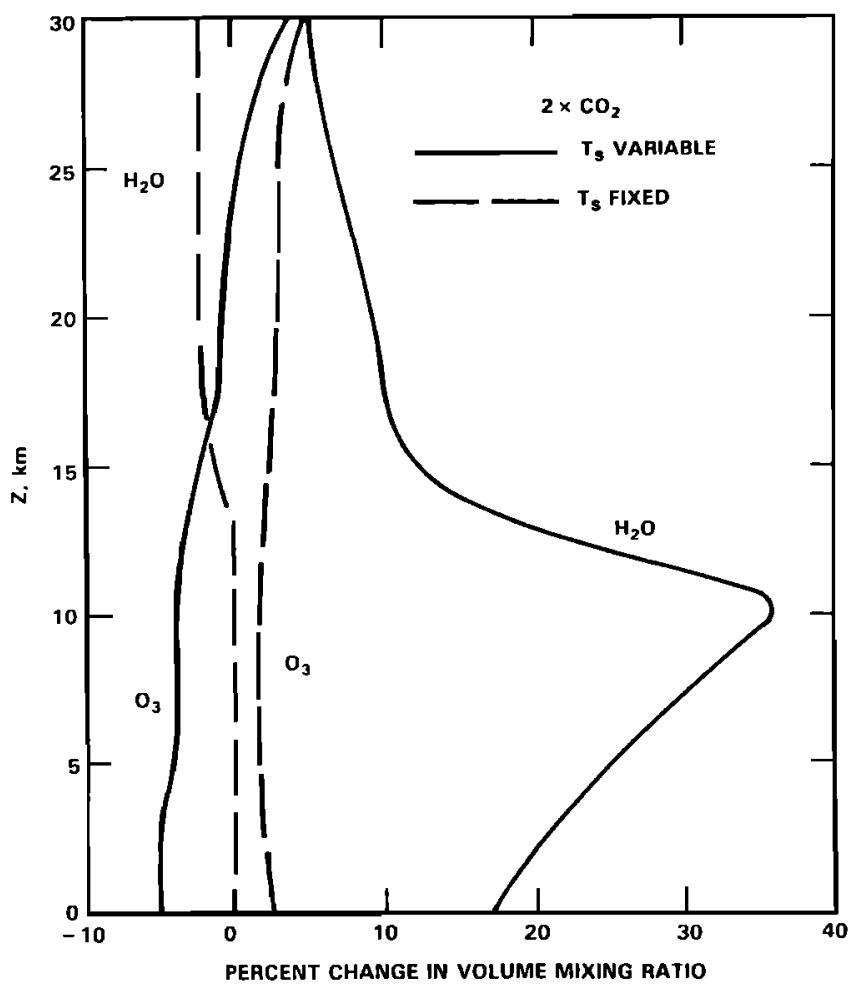

Fig. 14. Indirect effects of $\mathrm{CO}_{2}$ doubling on $\mathrm{H}_{2} \mathrm{O}$ and $\mathrm{O}_{3}$, when both stratospheric and tropospheric temperatures are allowed to vary (solid lines) and when only stratospheric temperatures are allowed to vary in response to $\mathrm{CO}_{2}$ increase (dashed lines) (from the onedimensional model results of Callis et al. [1983]).

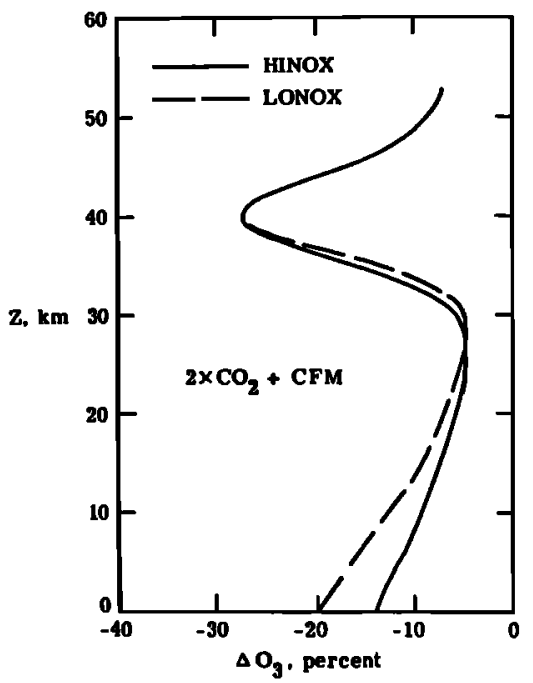

Fig. 15. Computed changes in $\mathrm{O}_{3}$ due to the combined effects of $\mathrm{CO}_{2}$ doubling and CFM increase (from the one-dimensional) model results of Callis et al. [1983]. HINOX and LONOX refer to high and low concentrations of assumed background values for $\mathrm{NO}_{\boldsymbol{x}}$.

leading to increased lifetimes (and hence concentrations) of these species with attendant perturbations to the infrared radiative balance. Increases in tropospheric methane will, provided sufficient amounts of $\mathrm{NO}_{x}$ are present, lead to enhanced ozone production through (R4) and the reaction

$$
\mathrm{CH}_{3} \mathrm{O}_{2}+\mathrm{NO} \rightarrow \mathrm{CH}_{3} \mathrm{O}+\mathrm{NO}_{2}
$$

followed by (R5) and (R6), where productions of $\mathrm{CH}_{3} \mathrm{O}_{2}$ and $\mathrm{HO}_{2}$ are enhanced. Two-dimensional model estimates show that tropospheric ozone increases due to increased methane levels vary strongly with latitude, height, and season [Crutzen and Gidel, 1983; Isaksen and Stordal, 1986]. In twodimensional models the most pronounced ozone increase is obtained at equatorial latitudes, with ozone increases of approximately $20 \%$ in the middle and upper troposphere for a doubling of present methane levels (see Figure 17). The greenhouse effect of enhanced tropospheric $\mathrm{O}_{3}$ amplifies the $\mathrm{CH}_{4}$

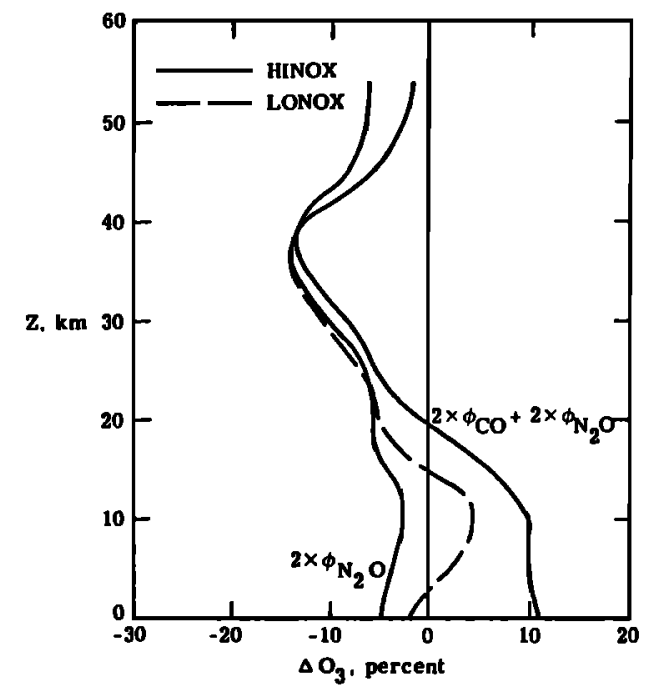

Fig. 16. Indirect effects of increases in fluxes $(\phi)$ of $\mathrm{CO}$ and $\mathrm{N}_{2} \mathrm{O}$ on $\mathrm{O}_{3}$ (from the one-dimensional model results of Callis et al. [1983]). 


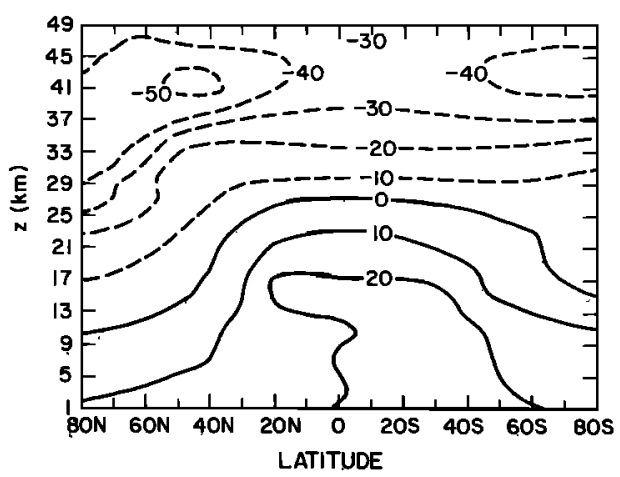

Fig. 17. Latitudinal-height cross-section of future ozone changes (in percent) due to releases of CFCs (CFC11 and CFC12), $\mathrm{N}_{2} \mathrm{O}$, and $\mathrm{CH}_{4}$, estimated in a two-dimensional diąbatic circulation model [Isaksen and Stordal, 1986]. The following assumptions are made with regard to future release rates and concentration rates: CFCs are in steady state with 1980 release rates, $\mathrm{N}_{2} \mathrm{O}$ increases with a factor of 1.4 from its 1980 value ( $300 \mathrm{ppb}$ at the surface), and $\mathrm{CH}_{4}$ increases with a factor of 2 from its 1980 value ( $1.65 \mathrm{ppm}$ at the surface). The numbers given are for February.

greenhouse effect by as much as $75 \%$ [Owens et al., 1985, Table 8].

Furthermore, increases in $\mathrm{CH}_{4}$ are calculated to lead to similar but less pronounced increases in lower latitudinal and mid-latitudinal stratospheric ozone through their effect on $\mathrm{HO}_{x}, \mathrm{Cl}_{x}, \mathrm{NO}_{x}$ species [World Meteorological Organization, 1981]. For example, $\mathrm{CH}_{4}$ can mitigate the ozone destruction by the chlorine catalytic cycle in the middle stratosphere (around $40 \mathrm{~km}$ ), because it can transform the $\mathrm{Cl}$ atoms to $\mathrm{HCl}$ [Brühl and Crutzen, 1984]. An additional effect is that oxidation of methane may lead to substantial increases in $\mathrm{H}_{2} \mathrm{O}$ levels in the middle and upper stratosphere [see Callis et al., 1983; Owens et al., 1985].

4.2.4. Effects of $\mathrm{CO}$. Carbon monoxide is itself not radiatively active and therefore does not manifest any direct effects on the earth-atmosphere radiative balance. The concentrations of $\mathrm{CO}, \mathrm{OH}$, and $\mathrm{CH}_{4}$ are interdependent because of the important role of $\mathrm{OH}$ in oxidizing $\mathrm{CO}$ and $\mathrm{CH}_{4}$ in the lower atmosphere (for example, see Thompson and Cicerone [1986] for a recent discussion). CO scavenges atmospheric $\mathrm{OH}$ through the reaction

$$
\mathrm{CO}+\mathrm{OH} \rightarrow \mathrm{CO}_{2}+\mathrm{H}
$$

The reduction of tropospheric $\mathrm{OH}$, as noted earlier, can, in turn, affect the abundance of numerous other species including $\mathrm{O}_{3}, \mathbf{C H}_{4}$, and hydrocarbons which are not fully halogenated (Sze [1977], Logan et al. [1978], and Thompson and Cicerone [1986], to name a few). This has been discussed earlier in reference to the $\mathrm{CH}_{4}$ increase.

Large interhemispheric differences in the present-day atmosphere are exhibited by $\mathrm{CO}$ due primarily to anthropogenic emissions [Logan et al., 1981]. In addition, increases in tropospheric $\mathrm{CO}$ have been suggested by recent studies [Rasmussen and Khalil, 1981; Fraser et al., 1981; Graedel and McRae, 1980; Khalil and Rasmussen, 1984]. For a doubling of the surface flux of $\mathrm{CO}$ (leading to a factor of 2.5 increases in $\mathrm{CO}$ ), the $\mathrm{OH}$ decrease through (R14) can lead to increases in $\mathrm{CH}_{4}$ of about 40 to $50 \%$ and to increases in column $\mathrm{O}_{3}$ of about 12\% [Callis et al., 1983; Hameed et al., 1979; Hameed and Cess, 1983]. In the model calculations [Callis et al., 1983] the increase in $\mathrm{CH}_{4}$ also leads to a stratospheric $\mathrm{H}_{2} \mathrm{O}$ increase of about 7 to $12 \%$. More recent calculations by Thompson and Cicerone [1986] suggest that roughly 24 to $37 \%$ of the observed $\mathrm{CH}_{4}$ increase can be explained by anthropogenic sources of $\mathrm{CO}$.

4.2.5. Effects of $\mathrm{N}_{2} \mathrm{O}$. Weiss [1981] has reported data that suggest that atmospheric $\mathrm{N}_{2} \mathrm{O}$, currently at levels of 300 ppbv, was increasing at the rate of $0.2 \%$ per year between the years of 1976 and 1980. Khalil and Rasmussen [1983] suggest an increase of $0.3 \%$ per year between the years of 1978 and 1981

The indirect effects of increases of atmospheric $\mathrm{N}_{2} \mathrm{O}$ arise from the reaction

$$
\mathrm{N}_{2} \mathrm{O}+\mathrm{O}\left({ }^{1} D\right) \rightarrow 2 \mathrm{NO}
$$

Reactions (R9) is the principal source of stratospheric $\mathrm{NO}_{y}\left(=\mathrm{NO}+\mathrm{NO}_{2}+\mathrm{HNO}_{3}+\mathrm{NO}_{3}+\mathrm{HNO}_{4}+\mathrm{HNO}_{2}+\right.$ $\left.2 \times \mathrm{N}_{2} \mathrm{O}_{5}+\cdots\right)$. Consequently, increases in atmospheric $\mathrm{N}_{2} \mathrm{O}$ levels will lead to increases in stratospheric $\mathrm{NO}_{y}$ and the subsequent radiation of stratospheric $\mathrm{O}_{3}$ by catalytic destruction through the reactions

$$
\begin{gathered}
\mathrm{NO}+\mathrm{O}_{3} \rightarrow \mathrm{NO}_{2}+\mathrm{O}_{2} \\
\mathrm{NO}_{2}+\mathrm{O}+\mathrm{O}_{2}
\end{gathered}
$$

If increases in $\mathrm{N}_{2} \mathrm{O}$ occur at the same time as increases in the chlorine-bearing compounds (for example, $\mathrm{CF}_{2} \mathrm{Cl}_{2}, \mathrm{CFCl}_{3}$, and $\mathrm{CCl}_{4}$ ), the net effect will depend upon the details of the projected increases and their vertical distributions. Increasing stratospheric $\mathrm{NO}_{y}$ levels will provide a buffer for the stratospheric $\mathrm{O}_{3}$ against catalytic destruction by $\mathrm{Cl}_{x}(=\mathrm{Cl}+$ $\left.\mathrm{ClO}+\mathrm{HOCl}+\mathrm{ClNO}_{3}+2 \times \mathrm{ClO}_{2}+\cdots\right)$ through the reaction

$$
\mathrm{NO}_{2}+\mathrm{ClO}+M \rightarrow \mathrm{ClNO}_{3}+M
$$

where $\mathrm{ClNO}_{3}$ represents a temporary reservoir of relatively inactive chlorine. It will also affect the partitioning of chlorine species through the reaction

$$
\mathrm{ClO}+\mathrm{NO} \rightarrow \mathrm{Cl}+\mathrm{NO}_{2}
$$

The chemical perturbations induced by an $\mathrm{N}_{2} \mathrm{O}$ increase are so complicated that even the sign of the tropospheric $\mathrm{O}_{3}$ change is uncertain. For example, for a doubling of $\mathrm{N}_{2} \mathrm{O}$ surface flux (leading to a $93 \%$ increase in surface concentration of $\mathrm{N}_{2} \mathrm{O}$ ) the computed 0 - to $10-\mathrm{km}$ column change in $\mathrm{O}_{3}$ ranges from $-2 \%$ to $+4 \%$, depending upon the background levels of tropospheric $\mathrm{NO}+\mathrm{NO}_{2}$ (see Figure 16); the stratospheric $\mathrm{O}_{3}$ column decreases by about $7 \%$.

4.2.6. Effects of $\mathrm{NO}_{x}\left(\mathrm{NO}+\mathrm{NO}_{2}\right)$. As pointed out repeatedly in the earlier discussions, the indirect effects of trace gases depend critically on the tropospheric concentration of $\mathrm{NO}_{\boldsymbol{x}}$. Photochemical model calculations have also revealed the significant sensitivity of the computed tropospheric $\mathrm{O}_{3}$ to the concentration as well as the vertical distribution of $\mathrm{NO}_{x}$ Fishman and Crutzen, 1978; Liu et al., 1980]. Tropospheric $\mathrm{NO}_{x}$ has a variety of natural and anthropogenic sources [e.g., Logan, 1983]: combustion and biogenic emissions are major surface sources; high-flying aircraft and downward transport from the stratosphere are important upper tropospheric sources. In addition, lightning may also contribute significantly in the upper troposphere. The removal of $\mathrm{NO}_{x}$ is through wet and dry deposition, mostly after its conversion to soluble species such as $\mathrm{HNO}_{3}$ and $\mathrm{N}_{2} \mathrm{O}_{5}$. The exact removal 
process is not well understood and difficult to model without a realistic three-dimensional model.

The indirect climate effect of $\mathrm{NO}_{x}$ arises because of its effect on $\mathrm{O}_{3}$. Within the troposphere the chemistry and photochemistry of $\mathrm{NO}_{x}$ is an important source of $\mathrm{O}_{3}$ through (R4) to (R6). Within the upper troposphere of the northern hemisphere the $\mathrm{NO}_{x}$ emission from high-flying aircraft is considered to be as important a source as natural sources of $\mathrm{NO}_{x}$ [Liu et al., 1980].

Although all models agree that anthropogenic $\mathrm{NO}_{x}$ emissions at the surface and by aircraft will result in the increase of tropospheric $\mathrm{O}_{3}$, problems in modeling $\mathrm{NO}_{x}$ distribution make it difficult to obtain a reliable quantitative evaluation of the $\mathrm{O}_{3}$ increase, particularly in the boundary layer where nonmethane hydrocarbons play an important yet complex role in the photochemical production of $\mathrm{O}_{3}$. In the upper troposphere a model-calculated $\mathrm{O}_{3}$ increase in the northern hemisphere ranges from a few percent [Isaksen, 1980; Derwent, 1982; Crutzen and Gidel, 1983] to as high as $30 \%$ [Liu et al., 1980]. The major difference is due to assumed natural background $\mathrm{NO}_{\boldsymbol{x}}$ sources in the upper troposphere. In the lower troposphere the estimated $\mathrm{O}_{3}$ increase in the northern hemisphere is about $20 \%$ [Isaken, 1980].

From the above discussion it is probably reasonable to assume a $5 \%$ increase in the northern hemisphere tropospheric $\mathrm{O}_{3}$ for the decade of 1970 [e.g., Liu et al., 1980; Isaken, 1980] owing to anthropogenic $\mathrm{NO}_{x}$ emissions. The northern hemisphere surface-troposphere radiative heating due to this $\mathrm{O}_{3}$ increase is roughly a third of that due to the observed $\mathrm{CO}_{2}$ increase for the decade of 1970.

4.2.7. Effects of halogenated hydrocarbons. A large number of halogenated hydrocarbons (Table 8 ) have direct effects (Figure 13) as well as indirect effects in both the troposphere and the stratosphere. Species not fully halogenated may be expected, at elevated concentrations, to contribute to the reduction of tropospheric $\mathrm{OH}$ with subsequent effects on tropospheric $\mathrm{O}_{3}$ and $\mathrm{CH}_{4}$ taking place. However, this effect is expected to be small provided the concentrations of the species remain of the order of a few parts per billion by volume or less.

Some of these species released in the troposphere will be photodissociated in the stratosphere with the release of halogens which may catalytically destroy $\mathrm{O}_{3}$. Of most concern at present and for the immediate future is the catalytic destruction of ozone by chlorine released from the photodissociation of $\mathrm{CF}_{2} \mathrm{Cl}_{2}$ and $\mathrm{CFCl}_{3}$. This destruction occurs because of the reactions

$$
\begin{aligned}
& \mathrm{Cl}+\mathrm{O}_{3} \rightarrow \mathrm{ClO}+\mathrm{O}_{2} \\
& \mathrm{ClO}+\mathrm{O} \rightarrow \mathrm{Cl}+\mathrm{O}_{2}
\end{aligned}
$$

Recent estimates suggest that steady state emissions of $\mathrm{CF}_{2} \mathrm{Cl}_{2}$ and $\mathrm{CFCl}_{3}$ may reduce the column sum of $\mathrm{O}_{3}$ by $3-5 \%$ with local reductions of 30 to $50 \%$ between 35 and 45 km (Cicerone et al: [1983], Wuebbles et al. [1983], and Owens et al. [1985], to name a few). Reductions in stratospheric $\mathrm{O}_{3}$ of such magnitudes will have a significant impact on stratospheric thermal structure (Figure 18). Furthermore, within the upper stratosphere the computed cooling due to CFC-induced $\mathrm{O}_{3}$ reduction is as large as that due to $\mathrm{CO}_{2}$ doubling (compare the "CFCs" curve with the " $2 \times \mathrm{CO}_{2}$ " curve in Figure 18).

Since the effect of the stratospheric $\mathrm{O}_{3}$ change on surface

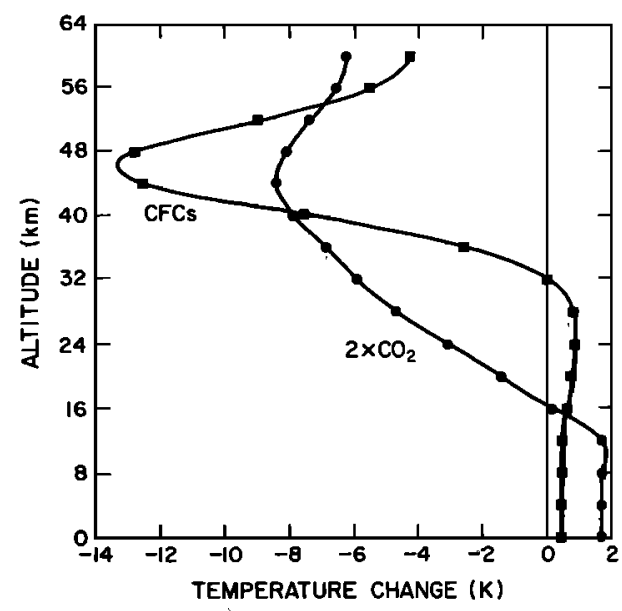

Fig. 18. Calculated temperature changes due to releases of CFC11 and CFC12 in the steady state (solid squares) and computed effect for $2 \times \mathrm{CO}_{2}$ (solid circles) [Owens et al.; 1985].

temperatures depends very critically on the vertical distribution of $\mathrm{O}_{3}$ change, the computed surface temperature effects have fluctuated in magnitude as well as sign over the years. For example, the computed $\mathrm{O}_{3}$ perturbation profiles that were reported prior to the early 1980 s yielded a slight surface cooling [Wang et al., 1980]. The more recent profiles of $\mathrm{O}_{3}$ change yield both a surface cooling [Callis et al., 1983] and a surface warming [Owens et al., 1985; Ramanathan et al., 1985]. The primary source of the difference is the magnitude of $\mathrm{O}_{3}$ changes in the upper troposphere and lower stratosphere, an issue which is somewhat unresolved at this time.

Irrespective of the sign of the computed surface temperature effect, the magnitude is nonnegligible. For example, the recent studies of Owens et al. [1985] and Ramanathan et al. [1985] estimate a surface warming of $0.1 \mathrm{~K}$ due to an $\mathrm{O}_{3}$ change resulting from steady state injection of CFCs at constant mid1970 s emission rates, which is about $25-30 \%$ of the computed warming due to the direct greenhouse effect of the CFCs. Furthermore, $\mathrm{O}_{3}$ effects on climate depend on season and latitude (see section 2.2), and both of these effects have been ignored in current climate model studies. Clearly, the $\mathrm{O}_{3}$-climate effects resulting from the addition of chlorines to the stratosphere deserves continued study.

\section{Transient Climatic Effects of Increasing ATMOSPHERIC $\mathrm{CO}_{2}$}

\subsection{Observed Increases in $\mathrm{CO}_{2}$}

Measurements taken at Mauna Loa, Hawaii, show that the $\mathrm{CO}_{2}$ concentration has increased from $315 \mathrm{ppmv}$ in 1958 to 342 ppmv in 1983 [Elliott et al., 1985] (see Figure 19), an 8\% increase in 25 years. A variety of direct $\mathrm{CO}_{2}$ measurements and indirect reconstructions indicate that the preindustrial $\mathrm{CO}_{2}$ concentration during the period 1800 to 1850 was $270 \pm 10 \mathrm{ppmv}$ [World Meteorological Organization (WMO), $1983 b]$. Analyses of the future usage of fossil fuels suggest that the $\mathrm{CO}_{2}$ concentration will reach twice the preindustrial value by 2100 [Nordhaus and Yohe, 1983]. The change in surface air temperature induced by a doubling of $\mathrm{CO}_{2}$ as simulated by climate models was discussed in section 3.2. The computed changes in global mean surface air temperature ranged from 1.3 to $4.2 \mathrm{~K}$ with the three most recent GCM results falling near the upper end of this range (see Table 7). Since such a 


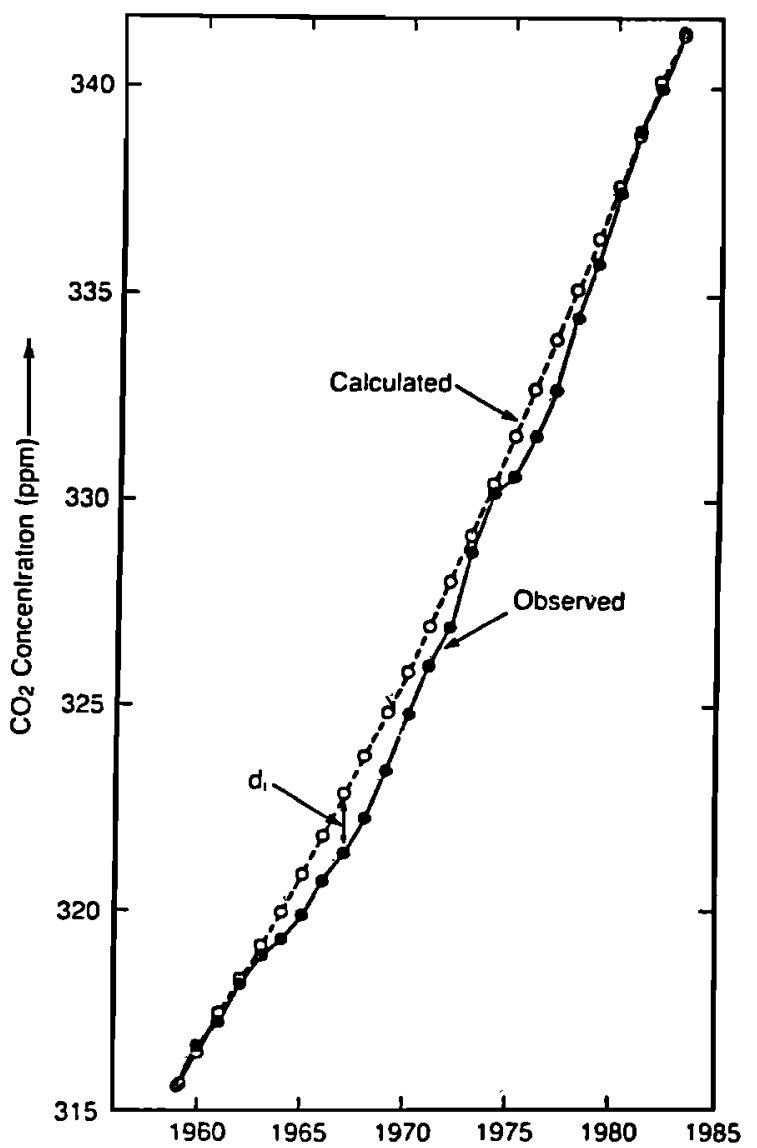

Fig. 19. Concentration of atmospheric $\mathrm{CO}_{2}$ at Mauna Loa Observatory, Hawaii, from 1958 to 1983 . The "calculated" curve is the curve used in the climate model calculations shown in Figure 21.

global warming represents about 25 to $100 \%$ of that which is estimated to have occurred during the 10,000 -year transition from the last ice age to the present interglacial [Gates, 1976; Imbrie and Imbrie, 1979], there is considerable interest in the identification of a $\mathrm{CO}_{2}$-induced climatic change and in the potential impacts of such a change on the spectrum of human erideavors.

The majority of the simulations of $\mathrm{CO}_{2}$-induced climate change have been performed to determine the change in the equilibrium climate of the earth resulting from an abrupt increase in $\mathrm{CO}_{2}$ such as doubling from 300 to 600 ppmv. These equilibrium climate change simulations have not been concerned with the time required for the climate change to reach its equilibrium. More recent studies have focused on the transient response of elimate to both abrupt and realistic increases in the $\mathrm{CO}_{2}$ concentration.

\subsection{Transient Effects}

The equilibrium temperature increase corresponding to the $\mathrm{CO}_{2}$ increase from the year 1850 to 1980 can be determined using (1) with the direct radiative forcing $\Delta Q$ scaled to that for a $\mathrm{CO}_{2}$ doubling, $\Delta Q_{2 x}$. This scaling yields [Augustsson and Ramanathan, 1977]

$$
\Delta Q=\Delta Q_{2 x}\left\{\frac{\ln C(1980) / C(1850)]}{\ln 2}\right\}
$$

where $C$ is the $\mathrm{CO}_{2}$ concentration. Combining these equations and noting that $\left(\Delta T_{s}\right)_{2 x}=\Delta Q_{2 x} / \lambda$ (see (1) of section 3.2) yields

$$
\Delta T_{s}=\left(\Delta T_{s}\right)_{2 x}\left\{\frac{\ln [C(1980 / C(1850)]}{\ln 2}\right\}
$$

If we assume that $\left(\Delta T_{s}\right)_{2 x} \approx 4 \mathrm{~K}$ on the basis of the results from the Geophysical Fluid Dynamics Laboratory (GFDL), Goddard Institute for Space Studies (GISS), and National Center for Atmospheric Research (NCAR), models, then for the $\mathrm{CO}_{2}$ concentration increase from 270 (year 1850) to 338 ppmv (year 1980), $\Delta T_{s}=1.3 \mathrm{~K}$. However, the reconstructed northern hemisphere surface air temperature record (see Figure 1) indicates a warming from 1880 to 1980 of about 0.6 K. Does this difference mean that the sensitivity of the GCMs is too large by a factor of 2 ? The likely answer is, not necessarily, since the actual reponse of the climate system lags the equilibrium response because of the thermal inertia of the ocean. This can be illustrated by the energy balance model

$$
C_{s} \frac{d \Delta T_{s}}{d t}=\Delta Q-\lambda \Delta T_{s}
$$

where $C_{s}$ is the heat capacity of the upper ocean. When equilibrium is achieved, $d \Delta T_{s} / d t=0$ and $\left(\Delta T_{s}\right)_{\mathrm{eq}}=\Delta Q / \lambda$. However, the transient solution

$$
\Delta T_{s}(t)=\left(\Delta T_{s}\right)_{\mathrm{eq}}\left(1-e^{-t / \varepsilon_{e}}\right)
$$

shows that equilibrium is approached exponentially with a characteristic " $e$-folding" time $\tau_{e}=C_{s} / \lambda$. In the following two sections the studies of this lag of the climate system are reviewed.

\subsection{Results From Simplified Models}

The transient response of the climate system to an abrupt $\mathrm{CO}_{2}$ increase has been investigated with planetary energy balance, radiative-convective, and simplified atmospheric general circulation models in conjunction with box diffusion, box advection-diffusion, and two-box ocean models as well as with simplified oceanic general circulation models. The box diffusion ocean model consists of a fixed-depth mixed layer (the box) surmounting the thermocline and deep ocean in which vertical heat transport is treated as a diffusive process with prescribed thermal diffusivity $\kappa$. The box advection-diffusion ocean model is a box diffusion model with a prescribed value for oceanic upwelling. The two-box ocean model comprises a fixed-depth mixed-layer box and an intermediate water box which exchange heat vertically with a prescribed ventilation time.

The results from six studies of the transient response to abrupt heating are presented in Table 9. Hoffert et al. [1980], using a box advection-diffusion model, and Schneider and Thompson [1981], using a two-box ocean model, obtained $e$-folding times of 10 to 20 years. A slightly larger $e$-folding time of 25 years was obtained by Bryan et al. [1982] and Spelman and Manabe [1984] with a simplified coupled atmosphere-ocean general circulation model in which the geographical domain was restricted to a $120^{\circ}$-longitude sector extending from equator to pole, with the western half of the sector occupied by land at zero elevation and the eastern half by ocean with a uniform depth of $5000 \mathrm{~m}$. On the other hand, Hansen et al., [1984] used a box diffusion ocean model and obtained 27-, 55-, and 102-year $e$-folding times corresponding to assumed $\lambda$ values of $2.15,1.4$, and $1 \mathrm{Wm}^{-2} \mathrm{~K}^{-1}$, respec- 
TABLE 9. The $e$-Folding time $\tau_{e}$ for Abrupt Heating from Selected Climate Model Studies

\begin{tabular}{|c|c|c|}
\hline Reference & Model & $\begin{array}{c}\tau_{e}, \\
\text { years }\end{array}$ \\
\hline Hoffert et al. $[1980]$ & $\begin{array}{l}\text { Planetary energy balance climate } \\
\text { model and a box advection- } \\
\text { diffusion ocean model }\end{array}$ & $8-20$ \\
\hline $\begin{array}{l}\text { Schneider and Thomp- } \\
\text { son }[1981]\end{array}$ & $\begin{array}{l}\text { Planetary energy balance model } \\
\text { and a two-box diffusion ocean model }\end{array}$ & 13 \\
\hline $\begin{array}{l}\text { Bryan et al. }[1982] \\
\text { Spelman and Manabe } \\
\text { [1984] }\end{array}$ & $\begin{array}{l}\text { Coupled atmosphere-ocean general } \\
\text { circulation model with simplified } \\
\text { geography and topography }\end{array}$ & 25 \\
\hline Hansen et al. [1984] & $\begin{array}{l}\text { Radiative-convective climate model } \\
\text { and a box diffusion ocean model }\end{array}$ & $\begin{array}{r}27 \\
55 \\
102\end{array}$ \\
\hline Bryan et al. [1984] & $\begin{array}{l}\text { Global oceanic general circulation } \\
\text { model }\end{array}$ & 100 \\
\hline $\begin{array}{l}\text { Siegenthaler and } \\
\text { Oeschger [1984] }\end{array}$ & $\begin{array}{l}\text { Planetary energy balance climate } \\
\text { model and a box diffusion ocean } \\
\text { model }\end{array}$ & 60 \\
\hline
\end{tabular}

tively. Bryan et al. [1984] used an uncoupled global oceanic general circulation model and found an $e$-folding time of about 100 years in response to an imposed $0.5 \mathrm{~K}$ upper ocean surface warming. Lastly, Siegenthaler and Oeschger [1984] obtained a 60-year $e$-folding time in their study using a box diffusion model.

The studies presented in Table 9 as well as the more recent studies of Harvey [1986] and Harvey and Schneider [1985] indicate that the $e$-folding time $\tau_{e}$ lies between 10 and 100 years. If $\tau_{e} \sim 10$ years, then the actual response of the climate system would be quite close to the equilibrium response, and the disparity between the latter for the 1850 to 1980 warming and that observed would mean that the climate sensitivity of recent GCMs is larger than that of nature. On the other hand if $\tau_{e} \sim 100$ years, then the actual response of the climate system would be quite far from the equilibrium response, thus indicating that the sensitivity of GCMs may not be inconsistent with the observed temperature records.

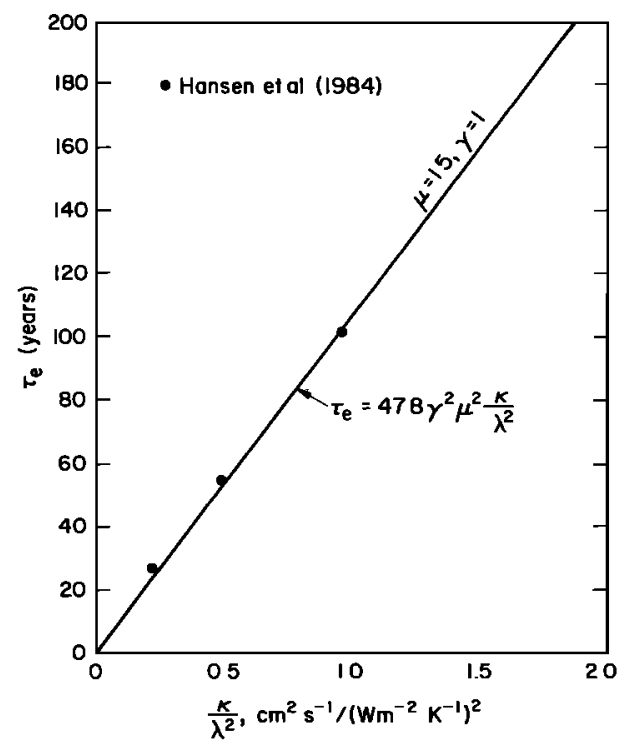

Fig. 20. The $e$-folding time $\tau_{e}$ versus $\kappa / \lambda^{2}$ for abrupt heating perturbations. The linear relation (solid line) is predicted by the analytical solution of Wigley and Schlesinger [1985]. The data points are from the numerical computations of Hansen et al. [1984] for $\kappa=1$ $\mathrm{cm}^{2} \mathrm{~s}^{-1}$.

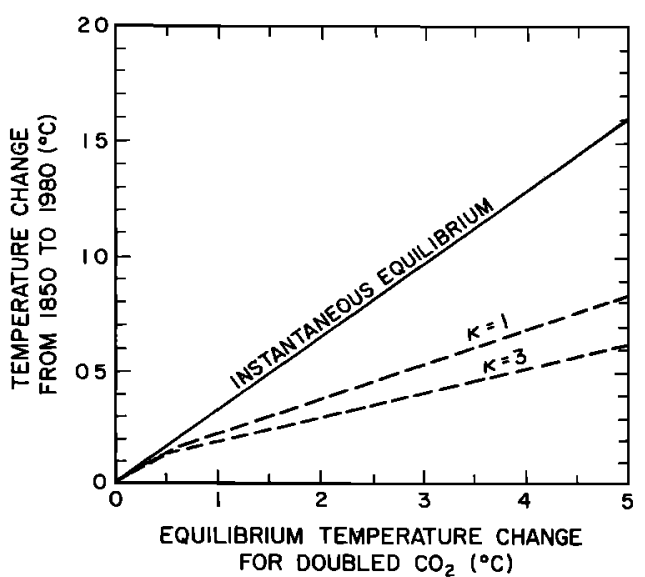

Fig. 21. Temperature change from 1850 to 1980 versus the equilibrium temperature change for doubled $\mathrm{CO}_{2}$. The instantaneous equilibrium curve is given by equation (2). The curves $k=1$ and $\kappa=3$ are from the results of Wigley and Schlesinger [1985].

The factors that contribute to the wide range in $\tau_{e}$ have been investigated by Wigley and Schlesinger [1985] using their analytical solution for the energy balance climate/box diffusion ocean model and by Hansen et al. [1984] using numerical solutions of the box diffusion model and a three-dimensional GCM. Both studies found that $\tau_{e}$ depends (approximately) quadratically on $\lambda^{-1}$ and linearly on the thermal diffusivity $\kappa$. As shown in Figure 20, the analytic result of Wigley and Schlesinger [1985] is in close agreement with the numerical results obtained by Hansen et al. [1984] for $\kappa=1 \mathrm{~cm}^{2} \mathrm{~s}^{-1}$. However, Harvey's [1986] box model results suggest that the $\tau_{e}$ dependence on $\lambda^{-1}$ is slightly less than quadratic for the box diffusion model and for the box advection-diffusion model $\tau_{e}$ varies as $\lambda^{-1.3}$. In view of the dependence of $\tau_{e}$ on $\lambda$ and $\kappa$, the determination of whether $\tau_{e} \sim 10$ or 100 years require a coupled global atmosphere-ocean general circulation model (AOGCM) in which both the climatic gain $\left(\lambda^{-1}\right)$ and the oceanic heat transport are self-determined. Long-term integrations from a simulation with such AOGCMs are currently not available. However, preliminary results from an AOGCM indicate that an energy balance/multibox ocean model with a self-consistent $\kappa$ adequately describes the time evolution of the $\left(2 \times \mathrm{CO}_{2}\right)-\left(1 \times \mathrm{CO}_{2}\right)$ differences in the surface-air temperature [Schlesinger et al., 1985]. The required thermal diffusivity $\kappa$ for the energy balance climate/box diffusion ocean model to represent the transient response of the AOGCM was determined to be $2.25 \mathrm{~cm}^{2} \mathrm{~s}^{-1}$ [Schlesinger et al., 1985].

\subsection{Results for a Realistic $\mathrm{CO}_{2}$ Increase}

The discussions thus far have been for the transient response of the climate system to an instantaneous doubling of the $\mathrm{CO}_{2}$ concentration. However, the $\mathrm{CO}_{2}$ concentration has not abruptly changed in the past nor is it likely to in the future, at least not by an instantaneous doubling. Instead, the $\mathrm{CO}_{2}$ concentration has increased more or less continuously over the observational period since 1958 (Figure 19).

Recently, Hansen et al. [1984] and Wigley and Schlesinger [1985] have estimated the temperature change from 1850 to 1980 induced by the increasing $\mathrm{CO}_{2}$ concentration during this 130-year period. Figure 21, based on the study of Wigley and Schlesinger [1985], shows the 1850-1980 surface temperature change as a function of the equilibrium surface temperature 
change for a doubled $\mathrm{CO}_{2}$ concentration. Let us assume that the latter is $4 \mathrm{~K}$ on the basis of the recent equilibrium warmings simulated by the GFDL, GISS, and NCAR atmospheric GCM/fixed-depth mixed-layer ocean models. If the climate system had no thermal inertia, the 1850-1980 surface temperature change would be in equilibrium with the instantaneous $1980 \mathrm{CO}_{2}$ concentration, and the warming would be given by (16). As shown in Figure 21, this instantaneous equilibrium warming would be $1.3 \mathrm{~K}$. However, when the heat capacity and vertical heat transport of the ocean are considered, as shown by the curves for the oceanic thermal diffusivities $\kappa=1$ and $\kappa=3 \mathrm{~cm}^{2} \mathrm{~s}^{-1}$, the $1850-1980$ warming is reduced to about 0.5 to $0.7 \mathrm{~K}$. This level of $\mathrm{CO}_{2}$-induced warming does not conflict with the temperature changes revealed in the observational record (see Figure 1).

Figure 21 also shows that even if the $\mathrm{CO}_{2}$ concentration were to increase no further in the future, the earth's surface temperature would continue to increase by about $0.7 \mathrm{~K}$ (equaling the balance of the $1.3 \mathrm{~K}$ equilibrium warming for our example) in its approach to its new equilibrium value. This delayed approach to the new equilibrium surface temperature brings out the following important issue concerning the transient effects: the present warming is "small" and perhaps within the natural variation of climate because the ocean sequesters heat within its interior, but because of this, when the warming becomes demonstrably evident, continued future warming is inevitable, even if the $\mathrm{CO}_{2}$ concentration were prevented from increasing further. As shown in section 6, this hidden but inevitable future warming can itself increase in the future as other greenhouse gases such as $\mathrm{N}_{2} \mathrm{O}, \mathrm{CH}_{4}$, and CFCs are added to the earth's atmosphere.

\section{Trace Gas EfFects on Observed and Future Climate Trends}

Greenhouse forcing of the climate system has accelerated in recent years owing to the growth of a number of trace gases. We illustrate this quantitatively by estimating the decadal increment in greenhouse forcing for several trace gases and compare this with the forcing due to increasing $\mathrm{CO}_{2}$ in the same decades.

\subsection{Conceptual Framework for the Assessment}

The potential effects of trace gases on past and future temperature trends have been estimated by numerous studies (Hansen et al., [1984], Brühl and Crutzen [1984], Wang et al. [1986], Ramanathan et al. [1985], and Dickinson and Cicerone [1986], to cite just the recent analyses). The present assessment, while it combines the salient features of the earlier work, is an independent analysis of the trace gas effects on past and future climate trends.

We do not explicitly employ a climate model but instead compute the zero climate feedback surface temperature change, $\left(\Delta T_{s}\right)_{0}$, from a modified version of the radiativeconvective model of Lacis et al. [1981]. The computed $\left(\Delta T_{3}\right)_{0}$ is then multiplied by the feedback factor $F$ (see (2) in section 3.2.2) to obtain the expected climate forcing, $\Delta T_{s}$.

The $\left(\Delta T_{s}\right)_{0}$ is the equilibrium change in surface air temperature which would occur as a result of a change in atmospheric composition in the absence of any climate feedbacks. As described in section $3.2,\left(\Delta T_{s}\right)_{0}$ is a nearly model-independent measure of the radiative forcing. For example, for a doubling of $\mathrm{CO}_{2},\left(\Delta T_{s}\right)_{0}$ for $\mathrm{RCMs}$ is in the range of 1.2 to $1.3 \mathrm{~K}$; the
RCM used in this study yields a value of

$$
\left[\Delta T_{s}\left(2 \times \mathrm{CO}_{2}\right)\right]_{\mathrm{o}}=1.26 \mathrm{~K}
$$

The $\left(\Delta T_{s}\right)_{0}$ also avoids current uncertainties in climate sensitivity; also, since it refers to equilibrium response, it is independent of uncertainties in climate response time.

The next issue concerns the choice of the feedback factor $F$. Climate feedbacks and climate sensitivity are discussed in section 3.2. It is sufficient for our purposes to note that the estimate of equilibrium global mean climate sensitivity reported by the National Academy of Sciences [Charney, 1979; Smagorinsky, 1982] is

$$
\Delta T_{s}\left(2 \times \mathrm{CO}_{2}\right)=3 \pm 1.5 \mathrm{~K}
$$

The above climate sensitivity range covers a factor of 3 , with $\Delta T_{s}$ ranging from 1.5 to $4.5 \mathrm{~K}$. It is easier to justify the lower and the upper limits than the mean value of $3 \mathrm{~K}$. For example, RCMs generally yield a value of $2 \mathrm{~K}$, while GCMs with seasonal cycle and realistic geography yield values ranging from 3.5 to $4.2 \mathrm{~K}$ (see Table 7). Hence in this report we avoid the use of a mean value for $\Delta T_{s}$ but instead adopt the range recommended by the National Academy reports:

$$
1.5 \leq \Delta T_{s}\left(2 \times \mathrm{CO}_{2}\right) \leq 4.5 \mathrm{~K}
$$

Since the zero climate feedback forcing for doubled $\mathrm{CO}_{2}$ is $1.26 \mathrm{~K}$ for the present $\mathrm{RCM}$, the climate sensitivity range given by (21) corresponds to the feedback factor $F\left(=\Delta T_{s} /\right.$ $\left(\Delta T_{s}\right)_{0} ;(2)$ in section 3.2.2) of

$$
1.2 \leq F \leq 3.6
$$

It is because of this large range for $F$ that we have avoided the use of a specific climate model in the present analyses. In order to account for the climate sensitivity yielded by RCMs and GCMs, we adopt the following two values:

$$
\begin{array}{ll}
\Delta T_{s}\left(2 \times \mathrm{CO}_{2}\right)=2 \mathrm{~K} & F \approx 1.6 \\
\Delta T_{s}\left(2 \times \mathrm{CO}_{2}\right)=4 \mathrm{~K} & F \approx 3.2
\end{array}
$$

\subsection{Greenhouse Forcing From 1850 to the 1980 s}

The sources and observed trends for the trace gases are discussed extensively in published studies (Ramanathan et al. [1985] and WMO [1985], to cite a few). Hence only a brief summary is given in the ensuing discussions.

6.2.1. $\mathrm{CO}_{2}$. The abundance of atmospheric $\mathrm{CO}_{2}$ was 315 ppmv in 1958 when C. D. Keeling initiated accurate monitoring. Thus since a variety of techniques indicate that the $\mathrm{CO}_{2}$ abundance was $270 \pm 10 \mathrm{ppmv}$ in 1850 [WMO, 1983b], the mean decadal growth of $\mathrm{CO}_{2}$ for the period 1850-1960 was about 14 ppmv per decade. By contrast, the current rate of growth of $\mathrm{CO}_{2}$ is about 15 ppmv per decade. The decadal greenhouse forcing due to $\mathrm{CO}_{2}$ growth is illustrated in Figure 22 for the period 1850-1960 and for recent decades.

6.2.2. Chlorofluorocarbons. The release rates of $\mathrm{CF}_{2} \mathrm{Cl}_{2}$ (F12) and $\mathrm{CFCl}_{3}$ (F11) into the atmosphere can be estimated from production data available from the manufacturers [Chemical Manufacturers Association, 1982]. Under the assumption of 150- and 75-year lifetimes for F12 and F11, respectively, decadal growth rates are obtained which are in good agreement with recent atmospheric measurements [Geophysical Monitoring for Climatic Change, 1984]. The F11 and F12 lifetimes adopted here are slightly different from Ramanathan et al.'s [1985] values given in Table 8. The resulting 

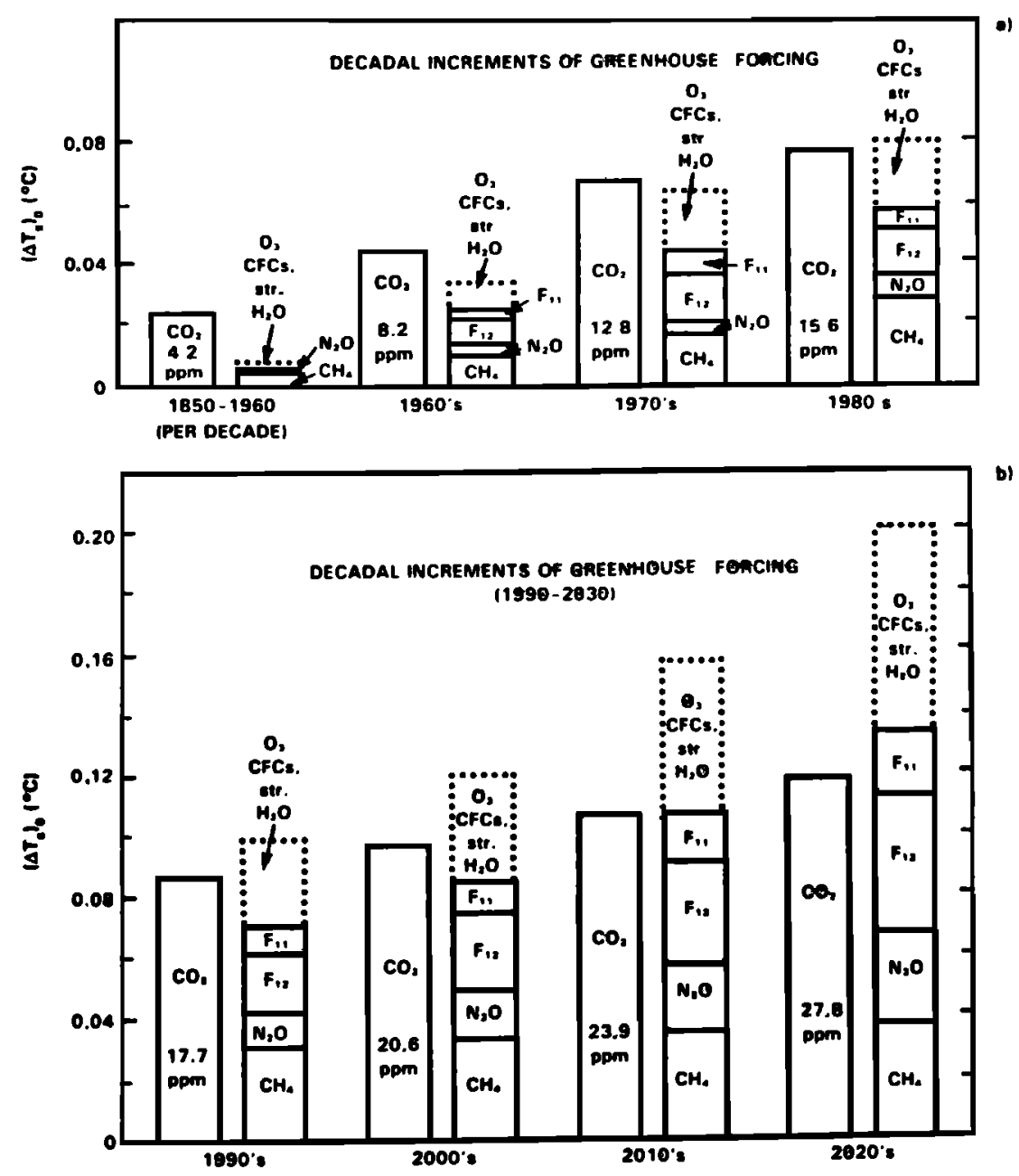

Fig. 22. Decadal additions to global mean greenhouse forcing of the climate system. The $\left(\Delta T_{9}\right)_{0}$ is the computed temperature change at equilibrium $(t \rightarrow \infty)$ for the estimated decadal increases in trace gas abundances, with no climate feedbacks included. Formulas for $\left(\Delta T_{3}\right)_{0}$ as a function of the trace gas abundances are given by Lacis et al. [1981]. (a) Past additions. Except for $\mathrm{O}_{3}$ and stratospheric $\mathrm{H}_{2} \mathrm{O}$, the estimated trace gas increases are based on measurements, as discussed in the text. (b) Future additions. Adopts case A scenario given in Table 10.

decadel climate forcings are shown in Figure 22. It is apparent that these chlorofluorocarbons now add substantial climate forcing, through their contribution was negligible in the period $1850-1960$.

Less abundant chlorine and fluorine compounds, such as $\mathrm{CHClF}_{2}$ (F22), $\mathrm{CCl}_{4}, \mathrm{CF}_{4}$, and $\mathrm{CH}_{3} \mathrm{CCl}_{3}$, also have significant growth rates and infrared absorption strengths (see Tables $1 a$, $1 b$, and 8). However, the growth histories and absorption strengths are on the whole less well known than for F11 and F12. $\mathrm{CCl}_{4}$ apparently had a higher growth rate in the 1960 s and 1970s than it does now, while $\mathrm{F} 22$ and $\mathrm{CH}_{3} \mathrm{CCl}$ have grown rapidly in recent years, with a higher growth rate than that of F11 and F12. In Figure 22 we include a greenhouse centribution for these other CFCs with a net radiative forcing that is $20 \%$ of that for F11 and F12. However, this is meant more as a reminder that these other CFCs need to be considered rather than as an accurate estimate of their greenhouse contribution.

6.2.3. $\mathrm{CH}_{4}$. The concentration of methane has been inreasing at rates varying from 1.5 to $1.8 \%$ per year during 1970 to 1979 [Gammon et al., 1985; Rasmussen and Khalil, 1986]. The rate of increase has reduced to about $1 \%$ per year during the 1979 to 1984 period [Rasmussen and Khalil, 1986]. Also, measurements of air bubbles trapped in polar ice cores [Craig and Chou, 1982; Rasmussen and Khalil, 1984] indicate that the methane abundance was about 0.7 ppmv from 25,000 years ago to 500 years ago, with an increase beginning sometime between 200 and 500 years ago. We estimate the $\mathrm{CH}_{4}$ greenhouse forcing for Figure 22 by taking the abundance at 1 ppmv in 1850,1.4 ppmv in 1958, $1.5 \mathrm{ppmv}$ in 1970, $1.65 \mathrm{ppmv}$ in 1980 , and $1.79 \mathrm{ppmv}$ in 1985 . The $1985 \mathrm{CH}_{4}$ concentration is slightly higher than the January 1985 concentration of 1.71 ppmv (for the Pacific northwest) reported by Rasmussen and Khalil [1986]. Furthermore, it should be noted that $\mathrm{CH}_{4}$ concentration undergoes latitudinal variations varying from about $1.55 \mathrm{ppmv}$ in the equatorial regions to about $1.76 \mathrm{ppmv}$ in the northern hemisphere middle to polar regions (L. P. Steele et al., unpublished manuscript, 1986; also see Gammon et al. [1985]). The values adopted in our study are representative of northern hemisphere mid-latitude values.

6.2.4. $\mathrm{N}_{2} \mathrm{O}$. Nitrous oxide was measured to be increasing at a rate of about $0.2 \%$ per year in the 1970's [Weiss, 1981]. Recent measurements [CDAC, 1983] suggest that the current growth rate may be closer to $0.3 \%$ per year. These values are 
used to estimate the $\mathrm{N}_{2} \mathrm{O}$ greenhouse forcing for Figure 22 . Although it seems likely that $\mathrm{N}_{2} \mathrm{O}$ may have had a small rate of increase in the period $1850-1958$, there are no observations providing a quantitative measure.

6.2.5. Stratospheric $\mathrm{H}_{2} \mathrm{O}$. Since the abundance of water vapor in the troposphere is controlled basically by atmospheric temperature and other meteorological variables, changes in tropospheric $\mathrm{H}_{2} \mathrm{O}$ are considered as a climate feedback mechanism rather than as a forcing mechanism. However, in the upper stratosphere, $\mathrm{H}_{2} \mathrm{O}$ is produced by methane oxidation, and therefore an increase of methane may increase stratospheric $\mathrm{H}_{2} \mathrm{O}$. The change of stratospheric $\mathrm{H}_{2} \mathrm{O}$ would be delayed after any increase in tropospheric $\mathrm{CH}_{4}$ by the time required for transport from the troposphere to the upper stratosphere. The greenhouse forcing of $\mathrm{H}_{2} \mathrm{O}$ in Figure 22 is based on the added stratospheric $\mathrm{H}_{2} \mathrm{O}$ which D. J. Wuebbles (private communication, 1985) estimates to be associated with the increase of $\mathrm{CH}_{4}$. It is apparent that the greenhouse warming from added stratospheric $\mathrm{H}_{2} \mathrm{O}$ is about $50 \%$ as great as the direct $\mathrm{CH}_{4}$ greenhouse warming. These estimates do not include the $\mathrm{CH}_{4}-\mathrm{O}_{3}$ feedback (see section 4).

6.2.6. $\mathrm{O}_{3}$. Ozone is an effective greenhouse gas because of its strong absorption band at $9.6 \mu \mathrm{m}$. Present understanding of atmospheric chemistry (for example, see Isaken and Sterdal [1986] and Owens et al. [1985]) suggests that growth of atmospheric CFCs will eventually deplete stratospheric $\mathrm{O}_{3}$ substantially and increase tropospheric $\mathrm{O}_{3}$, with a net columnintegrated reduction of $\mathrm{O}_{3}$. The net greenhouse effect of this would be a slight warming because of the greater greenhouse efficiency of tropospheric ozone molecules [Ramanathan and Dickinson, 1979; Owens et al., 1985]. In addition, as discussed in section 4, increases of atmospheric methane, carbon monoxide, and nitric oxides tend to increase tropospheric $\mathrm{O}_{3}$ (also see Thompson and Cicerone [1986]). However, a recent threedimensional transport model study [Levy et al., 1985] indicates the potential importance of transport in governing the $\mathrm{O}_{3}$ distribution. The relative importance of transport and hydrocarbon/nitrogen oxide chemistry in governing tropospheric ozone production is as yet an unresolved issue [Levy et al., 1985].

Recent measurements of $\mathrm{O}_{3}$ are not inconsistent with a long-term trend of increasing tropospheric ozone [Angell and Korshover, 1983; Bojkov and Reinsel, 1985]. For example, analyses of northern hemisphere ozonesonde data from 11 stations reveal a statistically significant $1.1 \%$ per year increase in the free troposphere ozone over a 15-year period; southern hemisphere ozone seems to have undergone very little change in the same period [Bojkov and Reinsel, 1985]. These and other findings [Angell and Korshover, 1983] based on observed ozone data are also consistent with estimates of ozone production from anthropogenically released hydrocarbons and nitrogen oxides [Isaksen, 1980], $\mathrm{NO}_{x}$ emissions from aircraft [Liu et al., 1980], and CO from incomplete combustion [Logan et al., 1978]. In spite of this apparent consistency between theory and observations, the large natural variability of tropospheric ozone when considered in conjunction with the poor spatial coverage of the ozone measurement stations prevents firm conclusions regarding trends.

We estimate the potential $\mathrm{O}_{3}$ greenhouse effect by using trends for $\mathrm{O}_{3}$ which were computed by Wuebbles et al. [1983] on the basis of scenarios for atmospheric methane, nitrous oxides, and carbon dioxide; however, we decreased this com- puted $\left(\Delta T_{s}\right)_{0}$ by the factor 0.5 because much of the $\mathrm{O}_{3}$ change would be confined to the hemispheric or smaller scale. The resulting tropospheric $\mathrm{O}_{3}$ climate forcing, indicated by a dotted bar in Figure 22, is very uncertain but is obviously a potentially important contributor to the greenhouse effect.

The following major conclusions follow directly from Figure 22:

1. Non- $\mathrm{CO}_{2}$ greenhouse gases are now adding to the greenhouse effect by an amount at least comparable to the effect of $\mathrm{CO}_{2}$; this is a fundamental change from the situation during the period $1850-1960$.

2. The rate of increase of the total greenhouse forcing is now 3-6 times greater than the mean rate for the period 1850 1960 , because of both an increase in the growth rate of $\mathrm{CO}_{2}$ and the recent growth of other trace gases.

3. The cumulative value of $\left(\Delta T_{3}\right)_{0}$ for the period $1850-1980$ is $0.56 \mathrm{~K}$; the $\mathrm{CO}_{2}$ increase contributes $0.4 \mathrm{~K}$, and the other trace gases contribute the balance of $0.16 \mathrm{~K}$. The radiative forcing of $0.56 \mathrm{~K}$ would yield an equilibrium surface-air temperature change of about $0.9 \mathrm{~K}(=0.56 \times 1.6)$ and about $0.6 \mathrm{~K}$ for a $\mathrm{CO}_{2}$ increase alone for a climate model whose equilibrium sensitivity is $\Delta T_{s}\left(2 \times \mathrm{CO}_{2}\right)=2 \mathrm{~K}$. These results are consistent with the earlier RCM estimates of Brühl and Crutzen [1984] ( $0.6 \mathrm{~K}$ for $\mathrm{CO}_{2}$ alone and $1 \mathrm{~K}$ for all gases), with those of Ramanathan et al. [1985] (0.6 K for $\mathrm{CO}_{2}$ alone and about $0.9 \mathrm{~K}$ for all gases), and with the more recent estimates of Dickinson and Cicerone [1986] (about $1 \mathrm{~K}$ for all gases) for surface air temperature. The range in the equilibrium surfaceair temperature change is 0.7 to $2 \mathrm{~K}$, where we have adopted (22) to multiply the $\left(\Delta T_{3}\right)_{0}$ of $0.56 \mathrm{~K}$ with the range in $F$.

4. The computed stratospheric cooling for the period $1850-1980$ is slightly under $1 \mathrm{~K}$ between 25 and $30 \mathrm{~km}$ and about $3 \mathrm{~K}$ between 35 and $45 \mathrm{~K}$. These calculations do not include the effects of $\mathrm{O}_{3}$ change due to the buildup of F11 and F12 which can amplify the cooling due to $\mathrm{a}_{2}$ increase by about $20 \%$.

\subsection{Greenhouse Forcing Projected Into Next Century}

We consider three scenarios (case A, case B, and case C) projecting trace gas greenhouse forcing into the future. The three scenarios are summarized in Table 10 , and the concentrations are given in Table 11. The use of more than one scenario seems essential because of major uncertainties in our understanding of the causes of the trace gas changes and the great difficulties in projecting economics, population, and other key factors. We compare these scenarios with the range of trace gas forcings estimated by Ramanathan et al. [1985] for 2030. The scenarios adopted by Ramanathan et al. [1985] are shown in Table 8 (see the column under the heading Possible Range).

The case A scenario is an extrapolation of current growth rates for measured gases, and it includes an allowance to approximate the effect of several gases that are poorly measured and/or have uncertain absorption strengths. The growth rate itself varies substantially from one period to the next. For example, as was mentioned earlier, $\mathrm{CH}_{4}$ concentrations have been increasing at rates varying from about $1.8 \%$ per year in the early 1970 s to about $1 \%$ per year in the early 1980 s. In case $A$ we adopt the maximum growth rates or increase in emission that is permitted by the data of the last decade. Cases $B$ and $C$ adopt a more conservative extrapolation of the available data. The resulting radiative forcing for this scenario is 
TABLE 10. Trace Gas Scenarios

\begin{tabular}{|c|c|c|c|}
\hline $\begin{array}{c}\text { Trace } \\
\text { Gas }\end{array}$ & $\begin{array}{l}\text { Case A: } \\
\text { Current Growth } \\
\text { Rate }\end{array}$ & $\begin{array}{c}\text { Case B: } \\
\text { Reduced Growth } \\
\text { Rate }\end{array}$ & Case C \\
\hline $\mathrm{CO}_{2}$ & $\begin{array}{l}1.5 \% \text { per year growth in } \\
\text { annual } \mathrm{CO}_{2} \text { increment }\end{array}$ & $\begin{array}{l}1.5 \% \text { per year growth to } 1990 \\
1.0 \% \text { per year from } 1990 \text { to } 2000 \\
0.5 \% \text { per year from } 2000 \text { to } 2010 \\
0 \% \text { per year after } 2010 \text { in } \\
\text { annual } \mathrm{CO}_{2} \text { increment }\end{array}$ & $\begin{array}{l}\text { time-dependent; } \\
\text { averages about } \\
2 \% \text { per year growth } \\
\text { in annual } \mathrm{CO}_{2} \\
\text { increment }\end{array}$ \\
\hline $\begin{array}{l}\mathrm{CFCl}_{3} \text { and } \\
\mathrm{CF}_{2} \mathrm{Cl}_{2}\end{array}$ & $\begin{array}{l}3 \% \text { per year growth in } \\
\text { emissions }\end{array}$ & $\begin{array}{l}3 \% \text { per year growth to } 1990 \\
2 \% \text { per year from } 1990 \text { to } 2000 \\
1 \% \text { per year from } 2000 \text { to } 2010 \\
0 \% \text { per year after } 2010\end{array}$ & $\begin{array}{l}1.5 \% \text { per year growth } \\
\text { in emissions }\end{array}$ \\
\hline $\mathrm{CH}_{4}$ & $\begin{array}{l}1.5 \% \text { per year growth in } \\
\mathrm{CH}_{4} \text { abundance }\end{array}$ & $\begin{array}{l}1.5 \% \text { per year growth to } 1990 \\
1.0 \% \text { per year from } 1990 \text { to } 2000 \\
0.5 \% \text { per year after } 2000\end{array}$ & $\begin{array}{l}1 \% \text { per year growth } \\
\text { in } \mathrm{CH}_{4} \text { abundance }\end{array}$ \\
\hline $\mathrm{N}_{2} \mathrm{O}$ & $\begin{array}{l}\text { Weiss [1981] formula: } \\
3.5 \% \text { per year growth to } 1990 \text {; } \\
\text { yields } 0.2 \% \text { per year } \\
\text { growth in abundance in } \\
1980,0.4 \% \text { per year in } 2000, \\
\text { and } 0.9 \% \text { per year } \\
\text { in } 2030\end{array}$ & $\begin{array}{l}\text { Weiss formula with } \\
3.5 \% \text { per year growth in } \\
\text { emissions } \\
2.5 \% \text { per year from } 1990 \text { to } 2000 \\
1.5 \% \text { per year from } 2000 \text { to } 2010 \\
0.5 \% \text { per year after } 2010 \text {; yields } \\
0.2 \% \text { per year growth } \\
\text { in abundance in } 1980 \text {, } \\
0.33 \% \text { per year in } 2000 \text {, and } \\
0.34 \% \text { per year in } 2030\end{array}$ & $\begin{array}{l}0.25 \% \text { per year growth } \\
\text { in } \mathrm{N}_{2} \mathrm{O} \text { abundance }\end{array}$ \\
\hline $\begin{array}{l}\mathrm{O}_{3} \text { and } \\
\text { other } \\
\text { trace } \\
\text { gases }\end{array}$ & $\begin{array}{l}\text { assumed greenhouse } \\
\text { forcing by these gases } \\
\text { is the same as that of } \\
\mathrm{CF}_{2} \mathrm{Cl}_{2} \text { and } \mathrm{CFCl}_{3}\end{array}$ & none & $\begin{array}{l}\text { includes only } \mathrm{O}_{3} \\
\text { effects. } \mathrm{O}_{3} \text { change } \\
\text { is explicitly computed } \\
\text { from a chemistry } \\
\text { model }\end{array}$ \\
\hline
\end{tabular}

*The $\mathrm{CO}_{2}$ increment in 1985 was taken as $1.5 \mathrm{ppmv}$, and this increment increased by $1.5 \%$ per year in case A. This case is appropriate if fossil fuel use increases by $1.5 \%$ per year and the "airborne fraction" of $\mathrm{CO}_{2}$ remains constant, for example. Note that this growth rate is much less than the 4\% per year growth rate that existed in the 100 years before 1973.

shown in Figure $22 b$ and is near the middle of the range estimated by Ramanathan et al. [1985]. The case B scenario includes only five greenhouse gases that are measured reasonably well, and it assumes rapidly decreasing growth rates. The resulting radiative forcing is near the lower limit of the range estimated by Ramanathan et al. [1985].

In case $\mathrm{A}$ (current growth rates), $\mathrm{CO}_{2}$ increases at a constant growth rate from $270 \mathrm{ppmv}$ in 1850 to $315 \mathrm{ppmv}$ in 1958 , as observed by C. D. Keeling for the interval 1958-1984 and subsequently with a $1.5 \%$ growth of the annual increment. $\mathrm{CFCl}_{3}$ and $\mathrm{CF}_{2} \mathrm{Cl}_{2}$ emissions are from reported rates to date and assume a $3 \%$ per year increased emission in the future, with atmospheric lifetimes for the gases of 75 and 150 years, respectively. $\mathrm{CH}_{4}$ increases at a constant growth rate from $1 \mathrm{ppmv}$ in 1850 to $1.4 \mathrm{ppmv}$ in $1958,1.51 \mathrm{ppmv}$ in 1970 and $1.79 \mathrm{ppmv}$ in 1985 , and $1.5 \%$ per year thereafter. $\mathrm{N}_{2} \mathrm{O}$ increases according to the semiempirical formula of Weiss [1981], the rate being $0.1 \%$ per year in $1958,0.2 \%$ per year in $1980,0.4 \%$ per year in 2000 , and $0.9 \%$ per year in 2030 . Potential effects of several other trace gases (such as $O_{3}$, stratospheric $\mathrm{H}_{2} \mathrm{O}$, and chlorine and fluorine compounds other than F11 and F12) are approximated by multiplying the effect of F11 and F12 by a factor of 2 .

In case $B$ (reduced growth rates) the annual increment in $\mathrm{CO}_{2}$ is reduced from $1.5 \%$ today to $1 \%$ in $1990,0.5 \%$ in 2000 , and 0 in 2010 , which compares to $\approx 4 \%$ during the period 1900-1970 and is below projected rates for population growth; the resulting $\Delta \mathrm{CO}_{2}$ is constant at $1.9 \mathrm{ppm} \mathrm{yr}^{-1}$ after 2010. The annual growth in $\mathrm{CF}_{2} \mathbf{C l}_{2}$ and $\mathrm{CFCl}_{3}$ emissions is reduced from $3 \%$ today to $2 \%$ in $1990,1 \%$ in 2000 , and 0 in 2010; because of their finite lifetimes, the annual increments in atmospheric abundance decrease with time after 2010. The methane annual growth rate decreases from $1.5 \%$ today to $1 \%$ in 1990 to $0.5 \%$ in 2000 . $\mathrm{N}_{2} \mathrm{O}$ increases are based on Weiss' [1981] formula, but the parameter specifying annual growth in anthropogenic emissions decreases from $3.5 \%$ today to $2.5 \%$ in $1990,1.5 \%$ in 2000 , and $0.5 \%$ in 2010 . No increases are included for other chlorofluorocarbons, $\mathrm{O}_{3}$, stratospheric $\mathrm{H}_{2} \mathrm{O}$, or any other gases.

The case $\mathbf{C}$ scenario falls in between case $A$ and case $B$. Case $\mathrm{C}$, like case $\mathrm{A}$, adopts current growth rates but chooses the lower limit of the observed growth rates. For example, it

TABLE 11. Trend in Concentrations

\begin{tabular}{|c|c|c|c|c|c|c|c|c|c|c|}
\hline Date & & $\begin{array}{l}\mathrm{CO}_{2} \\
\mathrm{ppm}\end{array}$ & & $\begin{array}{l}\mathrm{CH}_{4}, \\
\text { ppm }\end{array}$ & & $\begin{array}{l}\mathrm{N}_{2} \mathrm{O}, \\
\mathrm{ppb}\end{array}$ & & $\begin{array}{l}\mathrm{Cl}_{3} \mathrm{~F}, \\
\mathrm{pb}\end{array}$ & & $\begin{array}{l}\mathrm{l}_{2} \mathbf{F}_{2}, \\
\mathrm{pb}\end{array}$ \\
\hline 1850 & & 270 & & 1.00 & & 282 & & & & \\
\hline 1900 & & 290 & & 1.17 & & 284 & & & & \\
\hline 1958 & & 315 & & 1.40 & & 293 & & .01 & & .03 \\
\hline 1970 & & 325 & & 1.51 & & 297 & & .07 & & .13 \\
\hline 1985 & & 346 & & 1.79 & & 305 & & .24 & & .40 \\
\hline \multirow[b]{2}{*}{ Date } & \multicolumn{2}{|c|}{$\mathrm{CO}_{2}, \mathrm{ppm}$} & \multicolumn{2}{|c|}{$\mathrm{CH}_{4}, \mathrm{ppm}$} & \multicolumn{2}{|c|}{$\mathrm{N}_{2} \mathrm{O}, \mathrm{ppb}$} & \multicolumn{2}{|c|}{$\mathrm{CCl}_{3} \mathrm{~F}, \mathrm{ppb}$} & \multicolumn{2}{|c|}{$\overline{\mathrm{CCl}_{2}} \mathrm{~F}_{2}, \mathrm{ppb}$} \\
\hline & $\mathbf{A}$ & B & A & B & A & B & $\mathbf{A}$ & B & A & B \\
\hline 2000 & 372 & 371 & 2.24 & 2.12 & 319 & 318 & 0.42 & 0.41 & 0.72 & 0.71 \\
\hline 2015 & 404 & 400 & 2.80 & 2.28 & 343 & 335 & 0.71 & 0.61 & 1,22 & 1.07 \\
\hline 2030 & 445 & 428 & 3.50 & 2.46 & 383 & 353 & 1.15 & 0.78 & 1.99 & 1.41 \\
\hline 2050 & 515 & 466 & 4.71 & 2.72 & 483 & 377 & 2.13 & 0.96 & 3.72 & 1.80 \\
\hline 2100 & 818 & 562 & 9.91 & 3.49 & 1432 & 439 & 9.68 & 1.24 & 17.00 & 2.60 \\
\hline
\end{tabular}

From 1985 to 2100 the concentrations are derived from the scenarios A and B shown in Table 10. 


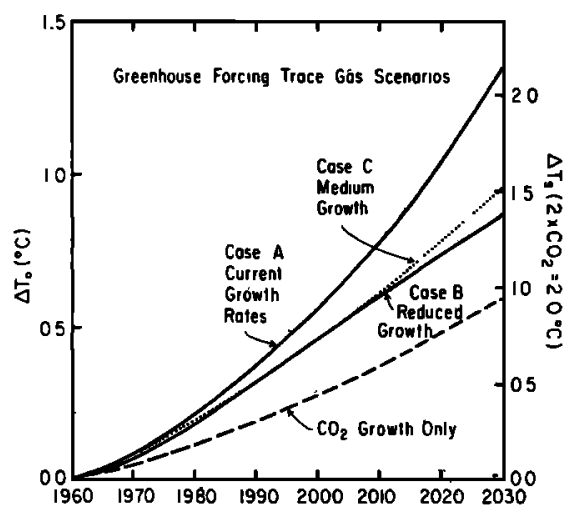

Fig. 23. Greenhouse forcing for three trace gas scenarios: case A, which uses current growth rates, case $B$; which assumes substantial reductions in growth, as described in the text, and case $\mathrm{C}$, which is similar to case A but with medium growth rate. See Table 10 for further details. $\Delta T_{0}$ is the equilibrium greenhouse warming for no climate feedbacks. The "doubled $\mathrm{CO}_{2}$ " level of forcing occurs when the $\mathrm{CO}_{2}$ and trace gases added subsequent to 1958 provide a radiative forcing equivalent to a doubling of $\mathrm{CO}_{2}$ from $315 \mathrm{ppm}$ to 630 ppm. The " $\mathrm{CO}_{2}$ growth only" curve applies to the case A scenario.

adopts $1.5 \%$ per year growth in $\mathrm{CFCl}_{3}$ and $\mathrm{CF}_{2} \mathbf{C l}_{2}$ emissions as opposed to the $3 \%$ per year growth assumed in case $\mathrm{A}$; the growth in $\mathrm{CH}_{4}$ abundance is reduced to $1 \%$ per year instead of $1.5 \%$ per year in case $\mathrm{A}$. Furthermore, trace gases other than $\mathrm{CO}_{2}, \mathrm{CFCl}_{3}, \mathrm{CF}_{2} \mathrm{Cl}_{2}, \mathrm{CH}_{4}, \mathrm{~N}_{2} \mathrm{O}$, and $\mathrm{O}_{3}$ are not included in case $C$.

The case $A$, case $B$, and case $C$ scenarios are summarized in Table 10; the time-dependent concentrations for case $A$ and case $B$ are shown in Table 11. The computed greenhouse forcings are illustrated in Figure 23 for the period 1960-2030. Case $A$ yields a forcing that has a slightly larger forcing than the nominal scenario of Ramanathan et al. [1985] (see Figure

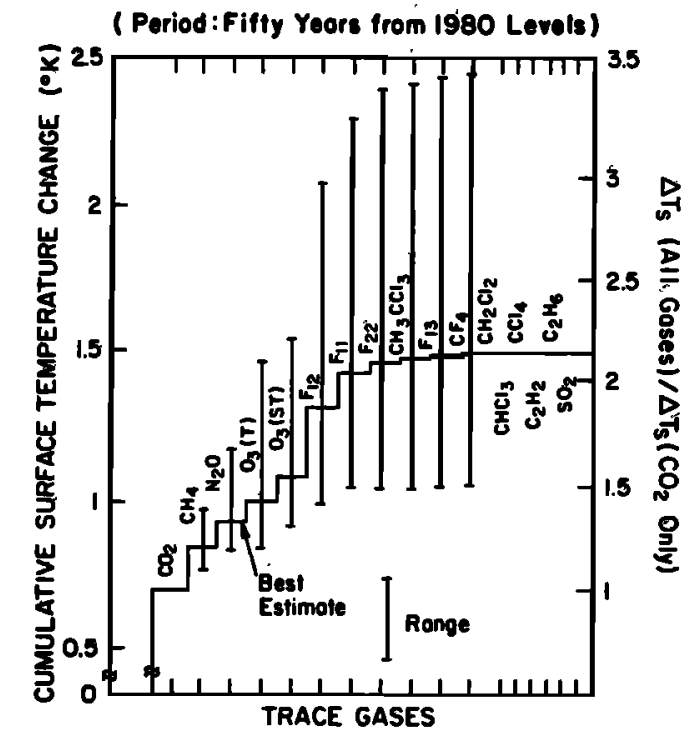

Fig. 24. Curnulative equilibrium surface temperature warming due to increases of $\mathrm{CO}_{2}$ and other trace gases, for the trace gas scenario of Table 10. In this one-dimensional model calculation, the surface-air temperature change is larger than the surface temperature change by about $10 \%$ [Ramanathan et al., 1985]. The $(\Delta T)_{0}$ can be obtained by dividing the indicated surface temperature change by a feedback factor $(F)$ of about 1.5 .

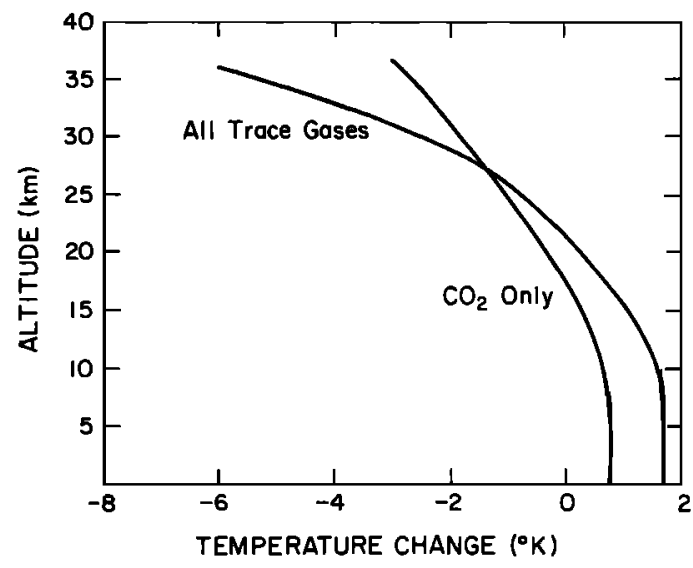

Fig. 25. Atmospheric temperature change due to $\mathrm{CO}_{2}$ and other trace gases. Radiative-convective model results employing the scenario in Table 8.

24). Case $A$ yields a forcing equivalent to doubled $\mathrm{CO}_{2}$ (with $1 \times \mathrm{CO}_{2}$ defined as $315 \mathrm{ppm}$ ) before 2030; case $\mathrm{C}$ yields this level slightly after 2030; while case $B$ yields this level of forcing before 2060. The time to reach effective doubled $\mathrm{CO}_{2}$ forcing is greatly accelerated by the non- $\mathrm{CO}_{2}$ trace gases, which provide roughly half of the greenhouse forcing. A comparison of the forcing by $\mathrm{CO}_{2}$ and other trace gases is illustrated clearly in Figure 24, taken from Ramanathan et al. [1985]; although the relative contributions of the various trace gases in their scenario are somewhat different from either case $A$ or $\ddot{B}$, the results are qualitatively very similar. The following points should be noted first before comparing the Ramanathan et al. [1985], hereinafter referred to as $R$, results with those shown in Figure 23. The one-dimensional RCM model of $R$ computes both surface temperature $\left(T_{\theta}\right)$ and surface-air temperature $\left(T_{s}\right)$. In the $\mathrm{R}$ model the computed $\Delta T$, is larger than $\Delta T_{o}$ by about $10-13 \%$. For $\mathrm{CO}_{2}$ doubling the $\mathrm{R}$ model yields a $\Delta T_{\theta} \sim 1.9 \mathrm{~K}$ and a $\Delta T_{s} \sim 2.1 \mathrm{~K}$. The $\mathrm{R}$ model results in Figure 24 show that for the period 1980-2030 the equilibrium surface warming, i.e., $\Delta T_{g}$, is $1.54 \mathrm{~K}\left(\Delta T_{s} \sim 1.7 \mathrm{~K}\right)$ due to all gases including $\mathrm{CO}_{2}$ and the surface warming due to the $\mathrm{CO}_{2}$ increase alone is $0.71 \mathrm{~K}\left(\Delta T_{s} \sim 0.8 \mathrm{~K}\right)$. For the same period of 1980-2030 the case A scenario in Figure 23 yields (for the $\Delta T_{s}\left(2 \times \mathrm{CO}_{2}\right)=2 \mathrm{~K}$ model) a $\Delta T_{s}$ of $1.8 \mathrm{~K}$ for all gases including $\mathrm{CO}_{2}$ and a $\Delta T_{s}$ of $0.8 \mathrm{~K}$ for the $\mathrm{CO}_{2}$ increase by itself. The cumulative $\Delta T_{s}$ for the case $B$ and case $C$ scenarios are 1.1 and 1.25 respectively (see Figure 23). The stratospheric $\mathrm{O}_{3}$ decrease due to CFCs also causes a surface warming, and the magnitude of about $0.1 \mathrm{~K}$ (see Figure 24 ) is roughly $30 \%$ of the direct greenhouse effect of CFCs. Other studies [e.g., Owens et al., 1985] also yields a warming of about $0.1 \mathrm{~K}$ due to the stratospheric $\mathrm{O}_{3}$ decrease resulting from the increase of F11 and F12.

The computed stratospheric temperature changes due to $\mathrm{CO}_{2}$ and other trace gases are substantial (see Figure 25). Above $30 \mathrm{~km}$ the cooling due to a $\mathrm{CO}_{2}$ increase (alone) is more than doubled by the other trace gases. The primary contribution to the enhancement in stratospheric cooling is the (computed) $\mathrm{O}_{3}$ decrease due to a CFC increase. To the extent that trace gases (other than $\mathrm{CO}_{2}$ ) cause a large surface/troposphere warming and a much larger stratospheric cooling, their direct climatic effects are virtually indistinguishable from those of $\mathrm{CO}_{2}$. 


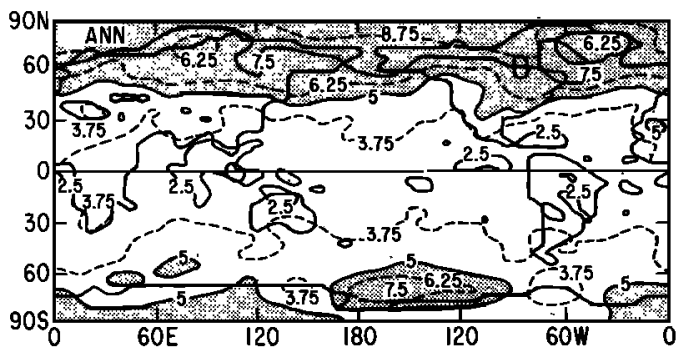

Fig. 26. Geographical distribution of the annual mean surface air warming (in degrees Celsius) in the $4 \times \mathrm{CO}_{2}$ experiment of Manabe and Stouffer [1980].

\subsection{Regional Effects}

There is general agreement that climate sensitivity is not globally uniform. Both empirical evidence from past climate changes and global climate models indicate that the surface air temperature response is magnified at high latitudes and thus somewhat muted at low latitudes, in comparison to the global mean tesponse. This high-latitude enhancement is expected on theoretical grounds, because the ice-snow albedo feedback only operates at high latitudes, and because the relative stability of the atmosphere there tends to confine surface warming or cooling to low altitudes. The high-latitude enhancement of the warming is illustrated in Figure 26, which shows model results for the annual mean surface-air temperature increase from the $4 \times \mathrm{CO}_{2}$ experiment of Manabe and Stouffer [1980]. Qualitatively similar results are obtained with other general circulation models [Hansen et al., 1984; Washington and Meehl, 1984].

\subsection{Equilibrium and Transient Temperature Response}

The climate forcings discussed above are given in terms of the equilibrium $(t \rightarrow \infty)$ response with no climate feedbacks. In order to convert these forcings to an expected temperature response, it is necessary to account for (1) climate feedback mechanisms and (2) the finite response time of the climate system. As was explained in section 5, these two effects are not independent; a greater positive climate feedback leads to a longer climate response time. Also note that although climate forcings usually can be computed with an accuracy of the order of $20 \%$ for a given change in atmospheric composition, the uncertainties in the strength of climate feedbacks and in the climate response time are much greater.

The transient temperature response involves additional complications because of the difficulty in properly accounting for the climate system's thermal inertia, which is due mainly to the large effective heat capacity of the oceans. Ocean circulation and mixing are not yet adequately observed, and ocean general circulation models are just reaching the point at which they can be applied to the transient climate problem. However, the essence of the ocean's effect in delaying the greenhouse warming can be demonstrated with a simple "box diffusion" model for the ocean [Oeschger et al., 1975; Cess and Goldenberg, 1981; Hansen et al., 1981]. In this model it is assumed that heat perturbations are rapidly mixed as a passive tracer into the deeper ocean in a way that can be approximated as one-dimensional diffusion. Although this model does not account for the buoyancy effects of sea surface temper- ature changes in modifying the penetration depth of the radiative forcing, it provides - a reasonable fit to the globally averaged results of a coupled ocean-atmosphere GCM (see Bryan et al. [1984] for further elaboration of this issue). The effective diffusion coefficient is estimated from measurements of transient tracers to be $\kappa=1--2 \mathrm{~cm}^{2} \mathrm{~s}^{-1}$ [Oeschger et al., 1975; Ostlund et al., 1976; Broecker et al., 1980]. The resulting relationships between equilibrium climate sensitivity, vertical diffusion coefficient, and ocean response time have been illustrated in section 5 above.

The expected warming of the ocean mixed layer is shown in Figure 27a for the trace gas scenario case $\mathrm{A}$ (current growth rates for $\mathrm{CO}_{2}, \mathrm{CH}_{4}, \mathrm{~N}_{2} \mathrm{O}, \mathrm{CF}_{2} \mathrm{Cl}_{2}$, and $\mathrm{CFCl}_{3}$ plus an allowance for other trace gases) and in Figure $27 b$ for the trace gas scenario case $\mathrm{B}$ (reduced growth rates with only $\mathrm{CO}_{2}, \mathrm{CH}_{4}$, $\mathrm{N}_{2} \mathrm{O}, \mathrm{CF}_{2} \mathrm{Cl}_{2}$, and $\mathrm{CFCl}_{3}$ included). In both cases, results are shown for two values of equilibrium climate sensitivity $\left(\Delta T_{s}(2\right.$ $\left.\times \mathrm{CO}_{2}\right)=2 \mathrm{~K}$ and $4 \mathrm{~K}$ ) and for two values of the vertical diffusion coefficient $\left(k=1 \mathrm{~cm}^{2} \mathrm{~s}^{-1}\right.$ and $\left.2 \mathrm{~cm}^{2} \mathrm{~s}^{-1}\right)$.
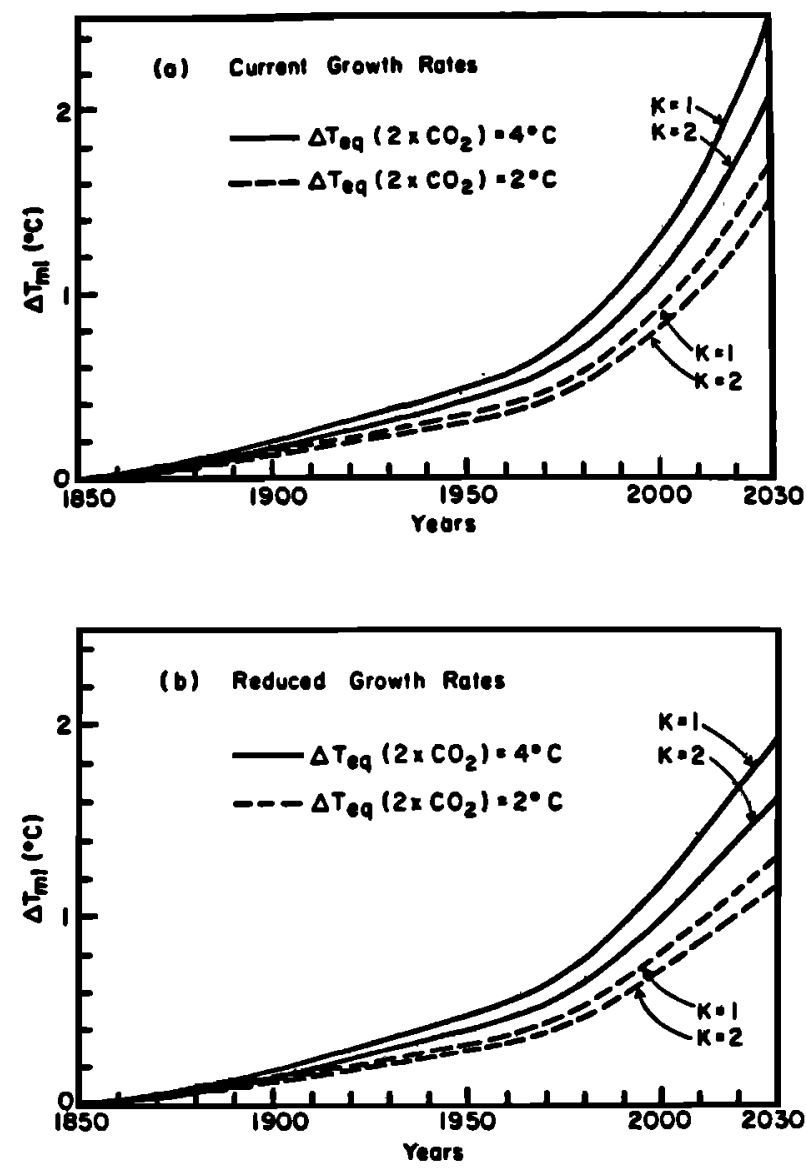

Fig. 27. Ocean mixed layer temperature response to the two trace gas scenarios in Tables 1 and 2 in a one-dimensional radiativeconvective model with a box diffusion ocean: (a) case $\mathrm{A}$ (current growth rates for $\mathrm{CO}_{2}, \mathrm{CH}_{4}, \mathrm{~N}_{2} \mathrm{O}, \mathrm{CF}_{2} \mathrm{CCl}$, and $\mathrm{CFCl}_{3}$ plus an allowance for other trace gases) and $(b)$ case $\mathrm{B}$ (reduced growth rates with only $\mathrm{CO}_{2}, \mathrm{CH}_{4}, \mathrm{~N}_{2} \mathrm{O}, \mathrm{CF}_{2} \mathrm{Cl}_{2}$, and $\mathrm{CFCl}_{3}$ included). Results are shown for two values of the equilibrium climate sensitivity and two values of the vertical diffusion coefficient (in square centimeters per second). 


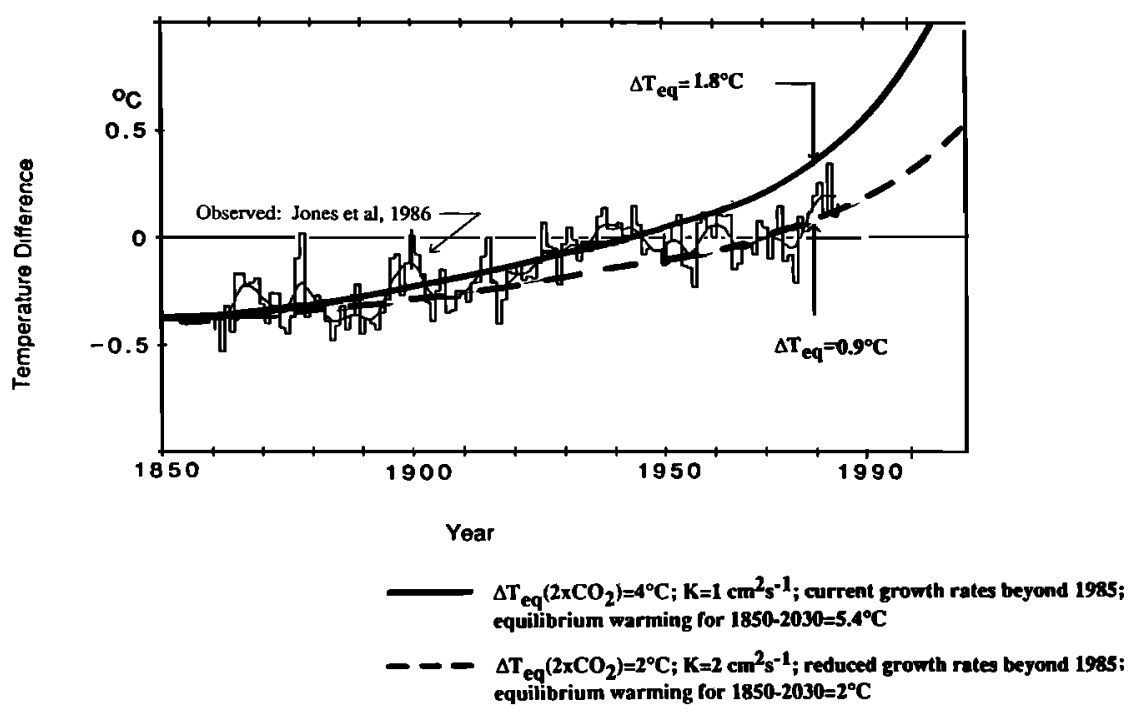

Fig. 28. Comparison of observed and computed global annual mean temperatures. The observed curve is taken from Jones et al. [1986]. The computed values are taken from Figure 27.

In order to facilitate interpretation of the transient results, the equilibrium $\Delta T_{\text {s }}$ results are summarized below for the model with $\Delta T_{s}\left(2 \times \mathrm{CO}_{2}\right)=2 \mathrm{~K}$. For the $1850-1980$ period both case A (Figure 27a) and case B (Figure 27b) yield an equilibrium $\Delta T_{s}$ of $0.9 \mathrm{~K}$ (see major conclusion 3 in section 6.2). For the 1980-2030 period the equilibrium $\Delta T_{s}$ for case $A$ and case $B$ are about 1.8 and $1.1 \mathrm{~K}$, respectively (as inferred from Figure 23). The range in equilibrium $\Delta T_{s}$, in view of the range in climate sensitivity given by (21), is 0.7 to $2 \mathrm{~K}$ for the 1850-1980 period, while for the $1980-2030$ period the range is 0.8 to $2.4 \mathrm{~K}$ for case $\mathrm{B}$ and is 1.4 to $4.1 \mathrm{~K}$ for case $\mathrm{A}$.

These models show a warming of the mixed layer between 0.4 and $0.8 \mathrm{~K}$ for the period 1850-1980. This range is not inconsistent with the estimated increase of about $0.5 \mathrm{~K}$ in the observed global average near-surface temperature in that period [Jones et al., 1986] (also see Figure 28). While the agreement with observed temperature trends is encouraging, it is difficult to conclude much from this comparison, because (1) other climate forcings are likely to have operated over this time scale (variations in stratospheric and tropospheric aerosols, changes in ground albedo due to desertification and changes in forest cover, and possible variations of solar irradiance are some of the other important radiative forcings; (2) the model computations do not simulate the details of the observed temperature trends, particularly the relatively constant temperatures that were maintained between the $1940 \mathrm{~s}$ and 1970s; and (3) the observed temperature records (not shown here) reveal significant land-ocean as well as interhemispheric asymmetries, and the causes for such symmetries are unknown.

The computed surface-air temperature change for the period from 1850 to 2030 in the range of 1.2 to $2.4 \mathrm{~K}$ (see the lowest estimate in Figure $27 b$ and the largest estimate in Figure 27a). The equilibrium change for the cases shown in Figure 27 is in the range of 2 to $5.4 \mathrm{~K}$, and the difference between the two ranges reflects the potential influence of the oceans in delaying the "signal." If the oceans indeed have a significant delaying effect on the equilibrium warming, and if the decadal rates of increase in trace gas concentrations continue unabated (at the present rates) for the next several decades, then the climate system would be increasingly in a state of disequilibrium with the radiative forcing by the trace gases [Hansen et al., 1984].

\section{CONClusions AND UNRESOlVED IsSuES}

\subsection{Summary of Assessment}

Measurements of trace gas concentrations that are accurate enough to establish global long-term trends began in the late 1950 s for $\mathrm{CO}_{2}$ and in the middle to late 1970 s for gases such as $\mathrm{CH}_{4}, \mathrm{CFCs}$, and $\mathrm{N}_{2} \mathrm{O}$. These instrumental records have clearly established the fact that $\mathrm{CO}_{2}, \mathrm{CH}_{4}, \mathrm{CFC} 11, \mathrm{CFC} 12$, $\mathrm{N}_{2} \mathrm{O}$, and $\mathrm{CH}_{3} \mathrm{CCl}_{3}$ (to cite just the radiatively important gases) have been increasing since the beginning of the record. The 1985 concentrations of $\mathrm{CFC} 11, \mathrm{CFC} 12$, and $\mathrm{CH}_{3} \mathrm{CCl}_{3}$ are double their observed values in 1975 [Rasmussen and Khalil, 1986]; $\mathrm{CO}_{2}$ has increased from about $315 \mathrm{ppmv}$ in 1958 to about $345 \mathrm{ppmv}$ in 1985; $\mathrm{CH}_{4}$ and $\mathrm{N}_{2} \mathrm{O}$ have increased at an average rate of $1 \%$ per year and $0.25 \%$ per year, respectively, during 1975-1985. Furthermore, inferences based on gases trapped in ice cores suggest that the increase in $\mathrm{CO}_{2}$ and $\mathrm{CH}_{4}$ is not a recent phenomenon but began before the middle nineteenth century.

A basic theme that emerges from the discussions presented in this paper is that the observed increases in these gases and their potential climatic effects are largely determined by the interactions between radiation, dynamics, chemistry, and the natural as well as anthropogenic sources and sinks of these gases. Recent research on the trace gas problem has significantly improved our understanding of the nature of the interactions. But we are still far from unraveling many of the complexities of these interactions, and as a result, even the most comprehensive climate model results are subject to large uncertainties. In what follows, we will present a summary of the model estimates of the trace gas climate effects and the uncertainties in the estimated effects. 
The analyses and the model calculations presented here reveal the following climatic effects of trace gases:

1. From the preindustrial era to the 1950 s the greenhouse effect of $\mathrm{CO}_{2}$ was the major source of anthropogenic impact on climate; this picture has changed drastically since the early 1960s. During the last two decades or so, trace gases other than $\mathrm{CO}_{2}$ have begun to contribute as much as the $\mathrm{CO}_{2}$ increase to the upward trend in anthropogenically induced radiative forcing.

2. The cumulative effect of the increase in $\mathrm{CO}_{2}$ and other trace gases for the period from 1850 to 1980 is an equilibrium surface warming of 0.7 to $2 \mathrm{~K}$, where the threefold uncertainty is due to current uncertainties in climate sensitivity. The contribution of the non- $\mathrm{CO}_{2}$ trace gases to the cumulative equilibrium warming is about $30 \%$. Time-dependent calculations with a box diffusion ocean model suggest that about $0.4-0.8 \mathrm{~K}$ of the ( 0.7 to $2 \mathrm{~K}$ equilibrium value) surface warming should have occurred during 1850 to 1980 .

3. A variety of scenarios that employ the upper and lower range of the observed growth rates of trace gas concentrations or their emission rates show that trace gases other than $\mathrm{CO}_{2}$ can have as much impact as $\mathrm{CO}_{2}$ on future trends of surfacetroposphere-stratosphere temperatures. For the various trace gas scenarios considered in this study, the equilibrium surface warming for the period 1980 to 2030 ranges from 0.8 to $4.1 \mathrm{~K}$. This wide range is due to the range in the assumed scenarios as well as that due to the uncertainty in climate model sensitivity.

4. Thus for the 180 -year period from 1850 to 2030 , our assessment suggests a trace gas-induced cumulative equilibrium surface warming in the range of 1.5 to $6.1 \mathrm{~K}$. Because of the huge thermal inertia of the world oceans, only about 40 to $50 \%$ of the above equilibrium warming will be realized by the year 2030 . Consequently, the climate system would be increasingly in a state of disequilibrium with the radiative forcing by the trace gases.

5. In addition to $\mathrm{F} 11, \mathrm{~F} 12, \mathrm{CH}_{4}, \mathrm{~N}_{2} \mathrm{O}$, and $\mathrm{O}_{3}$, other radiatively active gases, F13, F114, F115, F14, and F13B1 (Table 8), with long lifetimes of the order of 100-500 years, may also become important if their growth rates increase for the next several hundred years such that their concentrations reach values of around a part per billion or more. The current concentrations of these gases are so small that they are projected to have a negligible impact on a 50 - to 100 -year time scale.

\subsection{Changes in Other Climate Forcing Terms}

In order to focus our discussions, we show in Figure 28 the globally averaged observed temperatures along with the model-estimated values for the trace gas trends adopted in this study. Before using a comparison such as the one shown in Figure 28 to verify model predictions, we have to first understand the causes of the decadal climate changes. Trace gas increases are only one of the many factors that modify the radiative forcing of the climate.

Decadal-scale changes in the radiative forcing of the planet can also result from natural causes: changes in the solar output, volcanic eruptions, desertification, and changes in the sea ice are the importance examples. Furthermore, trace gas increases are not the only mechanism by which anthropogenic effects modify the climate. Other potentially important anthropogenic effects are modification of the surface albedo by deforestation, modification of the absorbed solar radiation by increasing the aerosol content of the lower atmosphere, and deposition of waste heat. Only during the last 5 to 10 years have we begun to quantify the effects of solar constant variations and volcanic aerosols. Even this limited data set indicates the potential importance of these natural variations. For example, the solar irradiance (at the top of the atmosphere) has decreased by about $0.1 \%$ from 1980 to 1985 [Wilson et al., 1986]. According to model calculations, a major volcanic eruption, such as El Chichon in 1982, can cause a global cooling of the order of $0.2 \mathrm{~K}$ nearly 6 years after the eruption [Harshvardan et al., 1984]. The quantitative effects of the other anthropogenic factors (deforestation and aerosol content) are largely unknown.

Decadal-scale climate changes can also occur without any perturbations to the radiative heating of the planet. The nonlinear interactions between the various internal components, i.e., the ocean, the atmosphere, and the land, may give rise to climate fluctuations. Inferring the relative importance of forced (external radiative heating) and unforced (internally induced by nonlinear interactions) changes in governing the observed climate changes is an important prerequisite for verifying the greenhouse theory of climate change.

\subsection{Theoretical and Modeling Issues}

The response of clouds to climate change is one of the major sources of uncertainty in the greenhouse theory of climate change. This cloud-climate feedback can influence not only the equilibrium climate sensitivity but also the transient response of the climate system to time-varying trace gas concentrations. The influence on the transient response arises because the $e$-folding thermal response time of the coupled ocean-atmosphere system depends inversely upon a nonlinear function of the climate feedback parameter. The important role of cloud feedback as well as that of ocean-atmosphere interactions are covered in ample detail in papers related to the $\mathrm{CO}_{2}$ climate problem (e.g., Dickinson, 1985; CDAC, 1983]. In what follows, we will focus on the issues that are unique to the non- $\mathrm{CO}_{2}$ trace gases.

7.3.1. Interactions in the troposphere. Additions of both chemically active gases (for example, $\mathrm{CO}$ and $\mathrm{NO}_{x}$ ) and of radiatively active gases (for example, $\mathrm{CH}_{4}$ ) were shown to lead to substantial increases in tropospheric $\mathrm{O}_{3}$ and $\mathrm{CH}_{4}$ which in turn enhance the greenhouse effect. This indirect climate effect was shown to be as large as the direct radiative effect. Furthermore, $\mathrm{CH}_{4}$ and $\mathrm{O}_{3}$ concentrations were also modulated by the feedback between temperature and $\mathrm{H}_{2} \mathrm{O}$. The principal constituents that are responsible for these chemistry-climate interactions in the troposphere are the radicals $\mathrm{OH}$ and $\mathrm{HO}_{2}$. These interactions, which are illustrated schematically in Figure 29, are important not only for understanding climate sensitivity to trace gases but are also important for understanding the causal mechanisms for the observed trends in $\mathrm{CH}_{4}$ and $\mathrm{O}_{3}$. Many of the gases shown in Figure 29 have strong spatial and temporal variations. Hence current analyses of these interactions, which are largely based on onedimensional models, should be viewed merely as illustrative of their potential importance. For a more quantitative understanding of the interactions shown in Figure 29, the following key issues should be addressed.

1. The relative role of transport and chemistry in governing the behavior of $\mathrm{O}_{3}, \mathrm{NO}_{x}, \mathrm{OH}, \mathrm{CO}$, and $\mathrm{CH}_{4}$. The 


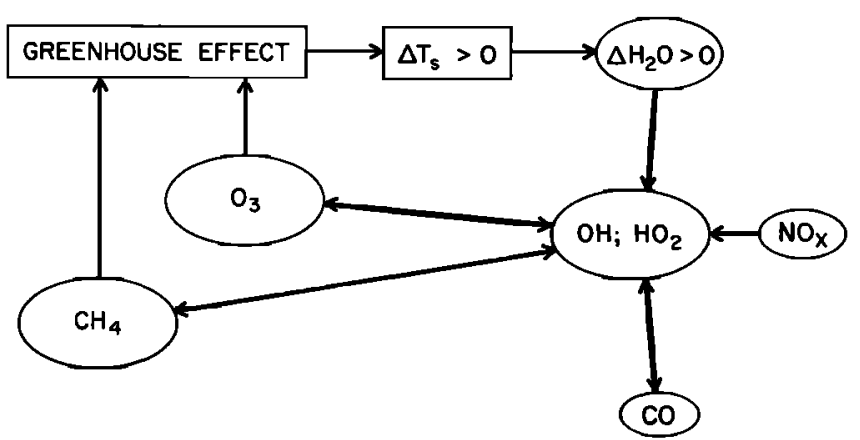

Fig. 29. Schematic of the climate-chemistry interactions involving $\mathrm{OH}$ and $\mathrm{HO}_{2}$ chemistry in the troposphere. Surface temperature increase $\left(\Delta T_{s}>0\right)$ due to the greenhouse effect of trace gases (including $\mathrm{CO}_{2}$ ) leads to an increase in $\mathrm{H}_{2} \mathrm{O}$ which contributes to an increase in $\mathrm{OH}$. The addition of $\mathrm{NO}_{x}, \mathrm{CO}$, and $\mathrm{CH}_{4}$ reacts with $\mathrm{OH}$ and $\mathrm{HO}_{2}$ to alter $\mathrm{CH}_{4}$ and tropospheric $\mathrm{O}_{3}$, which in turn modulates the greenhouse effect.

transport processes include downward transport of $\mathrm{O}_{3}$ and $\mathrm{NO}_{x}$ from the stratosphere, upward transport of pollutants (for example, $\mathrm{CO}$ ) from the boundary layer, and lateral transport. A quantitative study of this issue requires not only interactive transport-chemistry models but also simultaneous measurements of $\mathrm{O}_{3}, \mathrm{NO}_{x}, \mathrm{CO}$, and $\mathrm{H}_{2} \mathrm{O}$ (as the minimum set) at a few selected locations to verify the model assumptions and simulations [Levy et al., 1985].

2. Since the $T-\mathrm{H}_{2} \mathrm{O}$ feedback is an important issue for the chemistry involving $\mathrm{OH}$ and since the temperature change (due to the trace gas greenhouse effect) is expected to be a strong function of latitude, attention should be given to the latitudinal and seasonal dependence of the interactions.

3. The response of biogenic source molecules such as $\mathbf{C H}_{4}$ and $\mathrm{N}_{2} \mathrm{O}$ to surface temperature changes are not well known and should be examined for their potential role as a feedback mechanism.

7.3.2. Sensitivity of stratospheric $\mathrm{H}_{2} \mathrm{O}$. An important issue that has repeatedly come up during the last 5 years but still has not received a careful scrutiny concerns the sensitivity of stratospheric $\mathrm{H}_{2} \mathrm{O}$ to perturbations in tropical tropopause temperatures. As was discussed in earlier sections, GCMs and other models reveal the tropical tropopause temperatures to be quite sensitive to perturbations in $\mathrm{CO}_{2}, \mathrm{CFCs}$, and $\mathrm{O}_{3}$. However, current studies have focused largely on zonal average temperatures, whereas the entry of low levels of $\mathbf{H}_{2}$ into the stratosphere may depend on the extreme (cold) tropical tropopause temperatures rather than the zonally averaged value. Model studies with a special emphasis on the geographical regions where $\mathrm{H}_{2} \mathrm{O}$ enters the stratosphere in conjunction with special observational programs (for determining $\mathrm{H}_{2} \mathrm{O}$, temperature, and cloud distribution) are needed to shed new insights on this problem.

7.3.3. Interactions in the stratosphere. The continued growth of halogenated hydrocarbons in the troposphere presages reduced $\mathrm{O}_{3}$ in the stratosphere. The subsequent effects of such changes on atmospheric opacity, thermal and dynamical structure in the stratosphere, and stratosphere-troposphere exchange bear directly on concerns about climate-chemistry issues. For example, the radiative effect of stratospheric $\mathrm{O}_{3}$ perturbation due to CFCs can add (or ameliorate) as much as $30 \%$ to the surface warming due to the direct greenhouse effect of CFCs. Furthermore, latitudinal effects of the $\mathrm{O}_{3}$ change on thermal structure are important. To date, most of the coupled radiative-chemical calculations of $\mathrm{O}_{3}$ change have been performed with one-dimensional models. There is a strong need to develop coupled radiative-chemical-dynamical models (both two-dimensional ones and GCMs) and to examine the full scope of the climate-chemistry impact on tropospheric climate.

\subsection{Observational Issues}

One of the most challenging issues on the observational front is the accurate determination of the long-term (decadal) trends in $\mathrm{CO}, \mathrm{HO}_{x}, \mathrm{NO}_{x}$, tropospheric and stratospheric $\mathrm{O}_{3}$, and finally, tropospheric and stratospheric $\mathrm{H}_{2} \mathrm{O}$. There are large uncertainties in our current estimates of the rate of growth of $\mathrm{CO}, \mathrm{O}_{3}$, and $\mathrm{NO}_{x}$. The primary challenge is to design a strategy that will minimize the sampling errors, and such strategies can only evolve from active interactions between modeling and observational groups. The measurements of the above gases are also crucial for validating coupled transport-chemistry models.

Another equally important issue is the determination of trends in the radiative forcing (of the climate system) and the constituents that contribute to the radiative forcing. Included in this category are solar radiation and its spectral variation at the top of the atmosphere, planetary albedo and its spectral distribution in two or three wavelength regions (for example, UV, visible, and IR), stratospheric aerosols, tropospheric aerosols including arctic haze, and important radiatively active trace gases including $\mathrm{CO}_{2}, \mathrm{CH}_{4}, \mathrm{~N}_{2} \mathrm{O}, \mathrm{O}_{3}$ vertical distribution, F11, F12, F22, $\mathrm{CH}_{3} \mathrm{CCl}_{3}$, and stratospheric $\mathrm{H}_{2} \mathrm{O}$. Since the effects of aerosols, cloud feedback, and ice albedo feedback are manifested in the planetary albedo, accurate determination of the regional distribution and decadal trends in clear-sky and cloudy-sky planetary albedo should be one of the fundamental goals of future observational programs. The measurements described above are crucial for inferring the causal mechanisms for climate change. Of equal importance is continued monitoring of stratospheric, tropospheric, and surface temperatures. These measurements, if they are made with high-quality, excellent calibration and redundancy checks, can provide perhaps the only attractive approach for verifying the climate sensitivity of the models.

Finally, we have to develop and maintain an adequate spectroscopic data base for trace gases. For all of the CFCs and for a number of other compounds (for example, $\mathrm{CH}_{3} \mathrm{CCl}_{3}$, $\mathrm{PAN}$, and $\mathrm{CF} 3 \mathrm{Br}$ ) which have strong greenhouse effects, spectroscopic line parameters are either unavailable or unpublished. Furthermore, for the available data there are significant discrepancies in the measured band strengths (for example, F11 and F12 band strengths differ by $20 \%$ to $30 \%$ between different measurements). Moreover, current measurements do not separate out the contribution of the hot bands in the spectra; such identifications are crucial for incorporating the temperature dependence of the opacity in climate models. The availability of such measurements will promote line-by-line calculations which can then serve as a basis for treatment of the radiative effects of trace gases in climate models.

\section{APPENDIX: ACcuracy of Band Model APproaches for $\mathrm{CH}_{4}$}

Band models may be divided into two categories: narrowband models in which the long-wave spectrum is divided into 
spectral intervals ranging from $1 \mathrm{~cm}^{-1}$ in width, and broadband models which employ analytical expressions derived from either theory or laboratory data to treat the absorption within the entire band. In the evaluation of a band model, two issues are involved: (1) the ability of the band model to accurately characterize the total band absorptance for a homogeneous optical path through the gas (i.e., constant temperature and pressure) and (2) the ability of the band model to characterize absorption and emission along inhomogeneous paths (i.e., atmospheric applications). In order to treat inhomogeneous paths, a scaling approximation must be invoked in the band model.

The second item above is of particular importance with respect to broadband models. Although several broadband scaling approximations have been suggested [Chan and Tien, 1969; Cess and Wang, 1970; Edwards and Morizumi, 1970], there has not been a definitive examination of their accuracies.

The strategy of the present section is as follows. A reference line-by-line calculations will first be described, followed by the presentation of narrow-band and broadband models that are tuned, for a homogeneous gas, to the line-by-line calculation. Thus a hierarchy of band models is obtained, with these band models yielding virtually identical homogeneous band absorptances for the homogeneous case. The scaling approximations for the narrow-band and broadband models are evaluated by applying the models to atmospheric profiles (the inhomogeneous case). Accompanying this will be a brief discussion concerning pitfalls associated with the use of narrow-band models. The above treatment as well as the results to be presented subsequently are adopted from R. D. Cess et al. (unpublished manuscript, 1986).

The line-by-line calculations used the line locations and intensities from a Jet Propulsion Laboratory (JPL) data tape [Orton and Robiette, 1980], with the line intensities being renormalized to a total band intensity of $129 \mathrm{~cm}^{-2} \mathrm{~atm}^{-1}$ at $296 \mathrm{~K}$ [e.g., Varanasi et al., 1983]. The Lorentz half-width per unit pressure, $\gamma^{0}$, was taken to be

$$
\gamma^{0}\left(\mathrm{~cm}^{-1} \mathrm{~atm}^{-1}\right)=0.06(296 / T)
$$

for all lines, on the basis of Varanasi et al. [1983], who obtained a nitrogen-broadened value of 0.063 (with a standard deviation of 0.003 ) for 77 lines within the wave number interval $1300-1353 \mathrm{~cm}^{-1}$. In that there are roughly 12,500 lines on the JPL tape, adopting of $\gamma^{0}$ based on just 77 lines comprises a rather extensive extrapolation. Although the line-by-line calculations serve as a reference, there are still some uncertainties associated with line-by-line model results, because our knowledge of line half-widths is meager at best.

The narrow-band model is a modification of the Goody random band model [Goody, 1952], for which the transmittance of a spectral interval $\Delta \omega$ is given by

$$
T_{\Delta \omega}=\exp \left\{-\left(S_{\Delta \omega} w / \Delta \omega\right)\left[1+\left(S_{\Delta \omega} w / \pi \gamma\right)\right]^{-1 / 2}\right\}
$$

where $S_{\Delta \omega}$ is the sum of the line strengths within the interval, and $\bar{\gamma}$ is defined by

$$
S_{\Delta \omega} \bar{\gamma}=C\left[\sum\left(\gamma S_{J K}\right)^{1 / 2}\right]^{2}
$$

where $S_{J K}$ denotes the individual line strengths and the summation is over all lines within $\Delta \omega$. Conventionally, $C=4 / \pi$ to be consistent with the limit of strong nonoverlapping lines [e.g., Goody, 1964]. But if there is a significant number of coincident or near-coincident lines, $C<4 / \pi$, since coincident lines would be linearly summed. For present purposes, $\Delta \omega=5$ $\mathrm{cm}^{-1}$, with elaboration on this choice to be given later.

Turning next to the broadband model, a hybrid version of those proposed by Cess and Ramanathan [1972] and Ramanathan [1976] is adopted, for which the total band absorptance is expressed by

$$
A=2 A_{0} \ln \left\{1+\sum \frac{u}{D+[E+u(1+1 / \beta)]^{1 / 2}}\right\}
$$

where $E=(2-D)^{2}, u=S w / A_{0}$ with $S$ the total band intensity, $A_{0}$ is the bandwidth parameter, $\beta$ is proportional to the ratio of a mean line half-width to a mean line spacing, and here the summation refers to the two overlapping ${ }^{12} \mathrm{CH}_{4}$ and ${ }^{13} \mathrm{CH}_{4}$ isotope bands. For $D=2$, (27) reduces to the formulation of Cess and Ramanathan [1972], while for $D=0$ it coincides with that of Ramanathan [1976].

The relevant coefficients appearing within both the narrowband and broadband models have been evaluated through regression fits to homogeneous-gas line-by-line calculations, with the result that

$$
\begin{gathered}
C=0.753 \\
A_{0}\left(\mathrm{~cm}^{-1}\right)=68.2(T / 300)^{0.85 B} \\
\beta=0.211 P(300 / T)
\end{gathered}
$$

where $P$ is the pressure, and

$$
D=0.106
$$

As discussed above, one would anticipate that $C<4 / \pi=$ 1.273 if coincident lines are a factor, which may indeed be the case for the $v_{4}$ band owing to both line splitting and the presence of a $Q$ branch. But the considerable difference between (16) and $C=4 / \pi$ might include other factors, as will shortly be discussed.

A comparison of both the narrow-band and the broadband models with the line-by-line results is illustrated in Figure 30. A single curve is used for both band models since there is no distinguishable difference between them. Similar agreement with the line-by-line results exists for temperatures spanning the range from $220 \mathrm{~K}$ to $300 \mathrm{~K}$.

As discussed in more detail by R. D. Cess et al. (unpublished

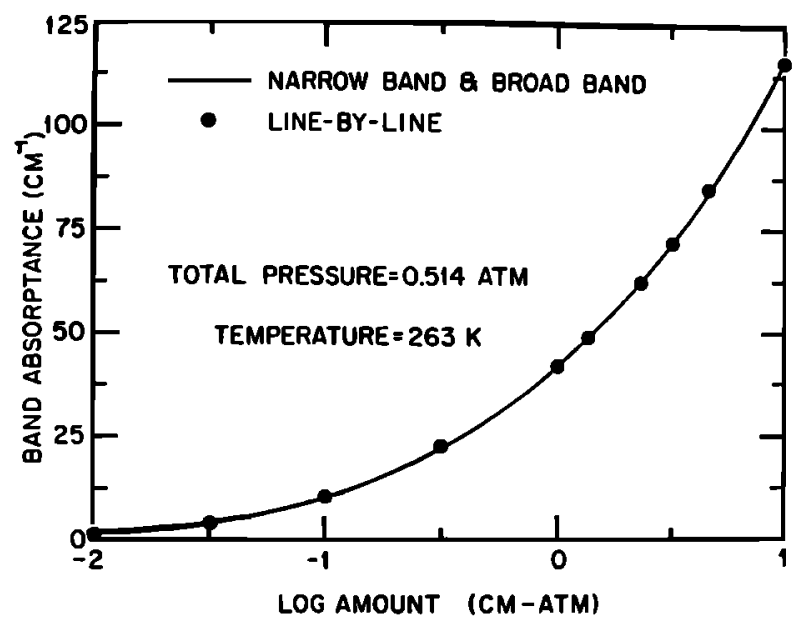

Fig. 30. Comparison of narrow-band, broadband, and line-byline determinations of the $\mathrm{CH}_{4}$ total band absorptance. The $\mathrm{CH}_{4}$ amount in $\mathrm{cm}$ atm refers to STP. 
TABLE 12. Comparison of Model Calculations for the Change in Infrared Flux Due to an Increase in $\mathrm{CH}_{4}$ Mixing Ratio from $1.75 \times 10^{6}$ to $3.5 \times 10^{6}$

\begin{tabular}{|c|c|c|c|c|}
\hline \multirow[b]{2}{*}{ Model } & \multirow{2}{*}{$\begin{array}{c}\text { Scaling } \\
\text { Approximation }\end{array}$} & \multirow[b]{2}{*}{ Top } & \multicolumn{2}{|c|}{ Flux Reduction, $\mathrm{W} \mathrm{m}^{-2}$} \\
\hline & & & Tropopause & Surface \\
\hline Line by line & & 1.78 & 1.78 & 2.40 \\
\hline Narrow-band & Curtis-Godson & $1.79(0.6)$ & $1.78(0.0)$ & $2.41(0.4)$ \\
\hline Broadband & Chan-Tien & $1.77(-0.6)$ & $1.78(0.0)$ & $2.61(8.8)$ \\
\hline Broadband & Edwards-Morizumi & $1.79(0.6)$ & $1.79(0.6)$ & $2.63(9.6)$ \\
\hline Broadband & Cess-Wang & $1.85(3.9)$ & $1.83(2.8)$ & $2.67(11.3)$ \\
\hline
\end{tabular}

Numbers in parentheses denote the percentage differences from the line-by-line values.

manuscript, 1986), the virtual equivalance of the band models with the line-by-line calculations allows an evaluation of band model scaling approximations. For this purpose the $\mathrm{McClat}$ chey et al. [1971] mid-latitude summer atmosphere has been employed, neglecting overlap with water vapor and clouds. Table 12 summarizes calculations for the reduction in infrared flux at the top of the model atmosphere $(25 \mathrm{~km})$, at the tropopause $(13 \mathrm{~km})$, and at the surface, for an increase in methane volumetric mixing ratio from $1.75 \times 10^{6}$ to $3.5 \times 10^{6}$.

The use of Curtis-Godson scaling within the narrow-band model is as described by Rodgers and Walshaw [1966]. Although this two-parameter scaling is exact in the weak-line and strong-line limits, the present atmospheric methane abundance lies between these two asymptotic limits. Thus methane serves as a good test of Curtis-Godson scaling, and Table 12 confirms the validity of this often-used scaling approximation.

For the broadband model, three different three-parameter scaling approximations are compared in Table 12 [Chan and Tien, 1969; Edwards and Morizumi, 1970; Cess and Wang, 1970]. All three scaling approximations overestimate the flux reduction at the surface, with Chen-Tien scaling producing the smallest errors for the three flux reduction calculations.

On a similar point, several band models which have been employed in atmospheric radiation calculations are compared in Table 13 with the line-by-line results. These include the conventional random band models of Goody [1952] and Malkmus [1967], the broadband model of Donner and Ramanathan [1980], and a broadband model of Cess and Chen [1975], which they developed for Jovian applications but which was utilized for terrestrial applications by Hameed et al. [1980]. The primary failing of the latter band model can be traced to the assumption by Cess and Chen [1975] that individual

TABLE 13. Comparison of Model Calculations for the Change in Infrared Flux Due to an Increase in $\mathbf{C H}_{4}$ Mixing Ratio From 1.75 $\times 10^{6}$ to $3.5 \times 10^{6}$

\begin{tabular}{llll}
\hline & & \multicolumn{2}{c}{ Flux Reduction, $\mathrm{W} \mathrm{m}^{-2}$} \\
\cline { 3 - 4 } \multicolumn{1}{c}{ Model } & \multicolumn{1}{c}{ Top } & \multicolumn{1}{c}{ Tropopause } & \multicolumn{1}{c}{ Surface } \\
\hline Line by line & 1.78 & 1.78 & 2.40 \\
Malkmus & $1.99(11.8)$ & $1.97(10.7)$ & $2.61(8.8)$ \\
Goody & $2.05(15.2)$ & $2.04(14.6)$ & $2.72(13.3)$ \\
Donner-Ramanathan & $1.55(-12.9)$ & $1.57(-11.8)$ & $2.17(-9.6)$ \\
Cess-Chen & $1.00(-43.8)$ & $1.00(-43.8)$ & $1.44(-40.0)$ \\
\hline
\end{tabular}

Curtis-Godson scaling is used for the Malkmus and Goody models, while Chan-Tien scaling is employed for the DonnerRamanathan and Cess-Chen models. The numbers in parentheses denote the percentage differences from the line-by-line values. multiplets could be treated as a single Lorentz line; i.e., they neglected line splitting.

Returning to the narrow-band model, the present $\mathrm{CH}_{4}$ example serves to illustrate certain pitfalls associated with random band models. Consider first the present choice $5 \mathrm{~cm}^{-1}$ intervals. As pointed out by Kiehl and Ramanathan [1983] for $\mathrm{CO}_{2}$, significant errors occur if one employs spectral intervals greater than $10 \mathrm{~cm}^{-1}$. This is due to the statistics of the band, as manifested by the averaging procedure of (26), being variable throughout the band. One way of minimizing this effect is to choose small intervals with the hope that this will produce near-uniform statistics within each interval. But if the intervals are too small, there will not be a sufficient number of lines within each interval to yield meaningful statistics.

Ideally, one would anticipate that there should be an interval range over which the computed band absorptance is invariant to the choice of interval size, with the intervals being sufficiently large so as to contain a statistically meaningful number of lines but at the same time sufficiently small so that (14) produces meaningful statistical averages. However, as illustrated in Figure 31, $\mathrm{CH}_{4}$ does not produce such a clearly defined range of intervals. The small plateau from roughly 5 to $8 \mathrm{~cm}^{-1}$ was the sole motivation for our choice of a $5 \mathrm{~cm}^{-1}$ interval size.

A second issue concerns the location of the intervals. Figure 32 illustrates a band absorptance calculation in which the locations of the interval spacings $\left(\Delta \omega=5 \mathrm{~cm}^{-1}\right)$ are progressively shifted, with a shift of $5 \mathrm{~cm}^{-1}$ denoting a return to the original interval locations. For example, a wave number shift equaling 0 corresponds to interval locations of 1200-1205 $\mathrm{cm}^{-1}$, etc., while for a wave number shift equaling $1 \mathrm{~cm}^{-1}$,

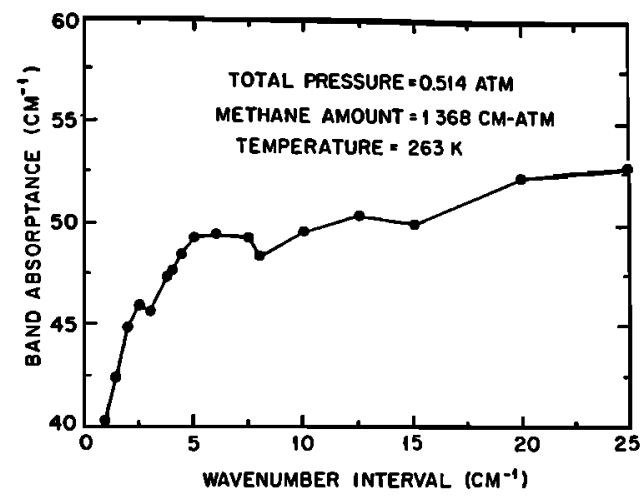

Fig. 31. Narrow-band $\mathrm{CH}_{4}$ total band absorption as a function of wave number interval $(\Delta \omega)$ as employed within the narrow-band model. The methane abundance of $1.368 \mathrm{~cm}$ atm (at STP) coincides with the atmospheric column abundance for a $\mathrm{CH}_{4}$ mixing ratio of $1.75 \times 10^{-6}$ 


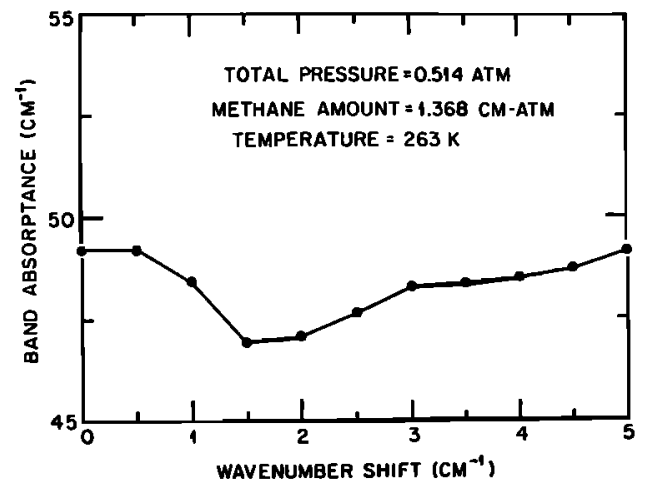

Fig. 32. Narrow-band $\mathrm{CH}_{4}$ total band absorption for $\Delta \omega=5$ $\mathrm{cm}^{-1}$ and as a function of wave number shift of the interval spacing. The methane abundance of $1.368 \mathrm{~cm}$ atm (at STP) coincides with the atmospheric column abundance for a $\mathrm{CH}_{4}$ mixing ratio of 1.75 $\times 10^{-6}$

these are 1201-1206 $\mathrm{cm}^{-1}$, etc. As may be seen in Figure 32, this can result in a $5 \%$ variation in band absorptance, an effect that is again related to a variation in band statistics within the $5 \mathrm{~cm}^{-1}$ intervals as the interval positions are shifted.

In addition to the problem of coincident or near-coincident lines, as was previously discussed with respect to (14), the effects portrayed within Figures 31 and 32 additionally influence the evaluation of $C$ as given by (16). For this reason the present narrow-band models should not be applied to conditions well removed from those for which (16) was evaluated.

As a final point, it must be emphasized that $\mathrm{CH}_{4}$ represents an extreme case concerning the points raised with respect to Figures 31 and 32, since the $v_{4}$ band possesses both line splitting and a $Q$ branch. Experience with vibration-rotation bands of other gases (D. P. Kratz and R. D. Cess, private communication, 1986) indicates that these problems are somewhat less severe in the absence of line splitting and are considerably less severe in the absence of both line splitting and a $Q$ branch.

Acknowledgments. We dedicate this paper to the memory of our dear colleague, F. M. Luther, who passed away September 13, 1986. We benefited significantly from consultations with the following scientists: J. T. Kiehl and C. Brühl for computing radiative heating due to trace gass; $\mathrm{S}$. Liu for contributing to the subsection on NO $\mathrm{N}_{x}$ and $\mathrm{R}$. T. Watson, M. Geller, S. Manabe, F. S. Rowland, P. J. Crutzen, R. E. Dickinson, R. Gammon, N. Husson, M. A. H. Smith, A. Ghazi, and $N$. Sundararaman for their comments on the text. We are very grateful to G. Escobar for preparing and proofreading this lengthy paper numerous times and to $\mathrm{E}$. Boettner for the final version. This paper would not have been completed without their enthusiastic and dedicated support. An earlier version of this paper constitutes chapter 15 of an international assessment report on ozone, and this assessment was cosponsored by three U.S. agencies, i.e., the National Aeronautics and Space Administration (NASA), the Federal Aviation Administration (FAA), and the National Oceanic and Atmospheric Administration (NOAA) and by three international agencies, the World Meteorological Organization (WMO), the United Nations Environmental Program (UNEP), and the Commission of European Communities (CEC).

\section{REFERENCES}

Angell, J. K., Annual and seasonal global temperature changes in the troposphere and lower stratosphere, 1960-1985, Mon. Weather Rev., 114, 1922-1930, 1986

Angell, J. K., and J. Korshover, Global variations in total ozone and layer-mean ozone: An update through 1981, J. Clim. Appl. Meteorol., 22, 1611-1627, 1983.

Arrhenius, S., On the influence of carbonic acid in the air upon the temperature of the ground, Philos. Mag., 41, 237-277, 1896.

Augustsson, T., and V. Ramanathan, $\mathbf{A}$ radiative-convective model study of the $\mathrm{CO}_{2}$ climate problem, J. Atmos. Sci., 34, 448-451, 1977.

Blake, D. R., and F. S. Rowland, World-wide increase in tropospheric methane, 1978-1983, J. Atmos. Chem., 4, 43-62, 1986.

Blake, D. R., E. W. Mayer, S. C. Tyler, Y. Makide, D. C. Montague, and F. S. Rowland, Global increase in atmospheric methane concentrations between 1978 and 1980, Geophys. Res. Lett., 9, 477-480, 1982.

Blanchet, J.-P. and R. List, On the optical properties of Arctic haze, in Aerosols and Their Climate Effects, edited by H. E. Gerber and A. Deepak, pp. 179-196, A. Deepak, Hampton, Va., 1984.

Bojkov, R., and G. C. Reinsel, Trends in tropospheric ozone concentration, in Atmospheric Ozone: Proceedings of the Quadrennial Ozone Symposium, Greece, 3-7 Sept., 1984, edited by C. S. Zerefos and A. Ghazi, pp. 775-781, D. Reidel, Hingham, Mass., 1985.

Boughner, R. E., The effect of increased carbon dioxide concentrations on stratospheric ozone, J. Geophys. Res., 83, 1326-1332, 1978.

Boughner, R. E., and V. Ramanathan, Climatic consequence of increasing $\mathrm{CO}_{2}$ : A study of the feedback mechanisms between increasing $\mathrm{CO}_{2}$ concentrations and the atmospheric ozone, water vapor, and thermal structure balance, paper presented at the Second Conference on Atmospheric Radiation, Am. Meteorol. Soc. Arlington, Va., Oct. 29-31, 1975.

Broecker, W. S., T. H. Peng, and R. Engh, Modeling the carbon system, Radiocarbon, 22, 565-598, 1980.

Brühl, C., and P. J. Crutzen, A radiative-convective model to study the sensitivity of climate and chemical composition to a variety of human activities, Stratosphere: Proceedings of a Working Party Meeting, Brussels, May 18, 1984, edited by A. Ghazi, pp. 85-94, Commission of the European Communities, Brussels, Belgium, 1984.

Bryan, K., F. G. Komro, S. Manabe, and M. J. Spelman, Transient climate response to increasing atmospheric carbon dioxide, Science, 215, 56-58, 1982.

Bryan, K., F. G. Komro, and C. Rooth, The ocean's transient response to global surface temperature anomalies, in Climate Processes and Climate Sensitivity, Geophys. Monogr. Ser., vol. edited by J. E. Hansen and T. Takahashi, pp. 29-38, AGU, Washington, D. C., 1984

Callis, L. B., M. Natarajan, and R. E. Boughner, On the relationship between the greenhouse effect, atmospheric photochemistry, and species distribution, J. Geophys. Res., 88, 1401-1426, 1983.

Carbon Dioxide Assessment Committee (CDAC), Changing Climate: Report of the Carbon Dioxide Assessment Committee, 496 pp., National Academy Press, Washington, D. C., 1983.

Cess, R. D., Climatic change: An appraisal of atmospheric feedback mechanisms employing zonal climatology, J. Atmos. Sci., 33, 18311843, 1976.

Cess., R. D., and S. C. Chen, The influence of ethane and acetylene upon the thermal structure of the Jovian atmosphere, Icarus, 26, 444-450, 1975.

Cess, R. D., and S. D. Goldenberg, The effect of ocean heat capacity upon global warming due to increasing atmospheric carbon dioxide, J. Geophys. Res., 86, 498-502, 1981.

Cess, R. D., and G. L. Potter, A commentary on the recent $\mathrm{CO}_{2}$-climate controversy, Clim. Change, 6, 365-376, 1984.

Cess, R. D., and V. Ramanathan, Radiative transfer within the atmospheres of Mars and that of Venus above the cloud deck, J. Quant. Spectrosc. Radiat. Transfer, 12, 933-945, 1972.

Cess, R. D., and L. S. Wang, A band absorptance formulation for nonisothermal gaseous radiation, Int. J. Heat Mass Transfer, 13, 547-555, 1970.

Cess, R. D., B. P. Briegleb, and M. S. Liau, Low-altitude cloudiness and climate feedback: Comparative estimates from satellite data, $J$. Atmos. Sci., 39, 53-59, 1982.

Chamberlin, T. C., An attempt to frame a working hypothesis of the cause of glacial periods on an atmospheric basis, J. Geol., 7, 545$548,1899$.

Chameides, W. L., S. C. Liu, and R. J. Cicerone, Possible variations in atmospheric methane, J. Geophys. Res., 82, 1795-1798, 1977.

Chan, S. H., and C. L. Tien, Total band absorptance of nonisothermal 
infrared-radiating gases, J. Quant. Spectrosc. Rad̀iat. Trànsfer, 9, 1261-1271, 1969.

Charlock, T. P., Cloud optical feedback and climate stability in a radiative-convective model, Tellus, 34, 245-254, 1982.

Charney, J., Carbon Dioxide and Climate: A Scientific Assessment, 33 pp., National Academy Press, Washington, D. C., 1979.

Chemical Manufacturers Association, Effect of chlorofluorocarbons on the atmosphere, report, rev. 17, edited by B. P. Block, H. Magid and R. B. Ward, 98 pp., Washington, D. C., 1982.

Cicerone, R. J., S. Walters, and S. C. Liu, Nonlinear response of stratospheric ozone column to chlorine injections, J. Geophys. Res., $88,3647-3661,1983$.

Craig, H., and C. C. Chou, Methane: The record in polar ice cores, Geophys. Res. Lett., 9, 1221-1224, 1982.

Crutzen, P. J., Role of the tropics in atmospheric chemistry, in The Geophysiology of Amazonia, Climate and the Biosphere, edited by $\mathbf{R}$. E. Dickinson, pp. 107-132, John Wiley, New York, 1987.

Crutzen, P. J., and L. T. Gidel, A two-dimensional photochemical model of the atmosphere, 2, The tropospheric budgets of the anthropogenic chlorocarbons, $\mathrm{CO}, \mathrm{CH}_{4}, \mathrm{CH}_{3} \mathrm{Cl}$ and the effect of the various $\mathrm{NO}_{x}$ sources on tropospheric ozone, J. Geophys. Res., 88 , 6641-6661, 1983.

Derwent, D. G., Two-dimensional model studies of the impact of aircraft emission on tropospheric ozone, Atmos. Environ., 16, 1997 2007, 1982.

Dickinson, R. E., Infrared radiative heating and cooling in the Venusian mesosphere, 1, Global mean radiative equilibrium, J. Atmos. Sci., 29, 1551-1556, 1972 .

Dickinson, R. E., Modeling climate changes due to carbon dioxide increases, in Carbon Dioxide Review, edited by W. C. Clark, pp. 101-133, Clarendon Press, New York, 1982.

Dickinson, R. E., Climate sensitivity, Adv. Geophys., 28A, 99-129, 1985.

Dickinson, R. E., and R. J. Cicerone, Future global warming from atmospheric trace gases, Nature, 319, 109-114, 1986.

Dickinson, R. E., S. C. Liu, and T. M. Donahue, Effect of chlorofluoromethane infrared radiation on zonal atmospheric temperature, J. Atmos. Sci., 35, 2142-2152, 1978.

Donner, L., and V. Ramanathan, Methane and nitrous oxide: Their effects on the terrestrial climate, J. Atmos. Sci., 37, 119-124, 1980.

Edwards, D. K., and S. J. Morizumi, Scaling of vibration-rotation band parameters for nonhomogeneous gas radiation, $J$. Quant. Spectrosc. Radiat. Transfer, 10, 175-188, 1970.

Elliott, W. P., L. Machta, and C. D. Keeling, An estimate of the biotic contribution to the atmospheric $\mathrm{CO}_{2}$ increase based on direct measurements at Mauna Loa Observatory, J. Geophys. Res., 90, 3741-3746, 1985.

Ellsaesset, H. W., M. C. MacCracken, J. J. Walton, and S. L. Grotch, Global climatic trends as revealed by the recorded data, Rev. Geophys., 24, 745-792, 1986.

Fels, S. B., and L. D. Kaplan, A test of the role of longwave radiative transfer in a general circulation model, J. Atmos. Sci., 33, 779-789, 1975.

Fels, S. B., J. D. Mahlman, M. D. Schwarzkopr, and R. W. Sinclair, Stratospheric sensitivity to perturbations in ozone and carbon dioxide: Radiative and dynamical response, $J$. Atmos. Sci., 37, 2266-2297, 1980.

Fishman, J., and P. J. Crutzen, The origin of ozone in the troposphere, Nature, 274, 855-858, 1978.

Fishman, J., V. Ramanathan, P. J. Crutzen, and S. C. Liu, Tropospheric ozone and climate, Nature, 282, 818-820, 1979.

Fouquart, Y., B. Bonnel, G. Brogniez, A. Cerf, M. Chaovi, L. Smith, and J. C. Vanhootte, Size distribution and optical properties of Saharan aerosols during Eclats, in Aerosols and Their Climate Ef fects, edited by H. E. Gerber and A. Deepak, pp. 35-62, A. Deepak, Hampton, Va., 1984.

Fraser, P. J., M. A. K. Khalil, R. A. Rasmussen, and A. J. Crowford, Trends of atmospheric methane in the southern hemisphere, Geophys. Res. Lett., 8, 1063-1066, 1981.

Fraser, P. J., M. A. K. Khalil, R. A. Rasmussen, and L. P. Steele, Tropospheric methane in the mid-latitudes of the southern hemisphere, J. Atmos. Chem., 1, 125-135, 1983.

Galindo, I., Anthropogenic aerosols and their regional scale climatic effects, in Aerosols and Their Climatic Effects, edited by H. E. Gerber and A. Deepak, pp. 245-260, A. Deepak, Hampton, Va., 1984.
Gammon, R., S. C. Wofsy, R. J. Cicerone, A. C. Delany, R. T. Harriss, M. A. K. Khalil, J. A. Logan, P. Midgley, and M. Prataer, Tropospheric trace gases, in Atmospheric Ozone 1985, Rep. 16, pp. 567 1167, World Meteorol. Org., Geneva, 1985.

Garcia, R. R., and S. Solomon, A numerical model of the zonally averaged dynamical and chemical structure of the middle atmosphere, J. Geophys. Res., 88, 1379-1400, 1983.

Gates, W. L., Modeling the ice-age climate, Science, 191, 1138-1144, 1976.

Geophysical Monitoring for Climatic Change, Summary report, edited by J. M. Harris and B. A. Bodhaine, 160 pp., NOAA Air Resour. Lab., Boulder, Colo., 1984.

Goody, R. M., A statistical model for water vapor absorption, $\boldsymbol{J}$. $\boldsymbol{R}$. Meteorol. Soc., 78, 165-169, 1952.

Goody, R. M., Atmospheric Radiation, 436 pp., Oxford University Press, New York, 1964.

Graedel, T. E., and J. E. McRae, On the possible increase of the atmospheric methane and carbon monoxide concentrations during the last decade, Geophys. Res. Lett., 7, 977-979, 1980.

Guthrie, P. D., C. H. Jackman, J. R. Herman, and C. J. McQuillan, A diabatic circulation experiment in a two-dimensional photochemical model, J. Geophys. Res., 89, 9589-9602, 1984.

Gutowski, W. J., Jr., W.-C. Wang, and P. H. Stone, Effects of dynamic heat fluxes on model climate sensitivity: Meridional sensible and latent heat fluxes, J. Geophys. Res., 90, 13,081-13,086, 1985.

Hameed, S., and R. D. Cèss, The impact of a global warming on biospheric sources of methane and its climatic consequences, Tellus, 35, 1-7, 1983.

Hameed, S., J. P. Pinto, and R. W. Stewart, Sensitivity of the predicted $\mathrm{CO}-\mathrm{OH}-\mathrm{CH}_{4}$ perturbation to tropospheric $\mathrm{NO}_{x}$ concentrations, J. Geophys. Res., 84, 763-768, 1979.

Hameed, S., R. D. Cess, and J. S. Hogan, Response of the global climate to changes in atmospheric chemical composition due to fossil fuel burning, J. Geophys. Res., 85, 7537-7545, 1980.

Hanel, R. A., B. J. Conrath, V. G. Kunde, C. Prabhakara, I. Revah, V. V. Salomonson, and G. Woiford, The Nimbus 4 infrared spectroscopy experiment, 1, Calibrated thermal emission spectra, $J$. Geophys. Res., 77, 2629-2641, 1972.

Hansen, J., D. Johnson, A. Lacis, S. Lebedeff, P. Lee, D. Rind, and G. Russell, Climate impact of increasing atmospheric carbon dioxide, Science, 213, 957-966, 1981.

Hansen, J., A. Lacis, D. Rind, G. Russell, P. Stone, I. Fung, R. Ruedy, and J. Lerner, Climate sensitivity: Analysis of feedback mechanisms, Climate Processes and Climate Sensitivity, Geophys. Monogr. Ser., vol. 29, edited by J. E. Hansen and T. Takahashi, pp. 130-163, AGU, Washington, D. C., 1984.

Harshvardhan, A., A. Arking, M. D. King, and M.-D. Chou, Impact of the El Chichón stratospheric aerosol layer on northern hemisphere temperatures, in Aerosols and Their Climatic Effects, edited by H. E. Gerber and A. Deepak, pp. 261-275, Hampton, Va., 1983.

Harvey, L. D. D., Effect of ocean mixing on the transient climate response to a $\mathrm{CO}_{2}$ increase: Analysis of recent model results, $J$ Geophys. Res., 91, 2709--2718, 1986

Harvey, L. D. D., and S. H. Schneider, Transient climate response to external forcing on $10^{\circ}-10^{4}$ year time scales, 2, Sensitivity experiments with a seasonal, hemispherically averaged, coupled, atmosphere, land, and ocean energy balance model, J. Geophys. Res., 90 2207-2222, 1985.

Hoffert, M. I., A. J. Callegari, and C.-T. Hsieh, The role of deep-sea heat storage in the secular response to climatic forcing, $J$. Geophys. Res., 85, 6667-6679, 1980.

Hunten, D., The philosophy of one-dimensional modeling, in Proceedings of the Fourth Conference on Climatic Impact Assessment Program, Rep. DOT-TSC-OST-75-38, edited by T. M. Hard and A. J. Broderick, pp. 147-155, Dep. of Transp., Washingtoń, D. C. 1975. (Available as NTIS $A D-A 068982$ from Natl. Tech. Inf. Serv., Springfield, Va.)

Idso, S. B., The climatological significance of a doubling of earth's atmospheric carbon dioxide concentration, Science, 207, 1462-1463, 1980.

Imbrie, J., and K. P. Imbrie, Ice Ages: Solving the Mystery, 224 pp., Enslow, Short Hills, N. J., 1979.

Isaksen, I. S. A., The tropospheric ozone budget and possible man made effects, paper presented at Quadrennial International Ozone Symposium, Am. Meteorol. Soc., Boulder, Colo., Aug. 1980.

Isaksen, I. S. A., and F. Stordal, Ozone perturbations by enhanced 
levels of $\mathrm{CFCs}, \mathrm{N}_{2} \mathrm{O}$, and $\mathrm{CH}_{4}$ : A two-dimensional diabatic circulation study including uncertainty estimates, J. Geophys Res., 91, 5249-5263, 1986.

Jones, D. D., T. M. L. Wigley, and P. B. Wright, Global temperature variations between 1861 and 1984, Nature, 322, 430, 1986.

Kagann, R. H., J. W. Elkins, and R. L. Sams, Absolute band strengths of halocarbons $F-11$ and $F-12$ in the 8- to $16-\mu \mathrm{m}$ region, $J$. Geophys. Res., 88, 1427-1432, 1983.

Kelly, P. M., P. D. Jones, T. M. L. Wigley, R. S. Bradley, H. F. Diaz, and $C . M$. Goodess, The extended northern hemisphere surface air temperature record: 1851-1984, paper presented at Conference on Climate Variations, Am. Meteorol. Soc., Boston, Mass., 1984.

Khalil, M. A. K., and R. A. Rasmussen, Increase and seasonal cycles in the atmospheric concentration of nitrous oxide $\left(\mathrm{N}_{2} \mathrm{O}\right)$, Tellus, $35 B, 161-169,1983$.

Khalil, M. A. K., and R. A. Rasmussen, Carbon monoxide in the earth's atmosphere: Increasing trend, Science, 224, 54-56, 1984.

Khalil, M. A. K., and R. A. Rasmussen, Interannual variability of methane, Possible effects of the El Niño-southern oscillation, Science, 232, 56-57, 1985.

Kiehl, J. T., and V. Ramanathan, $\mathrm{CO}_{2}$ radiative parameterization used in climate models: Comparison with narrow-band models and with laboratory data, J. Geophys. Res., 88, 5191-5202, 1983.

Ko, M. K. W., K. K. Tung, D. K. Weisenstein, and N. D. Sze, A zonal mean model of stratospheric tracer transport in isentropic coordinates: Numerical simulations for nitrous oxide and nitric acid, $J$. Geophys. Res., 90, 2313-2329, 1985.

Labitzke, K., B. Naujokat, and M. P. McCormick, Temperature effects on the stratosphere of the April 4, 1982 eruption of El Chichón, Mexico, Geophys. Res. Lett., 10, 24-26, 1983.

Labitzke, K., A. J. Miller, J. Angell, J. Deluisi, J. Frederick, J. Logan, C. Mateer, B. Naujokat, G. Reinsel, and G. Tiao, Ozone and temperature trends, in Atmospheric Ozone 1985, Rep. 16, pp. 789-819, World Meteorol. Org., Geneva, 1985.

Lacis, A., J. Hansen, P. Lee, T. Mitchell, and S. Lebedeff, Greenhouse effect of trace gases, 1970-1980, Geophys. Res. Lett., 8, 1035-1038, 1981.

Lenoble, J., A general survey of the problem of aerosol climatic impact, in Aerosols and Their Climatic Effects, edited by $\mathbf{H}$. E. Gerber and A. Deepak, pp. 279-294, A. Deepak, Hampton, Va. 1984.

Levine, J. S., C. P. Risnland, and G. M. Tennille, The photochemistry of methane and carbon monoxide in the troposphere in 1950 and 1985, Nature, 318, 254-257, 1985.

Levy, H., II, J. D. Mahiman, W. J. Moxim, and S. C. Liu, Tropospheric ozone: The role of transport, J. Geophys. Res., 90, 3753$3772,1985$.

Liu, S. C., T. M. Donahue, R. J. Cicerone, and W. L. Chameides, Effect of water vapor on the destruction of ozone in the stratosphere perturbed by $\mathrm{CIX}$ or $\mathrm{NO}_{x}$ pollutants, J. Geophys. Res., 81 , 3111-3118, 1976.

Liu, S. C., D. Kley, M. McFarland, J. D. Mahlman, and H. Levy II, On the origin of tropospheric ozone, J. Geophys. Res., 85, 75467552, 1980.

Logan, J. A., Nitrogen oxides in the troposphere: Global and regional budgets, J. Geophys. Res., 88, 10,785-10,807, 1983.

Logan, J. A., M. J. Prather, S. C. Wolsy, and M. B. McElroy, Atmospheric chemistry: Response to human influences, Philos. Trans. $R$. Soc. London, Ser. A, 290, 187-234, 1978.

Logan, J. A., M. J. Prather, S. C. Wofsy, and M. B. McElroy, Tropospheric chemistry: A global perspective, J. Geophys. Res., 86, 72107254, 1981.

Luther, F. M., and Y. Fouquart, Rep. WCP-93, 37 pp., World Meteorol. Org., Geneva, 1984.

Luther, F. M., D. J. Wuebbles, and J. S. Chang, Temperature feedback in a stratospheric model, $J$. Geophys. Res., 82, 4935-4942, 1977.

Mahlman, J. D., H. Levy II, and W. J. Moxim, Three-dimensional simulations of stratospheric $\mathrm{N}_{2} \mathrm{O}$ : Predictions for other trace constituents, J. Geophys. Res., 91, 2687-2707, 1986.

Malkmus, W., Random Lorentz band model with exponential tailed $S^{-1}$ intensity distribution, J. Opt. Soc. Am., 57, 323-329, 1967.

Manabe, S., and R. J. Stouffer, Sensitivity of a global climate model to an increase of $\mathrm{CO}_{2}$ concentration in the atmosphere, $J$. Geophys. Res., 85, 5529-5554, 1980.

Manabe, S., and R. T. Wetherald, Thermal equilibrium of the atmosphere with a given distribution of relative humidity, J. Atmos. Sci., 24, 241-259, 1967.
Manabe, S., and R. T. Wetherald, The effects of doubling with $\mathrm{CO}_{2}$ concentration on the climate of a general circulation model, $J$. Atmos. Sci., 32, 3-15, 1975.

Manabe, S., and R. T. Wetherald, On the distribution of climate change resulting from an increase in $\mathrm{CO}_{2}$-content of the atmosphere, J. Atmos. Sci., 37, 99-118, 1980.

McClatchey, R. A., R. W. Fenn, J. E. A. Selby, F. E. Volz, and J. S. Garing, Optical properties of the atmosphere, Rep. AFCRL-710279, 85 pp., Air Force Cambridge Res. Lab., Bedford, Mass., 1971.

McCormick, M. P., T. J. Swissler, W. H. Fuller, W. H. Hunt, M. T. Osborn, Airborne and ground-based lidar measurements of the El Chichón stratospheric aerosol from $90^{\circ} \mathrm{N}$ to $56^{\circ} \mathrm{S}$, Geofis. Int., 23-2, 187-221, 1984.

McElroy, M., S. Wofsy, J. Penner, and J. McConnell, Atmospheric ozone: Possible impact of stratospheric aviation, J. Atmos. Sci., 31 , 287-303, 1974.

Michalsky, J. J., B. M. Herman, and N. R. Larson, Mid-latitude stratospheric aerosol layer enhancement by El Chichón: The first year, Geophys. Res. Lett., II, 76-79, 1984.

National Research Council, Protection Against Depletion of Stratospheric Ozone by Chlorofluorocarbons, 392 pp., Committee on Impacts of Stratospheric Change, National Academy of Sciences, Washington, D. C., 1979.

Newell, R. E., and T. G. Dopplick, Questions concerning the possible influence of anthropogenic $\mathrm{CO}_{2}$ on atmospheric temperature, $J$. Appl. Meteorol., 18, 822-825, 1979.

Nordhaus, W. D., and G. W. Yohe, Future paths of energy and carbon dioxide emissions, in Changing Climate, pp. 87-153, National Academy of Sciences, Washington, D. C., 1983.

North, G. R., R. F. Cahalan, and J. A. Coakley, Jr., Energy balance climate models, Rev. Geophys., 19, 91-121, 1981.

Oeschger, H., U. Siegenthaler, U. Schotterer, and A. Gugelmann, A box diffusion model to study the carbon dioxide exchange in nature, Tellus, 27, 168-192, 1975.

Orton, G. S., and A. G. Robiette, A line parameter list for the $v_{2}$ and $v_{4}$ bands of ${ }^{12} \mathrm{CH}_{4}$ and ${ }^{13} \mathrm{CH}_{4}$, extended to $J^{1}=25$ and its application to planetary atmospheres, J. Quant. Spectrosc. Radiat. Transfer, 24, 81-95, 1980.

Ostlund, H. G., H. G. Dorsey, and R. Brescher, GEOSECS Atlantic radiocarbon and tritium results, Rep. 5, Univ. of Miami Tritium Lab. Data, Miami, Fla., 1976.

Owens, A. J., C. H. Hales, D. L. Filkin, C. Miller, J. M. Steed, and J. P. Jesson, A coupled one-dimensional radiative-convective, chemistry-transport model of the atmosphere, 1, Model structure and steady state perturbation calculations, J. Geophys. Res., 90, 2283-2311, 1985.

Peng, L., M. D. Chou, and A. Arking, Climate studies with a multilayer energy balance model, part I, Model description and sensitivity to the solar constant, J. Atmos. Sci., 39, 2639-2656, 1982.

Porch, W. M., and M. C. MacCracken, Parametric study to the effects of arctic soot on solar radiation, Atmos. Environ., 16, 1365-1371, 1982.

Pugh, L. A., and K. N. Rao, Intensities from infrared spectra, Mol. Spectrosc. Mod. Res., 2, 165-225, 1976.

Pyle, J. A., and C. F. Rogers, A modified diabatic circulation model for stratospheric tracer transport, Nature, 287; 711-714, 1980.

Quiroz, R. S., The isolation of stratospheric temperature change due to the El Chichón volcanic eruption from nonvolcanic signals, $J$. Geophys. Res., 88, 6773-6780, 1983.

Ramanathan, V., Greenhouse effect due to chlorofluorocarbons: Climatic implications, Science, 190, 50-52, 1975.

Ramanathan, V., Radiative transfer within the earth's troposphere and stratosphere: A simplified radiative-convective model, $J$. Atmos. Sci., 33, 1330-1346, 1976.

Ramanathan, V., Climatic effects of anthropogenic trace gases, in Energy/Climate Interactions, pp. 269-280, D. Reidel, Hingham, Mass., 1980.

Ramanathan, V., The role of ocean-atmosphere interactions in the $\mathrm{CO}_{2}$ climate problem, J. Atmos. Sci., 38, 918-930, 1981.

Ramanathan, V., and J. A. Coakley, Jr., Climate modeling through radiative-convective models, Rev. Geophys., 16, 465-489, 1978.

Ramanathan, V., and R. E. Dickinson, The role of stratospheric ozone in the zonal and seasonal radiative energy balance of the earth-troposphere system, J. Atmos. Sci., 36, 1084-1104, 1979.

Ramanathan, V., M. S. Lian, and R. D. Cess, Increased atmospheric $\mathrm{CO}_{2}$ : Zonal and seasonal estimates of the effect on the radiation energy balance and surface temperature, J. Geophys. Res., 84, 49494958, 1979. 
Ramanathan, V., R. J. Cicerone, H. B. Singh, and J. T. Kiehl, Trace gas trends and their potential role in climate change, $J$. Geophys. Res., 90, 5547-5566, 1985.

Ramaswamy, V., and J. T. Kiehl, Sensitivities of the radiative forcing due to large loadings of smoke and dust aerosols, J. Geophys. Res., 90, 5597-5613, 1985.

Rasmussen, R. A., and M. A. K. Khalil, Atmospheric methane $\left(\mathrm{CH}_{4}\right)$ Trends and seasonal cycles, J. Geophys. Res., 86, 9826-9832, 1981.

Rasmussen, R. A., and M. A. K. Khalil, Atmospheric methane in the recent and ancient atmospheres: Concentrations, trends, and interhemispheric gradient, J. Geophys. Res., 89, 11,599-11,605, 1984.

Rasmussen, R. A., and M. A. K. Khalil, Atmospheric trace gases Trends and distributions over the last decade, Science, 232, 16231624, 1986.

Reck, R. A., and D. L. Fry, The direct effect of chlorofluoromethanes on the atmospheric surface temperature, Atmos. Environ., 12, 25012503, 1978.

Reck, R. A., and J. R. Hummel, Influence of aerosol optical properties on surface temperatures computed with a radiative-convective model, Atmos. Environ., 15, 1727-1731, 1981.

Rinsland, C. P., J. S. Levine, and T. Miles, Concentration of methane in the troposphere deduced from 1951 infrared spectra, Nature, 318 245-249, 1985

Rodgers, C. D., and C. D. Walshaw, The computation of infrared cooling rate in planetary atmospheres, $Q$. J. R. Meteorol. Soc., 92 , 67-92, 1966.

Schlesinger, M. E., A review of climate model simulations of $\mathrm{CO}_{2}$-induced climatic change, Rep. 41, 135 pp., Clim. Res. Inst. Oregon State Univ., Corvallis, 1983.

Schlesinger, $\mathbf{M}$. E., Climate model simulation of $\mathrm{CO}_{2}$-induced climatic change, Adv. Geophys., 26, 141-235, 1984.

Schlesinger, M. E., and J. F. B. Mitchell, Model projections of equilibrium climate response to increased $\mathrm{CO}_{2}$ in The Potential Climatic Effects of Increasing Carbon Dioxide, Rep. DOE/ER-0237, edited by M. C. MacCracken and F. M. Luther, U.S. Department of Energy, pp. 81-148, U. S. Dep. of Energy, Washington, D. C., 1985.

Schlesinger, M. E., W. L. Gates, and Y.-J. Han, The role of the ocean in $\mathrm{CO}_{2}$-induced climate change: Preliminary results from the OSU coupled atmosphere-ocean general circulation model, in Coupled Ocean-Atmosphere Models, edited by J. C. J. Nihoul, pp. 447-478, Elsevier, New York, 1985.

Schneider, S. H., On the carbon dioxide-climate confusion, J. Atmos. Sci., 32, 2060-2066, 1975.

Schneider, S. H., and S. L. Thompson, Atmospheric $\mathrm{CO}_{2}$ and climate: Importance of the transient response, $J$. Geophys. Res., 86, 3135$3147,1981$.

Seiler, W., and R. Conrad, Contributions of tropical ecosystems to the global budgets of trace gases, especially $\mathrm{CH}_{4}, \mathrm{H}_{2}, \mathrm{CO}$ and $\mathrm{N}_{2} \mathrm{O}$, in The Geophysiology of Amazonia, Climate and the Biosphere, edited by R. E. Dickinson, pp. 133-162, John Wiley, New York, 1987.

Siegenthaler, U., and H. Oeschger, Transient temperature changes due to increasing $\mathrm{CO}_{2}$ using simple models, Ann. Glaciol., 5, 153$159,1984$.

Smagorinsky, J., Carbon Dioxide and Climate: A Second Assessment, 92 pp., National Academy Press, Washington, D. C., 1982.

Smith, M. A. H., C. P. Rinstand, D. Frieourch, and K. N. Rao, Intensities and collision broadening parameters from infrared spectra, in Molecular Spectroscopy in Modern Research, vol. 3, pp. 111248, Academic, New York, 1985.

Somerville, R. C. J., and L. A. Remer, Cloud optical thickness feedbacks in the $\mathrm{CO}_{2}$ climate problem, J. Geophys. Res., 89, 9668-9672, 1984

Spelman, M. J., and S. Manabe, Influence of oceanic heat transport upon the sensitivity of a model climate, J. Geophys. Res., 89, 571$586,1984$.

Stephens, G. L., S. Ackerman, and E. A. Smith, A shortwave parameterization revised to improve cloud absorption, J. Atmos. Sci., 41, $687-690,1984$

Sze, N. D., Anthropogenic CO emissions: Implications for the atmospheric CO-OH-CH ${ }_{4}$ cycle, Science, 195, 673-675, 1977

Thompson, A. M., and R. J. Cicerone, Possible perturbations to atmospheric $\mathrm{CO}, \mathrm{CH}_{4}$, and $\mathrm{OH}, J$. Geophys. Res., 9I, 10,853-10,864, 1986.

Twomey, S. A., M. Piepgrass, and T. L. Wolfe, An assessment of the impact of pollution on global albedo, Tellus, 36B, 356-366, 1984

Tyndall, J., On the absorption and radiation of heat by gases and vapors and on the physical connection of radiation, absorption and conduction, Philos. $M a g, 22,169-273,1861$.
Varanasi, P., and F. K. Ko, Intensity measurements in freon bands of atmospheric interest, J. Quant. Spectros. Radiat. Transfer, 17, 385389, 1977.

Varanasi, P., L. P. Giver, and F. P. J. Valero, Thermal infrared lines of methane broadened by nitrogen at low temperatures, J. Quant. Spectrosc. Radiat. Transfer, 30, 481-490, 1983.

Vupputuri, V. K. R., The structure of the natural stratosphere and the impact of chlorofluoromethanes on the ozone layer investigated in a 2-D time dependent model, Pure Appl. Geophys., 117, 448-485, 1978.

Wang, W.-C., and G. Molnar, A model study of the greenhouse effects due to increasing atmospheric $\mathrm{CH}_{4}, \mathrm{~N}_{2} \mathrm{O}, \mathrm{CF}_{2} \mathrm{Cl}_{2}$, and $\mathrm{CFCl}_{3}, J$. Geophys. Res., 90, 12,971-12,980, 1985.

Wang, W.-C., and P. H. Stone, Effect of ice-albedo on global sensitivity in a one-dimensional radiative-convective climate model, $J$. Atmos. Sci., 37, 545-552, 1980.

Wang, W.-C., Y. L. Yung, A. A. Lacis, T. Mo, and J. E. Hansen, Greenhouse effects due to man-made perturbations of trace gases, Science, 194, 685-690, 1976.

Wang, W.-C., J. P. Pinto, and Y. L. Yung, Climatic effects due to halogenated compounds in the earth's atmosphere, J. Atmos. Sci., $37,333-338,1980$

Wang, W.-C., W. B. Rossow, M.-S. Yao, and M. Wolfson, Climate sensitivity of a one-dimensional radiative-convective model with cloud feedback, J. Atmos. Sci., 38, 1167-1178, 1981.

Wang, W.-C., D. J. Wuebbles, W. M. Washington, R. G. Isaacs, and G. Molnar, Trace gases and other potential perturbations to global climate, Rev. Geophys., 24, 110-140, 1986

Washington, W. M., and G. A. Meehl, General circulation model experiments on the climatic effects due to a doubling and quadrupling of carbon dioxide concentration, J. Geophys. Res., 88, 6600 $6610,1983$.

Washington, W. M., and G. A. Meehl, Seasonal cycle experiment on the climate sensitivity due to a doubling of $\mathrm{CO}_{2}$ with an atmospheric general circulation model coupled to a simple mixed-layer ocean model, J. Geophys. Res., 89, 9475-9503, 1984.

Weiss, R. F., The temporal and spatial distribution of tropospheric nitrous oxide, J. Geophys. Res., 86, 7185-7195, 1981.

Wetherald, R. T., and S. Manabe, The effects of changing the solar constant on the climate of a general circulation model, J. Atmos. Sci., 32, 2044-2059, 1975.

Wigley, T. M. L., and M. E. Schlesinger, Analytical solution for the effect of increasing $\mathrm{CO}_{2}$ on global mean temperature, Nature, 315 649-652, 1985.

Wilkness, P. E., and R. E. Larson, Atmospheric radon measurements in the Arctic fronts, seasonal observations and transport of continental air to polar regions, J. Atmos. Sci., 41, 2347-2358, 1984.

Wilson, R. C., H. S. Hadson, C. Frohlich, and R. W. Brussa, Longterm downward trend in total solar irradiance, Science, 234, 1114 1117, 1986

World Climate Research Programme (WCP), Aerosols and their climatic effects, report of experts meeting, Williamsburg, Va., 28-30 March, 1983, Rep. WCP-55, World Meteorol. Org., Geneva, 1983.

World Meteorological Organization, The stratosphere, theory and measurements, Rep. 11, Geneva, 1981.

World Meteorological Organization (WMO), Potential climate effects of ozone and other minor trace gases, Rep. 14, Geneva, 1982.

World Meteorological Organization, World Meteorological Organization project on research and monitoring of atmospheric $\mathrm{CO}_{2}$, Rep. 10, edited by R. J. Bojkov, 42 pp., Geneva, $1983 a$.

World Meteorological Organization (WMO), Report of the WMO (CAS) meeting of experts on the $\mathrm{CO}_{2}$ concentrations from preindustrial times to I.G.Y. World Climate Programme, Rep. WCP53, 34 pp., Geneva, $1983 b$.

World Meteorological Organization (WMO), Global ozone research and monitoring project, in Atmospheric Ozone 1985, Rep. 16, p. 88, Geneva, 1985.

Wuebbles, D. J., F. M. Luther, and J. E. Penner, Effect of coupled anthropogenic perturbations on stratospheric ozone, J. Geophys. Res., 88, 1444-1456, 1983 .

L. Callis, Langley Research Center, National Aeronautics and Space Administration, Hampton, VA 23665.

R. Cess, State University of New York at Stony Brook, Long Island, NY 11794

J. Hansen and A. Lacis, Goddard Institute for Space Studies, $\mathrm{Na}$ tional Aeronautics and Space Administration, New York, NY 10025. 
I. Isaksen, University of Oslo, Blindern, Oslo 3, Norway.

W. Kuhn, University of Michigan, Ann Arbor, MI 48109.

J. Mahlman, Geophysical Fluid Dynamics Laboratory, Princeton, NJ 08540.

V. Ramanathan, Department of Geophysical Sciences, Room 501, University of Chicago, 5734 South Ellis Avenue, Chicago, IL 60637.
R. Reck, General Motors Co., Warren, MI 48090.

M. Schlesinger, Oregon State University, Corvallis, OR 97331.

(Received May 16, 1986; accepted February 9, 1987.) 